\title{
'A Light Railway Station for the City of Ottawa An Urban Gateway,
}

\author{
Karam G. Georges, B.A.S. \\ $=$ \\ A thesis submitted to the faculty of Graduate Studies and \\ Research in partial fulfillment of the requirements for the degree of \\ Master of Architecture (M. ARCH) Professional.
}

Carleton University, Ottawa, Ontario, Canada

Karam Georges (C) 2006 
Library and

Archives Canada

Published Heritage Branch

395 Wellington Street Ottawa ON K1A ON4

Canada
Bibliothèque et

Archives Canada

Direction du

Patrimoine de l'édition

395 , rue Wellington

Ottawa ON K1A ON4

Canada

\section{$978-0-494-16475-4$}

Your file Votre référence
ISBN:
Our file Notre reterence
ISBN:
NOTICE:

The author has granted a nonexclusive license allowing Library and Archives Canada to reproduce, publish, archive, preserve, conserve, communicate to the public by telecommunication or on the Internet, loan, distribute and sell theses worldwide, for commercial or noncommercial purposes, in microform, paper, electronic and/or any other formats.

The author retains copyright ownership and moral rights in this thesis. Neither the thesis nor substantial extracts from it may be printed or otherwise reproduced without the author's permission.
AVIS:

L'auteur a accordé une licence non exclusive permettant à la Bibliothèque et Archives Canada de reproduire, publier, archiver, sauvegarder, conserver, transmettre au public par télécommunication ou par l'Internet, prêter, distribuer et vendre des thèses partout dans le monde, à des fins commerciales ou autres, sur support microforme, papier, électronique et/ou autres formats.

L'auteur conserve la propriété du droit d'auteur et des droits moraux qui protège cette thèse. $\mathrm{Ni}$ la thèse ni des extraits substantiels de celle-ci ne doivent être imprimés ou autrement reproduits sans son autorisation.
In compliance with the Canadian

Privacy Act some supporting forms may have been removed from this thesis.

While these forms may be included in the document page count, their removal does not represent any loss of content from the thesis.

\section{Canada}

Conformément à la loi canadienne sur la protection de la vie privée, quelques formulaires secondaires ont été enlevés de cette thèse.

Bien que ces formulaires aient inclus dans la pagination, il n'y aura aucun contenu manquant. 


\section{Abstract}

Based on the actual plans for a major light railway addition for the city of Ottawa, the theoretical issues of sustainable urban planning and the integration of architecture into the existing fabric of the city, this thesis proposes a design for a light railway station. The design strategy of the station, on one hand, is triggered by visual experiences that commuters encounter along the main rail, providing the conceptual framework to tie together everyday experience, visual culture and built form. By this, the thesis stresses the importance of the narrative to create the setting for the station. On the other hand, the design strategy responds to the complex fabric of the site's immediate context, its multicultural makeup as well as its present infrastructure, which would in turn support, and be supported by, the light rail program.

This light rail station is to be constructed, with important innovations at a current and future hub in the city of Ottawa: namely, LeBreton Flats. Importantly, this project will not only encourage the use of mass transportation but will serve as a social hub and gateway to the immediate neighbourhoods. Further, the project introduces a multicultural locus for a community of local and international students. The design concepts for the rail hub will be explored using a multimedia narrative of different characters from the general public that use or rely on the transportation system. Based on the research, a complete design will be developed with the idea to create a multi-use structure, beyond the regular requirements of a train station, which will serve the needs of a vibrant community and reflect the dynamics of a changing city. As well, a concerted effort will be made to incorporate the building into the fluid and mobile context of the site, which sits at a confluence of several modes of transportation, with varied landscape and cityscape characteristics, as well as several cultural influences. 


\section{Table of Contents}

Title Page

Acceptance Form

Abstract $\quad$ i

Table of Contents $\quad$ ii

List of Figures $\quad$ V

Introduction 1

\section{Chapter 1}

1.1 Personal experiences and observations 4

$\begin{array}{lll}1.2 & \text { Site Analysis } & 4\end{array}$

1.3 Master plan - A Cultural and Transportation Hub 6

\section{Chapter 2}

2.1 Narrative and visual experience $\quad 7$

2.2 Story Line/Narrative 7

2.2.1 Video Study 7

$\begin{array}{ll}\text { 2.2.2 Display Cabinet } & 10\end{array}$

2.3. Greenaway and Narrative 11

2.4 Eisenstein and Montage $\quad 12$

2.5 From Montage to Architectural Principles of Form 15

$\begin{array}{lll}2.5 .1 & \text { Movement } & 19\end{array}$

$\begin{array}{ll}2.5 .2 \text { Depth } & 22\end{array}$ 
$\begin{array}{ll}\text { 2.5.4 Narrative } & 23\end{array}$

2.5.5 Positioning (metaphor of pose and gesture) 23

2.5.6 Collage (superimposition and Juxtaposition) 24

$\begin{array}{lll}\text { 2.5.7 Subject/object relationship } & 25\end{array}$

2.6 Design methodology 27

- Employing the Visual Analysis of Paintings to Derive Architectural Relationships

\section{Chapter 3}

3.1 The Site and its current development context 36

$\begin{array}{lll}3.2 & \text { Design Strategy }\end{array}$

3.3 The Project Concept 43

$\begin{array}{lll}\text { 3.3.1 Narrative } & 43\end{array}$

$\begin{array}{lll}\text { 3.3.2 Movement } & 43\end{array}$

3.4 Overall composition and layout of the project Strategy: Five Building - One Project 44

3.5 Design Project: Scope and Program 45

3.5.1 Train Station Program 46

3.5.2 Building 'B' Train/bus Stop Program 48

3.5.3 Building 'C' Library Threshold 49

3.5.4 Building ' $\mathrm{D}$ ' The Train Tower 51

3.5.5 Recreational centre $\quad 52$

$\begin{array}{lll}\text { 3.5.6 Walkways } & 54\end{array}$ 
Bibliography

Project Photographs

Project Panels and Drawings 


\section{List of Figures}

Figure 1

Figure 2

Figure 3

Figure 4

Figure 5

Figure 6

Figure 7

Figure 8

Figure 9

Figure 10

Figure 11

Figure 12

Figure 13

Figure 14

Figure 15

Figure 16

Figure 17

Figure 18
Collage showing the three experiential axes. Collage by author. (p. 8)

Still image from the digital representation. Image by author. (9)

Still image from the digital representation. Image by author. (9)

Still image from the digital representation. Image by author. (9)

Still image from the digital representation. Image by author. (9)

Display Cabinet showing the three representational strips. (10)

Detail from the display cabinet. Collage by author. (11)

Detail from the display cabinet. Graphite on paper. Drawing by author. (11)

Valentin Serov, Portrait of "Maria Yermelova" (1905). Oil on canvas. The Tretyakov Gallery, Moscow. (14)

Sketched Diagram of Serov's painting "Yermelova" by Sergei Eisenstein showing 4 viewpoints. Efimova, Alla and Mavovich Lev. Tekstura, Russian Essays on Visual Culture. Chicago:

University of Chicago Press, 1993. (14)

3-D analogues. Module by author. (15)

3-D analogues. Module by author. (15)

3-D analogues. Module by author. (16)

Image generated from the 3-D analogues. Image by author. (16) Image generated from the 3-D analogues. Image by author. (17) Image generated from the 3-D analogues. Image by author. (17) Image generated from the 3-D analogues. Image by author. (17) 3-D Bus/Stop Model. Image by author. (20) 
Figure 19

Figure 20

Figure 21

Figure22

Figure 23

Figure 24

Figure 25

Figure 26

Figure 27

Figure 28

Figure 29

Figure 30

Figure 31

Figure 32
3-D site model showing the project over view. Image and Model by author. (21)

Diego Velazquez' "Las Meninas" (The Maids of Honor) 1656. Oil on Canvas, Spain. (26)

Dark Dungeon (or Dark Prison) by G. B. Piranesi, 1743. from Prima Parte di Architetturee Prospective invetate ed incise da Gio. Piranesi architetto Veneziano...plate 2, drawing6. Ashmolean Museum, Oxford. (28)

Eisenstein's schematic outline of Piranesi's Dark Dungeon (Dark Prison) Eisenstein, Sergei. Nonindifferent Nature. Translated by Herbet Marshall. New York: Cambridge University Press, 1987, page 128. (28)

Eisenstein's sketched diagrams analyzing Piranesi's etching. (Nonindifferent Nature, 128) (28)

Eisenstein's sketched diagrams analyzing Piranesi's etching. (Nonindifferent Nature, 130) (28)

Eisenstein's sketched diagrams analyzing Piranesi's etching. (Nonindifferent Nature, 130) (28)

3 D collage showing design exploration. Collage by author. (29)

3 D collage showing design exploration. Collage by author. (30)

3 D collage showing design exploration. Collage by author. (30)

Collage showing juxtaposition of the abstracted 3-D analogues. Image by author. (32)

Collage showing exploration of site conditions, program and narrative. Image by author. (32)

Collage showing juxtaposition of the abstracted 3-D analogues. Image by author. (32)

Collage showing exploration of site conditions, program and narrative. Image by author. (32) 
Figure 33

Figure 34

Figure35

Figure36

Figure37

Figure38

Figure39

Figure 40

Figure 41

Figure 42

Figure 43

Figure 44

Figure 45

Figure 46
Collage showing juxtaposition of the abstracted 3-D analogues. . Image by author. (32)

2-D Collage. Image by author. (35)

Urban Master Plan, Development Context, Significant

Building and Structure, from the city of Ottawa. (37)

http://www.ottawa.ca/public_consult/bayview/concept/summary/ images/dev_context_and_significant buildings/.

Urban Master Plan- Heritage, from the city of Ottawa (37)

http://www.ottawa.ca/public_consultant/bayview/concept/summay/ images/heritage.jpg $>$

Proposed Development for Bayview site, from City of Ottawa.

Public Consultation. (38)

http://www.ottawa.ca/public consult/bayview/concept/images/

figure3_en.jpg $>$

Site Photograph from National Capital Commission. Carleton University Library- Geographic Information System. Sept. 2004. (38)

Urban Master Plan, Development Context, Significant

Building and Structure, from the city of Ottawa. (38)

http://www.ottawa.ca/public consult/bayview/concept/summary/

images/dev_context_and_significant_buildings.

Urban Master Plan Zoning for The Ottawa 20/20 Master plan.(39)

$\leq \mathrm{http}: / /$ www.canadascapital.gc.ca/corporate/parks_heritage/devel

opment_projects/

Park Boundary Plan: Existing Conditions, 2003 Photo from National Capital Commission. Carleton University libraryGeographic Information system. (41)

3-D Train station Model. Image by author. (46)

3-D Train/Bus Stop Model. Image by author. (48)

3-D library Extension Model. Image by author. (50)

3-D Train Tower Model. Image by author. (51)

3-D Recreational Centre Model. Image by author. (52) 
Figure 47

Figure 48

Figure 49

Figure 50

Figure 51

Figure 52

Figure 53

Figure 54

Figure 55

Figure 56

Figure 57

Figure 58

Figure 59

Figure 60

Figure 61

Figure 62

Figure 63

Figure 64

Figure 65

Figure 66
3-D Site Plan. Image by author (60)

3-D Model. Image by author (61)

3-D Model. Image by author (61)

3-D Model. Image by author (62)

3-D Model. Image by author (62)

3-D Model. Image by author (63)

3-D Model. Image by author (63)

3-D Model. Image by author (64)

Photoshop Panel showing Bayview Park. Panel by author (65)

Photoshop Panel - Perspective- Panel by author (66)

Photoshop Panel - Perspective- Panel by author (67)

Photoshop Panel - Perspective- Panel by author (68)

Photoshop Panel - Perspective- Panel by author (69)

Photoshop Panel - Perspective- Panel by author (70)

Photoshop Section Panel. Panel by author (71)

Community Centre Drawing Showing Plans and Sections

Drawing by author (72)

Train Station Plans. Drawing by author (73)

Train Station Sections. Drawing by author (74)

Library Plans-Sections-Elevations. Drawing by author (75)

Bus/Train Stop Plans-Sections-Elevations. Drawing by author (76) 


\section{Introduction}

A light-rail station at the central site of LeBreton Flats needs to be more than the stop before downtown; it needs to be a hub that connects the various modes of urban life, which can be facilitated through a fluid design that emphasizes both the traditional ideas of community and neighbourhood and the flow of contemporary society.

Mass transit systems are an essential element of our increasingly urban society. Our communities, jobs and relationships depend on our ability to move. The overall health of our transit system also plays a crucial role in maintaining the viability and liveability of our region. Too often, transit projects and programs are considered in isolation rather than how they work as interconnected systems within the city. Thus, the transit system is a means of achieving other important social goals, such as a stronger economy, a cleaner environment, better health, access to employment, more liveable neighbourhoods, expanded educational and recreational opportunities, and improved personal safety, to name a few. Consequently, the value of transit projects and programs should be measured by more than technical transportation statistics. Given the linkage between transportation and the health and sustainability of the city, it is particularly important to judge how well transit projects fit within the region's adopted growth strategy.

The objective of this project is to design an integrated transportation centre that emphasizes the active dynamics of exchange in a modern city, while encouraging a warm, open environment for the integration of various sectors of the urban environment. A series of interweaving narratives will provide the project with its fundamental design. 
The multiple perspectives of a variety of users will be explored to harmonize the everyday use of the facilities with a physical, built environment situated in its unique context. To execute this, the design process employs the cinematic theory of Sergei Eisenstein and Peter Greenaway, who both used montage and juxtaposition to engage issues of perception and experience.

These multiple levels of subjective reality have an objective corollary in the variety of uses that the design proposes. The western side of the site faces an area of light industry, a destination for many workers. The southern part of the site will face a residential area, and will house the more community-based facilities, such as a proposed library. The northern part looks toward the Ottawa River and the flats (a vast landscaped expanse), and will act as an entrance towards proposed recreational areas. The east is a gateway to the financial and political centre of the city. All of these areas will be interwoven and connected within the site, in order to provide a mix of uses, perspectives and narratives (programmed uses).

The complex will serve primarily as a threshold to the site of LeBreton Flats where the highly anticipated and greatly needed east-west rail line will pass before entering the downtown core. The building's program, however, will be more than a station, but rather will serve as a public centre, receiving input from all aspects of the city and distributing forms and ideas through various nodes in the network. For example, the station will bridge over the park and connect to new architectural programs including the proposed public library, restaurants, shops, community gardens, entertainment facilities, an 
exhibition hall, each a locus for the exchange of information and experiences, and each connected by varied and dynamic paths.

This research is an attempt to highlight some of the more beneficial aspects of Ottawa's culture: dynamic change, integration, growth and nature. However, urban renewal seems increasingly to be a reflection of the impersonal effects of capital or growth for growth's sake, rather than of a desire to employ an architectural vision that bolsters civic engagement or strengthen integrated, dynamic communities. Thus, my overall approach is towards a balanced architecture that reflects the changing needs and shapes of society, while at the same time creating enduring and healthy communities. 


\section{Chapter 1}

\section{1. Personal experiences and observations}

a) The development of the central issues of the thesis extends from my personal experiences as an international student, where the problems encountered by students are compounded by being thrown into a new culture. Further, this issue generally ties into the need of most North American cities, recognized by the school of New Urbanism, to create sustainable, integrated communities. This project will therefore be a series of multi-use structures with the usual cafés and shopping, but will also accommodate a library, gardens and many other features that are not typical associate with the traditional rail station.

b) LeBreton Flats is a point of intersection for four major universities in the Capital region: Carleton University, Ottawa University, Université de Saint Paul (St. Paul's University) and the University of Quebec in Hull. The programming of the O-train hub intends to bridge these educational institutions at LeBreton Flats, and this can be achieved by situating the public library along with recreational, spiritual and physical accommodations to facilitate the life of international students.

\section{2. Site Analysis}

The site lies at a confluence of rail, bus, bicycle, foot, and automobile pathways, and therefore combines the experience of all walks of urban life. While the train will bring the most people into the area, the site must remain a place where all travellers have a place, especially pedestrians, who increasingly seem to be losing ground to automobile traffic. As the city expands, this site will increasingly become a vital location, a threshold to the 
economic and political hub of downtown Ottawa. Also, according to the future light-rail plans for the city the site has the potential to be an educational centre as it lies at the intersection of four major universities. Furthermore, Ottawa is becoming increasingly attractive as a destination for immigrants. This area therefore, has the potential to become an important multicultural hub and destination.

In addition, the building will relate to its site and resonate with the ideas of transportation and movement; thus, the notion of fluidity will thus be a salient architectural feature. Spaces will flow and fold into one another with little segmentarity or predetermined division among them. The train platforms will connect easily with commercial areas and public spaces; but also serve as a condition where productive dialogues can occur. The form study responds to the (hyper) active and dynamic circulation of social energy in contemporary life. As well, fluid forms and juxtapositions allow for inhabited spaces with enhanced connections to natural flows and rhythms, and provide for new patterns and possibilities of lived experience. Furthermore, fluid movement can extend from the architecture and into the existing landscape which has its own natural order and structure. This is important as the site itself is already situated amidst a rich natural landscape and river-way which offers to the rail hub an opportunity to develop a facility using extensive green technology. This also accords with the general environmental motives behind mass transit: a decreased reliance on the car and subsequently cleaner air. 


\section{3. Master plan - A Cultural and Transportation Hub}

The idea is to provide an urbanized public link across a variety of transit methods, in order to give expression to the imposition of a new through-station that can also act as the nucleus of a new proposed educational, cultural and recreational student park. The project extends beyond the scope of a station; it becomes the gateway or the bridge that connects various urban functions. In keeping with the effort to make LeBreton more stately and also habitable, the master plan strongly emphasizes view corridors toward Parliament and the notion of a "gateway to the capital core." Guided by "new urbanism," the plan is to create a pedestrian-oriented, dense "family of buildings" that engages with the street ${ }^{1}$.

1 “Ottawa 20/20 Official Plan.” City of Ottawa Website, < http://www.ottawa2020.com 


\section{Chapter 2}

\subsection{Narrative and Visual Experience}

Because the site lies at the intersection of four major universities, the intention is to bridge these educational institutions with the greater community context. This can be achieved by situating the public library along with recreational, spiritual and physical accommodations to facilitate the life of students and local residents. In order to prefigure this integration, early investigations for the design were based on two representations: a small digital movie and a display cabinet. These provide the initial range of possibilities for the site, spatially, visually and phenomenologically. In addition, the thesis employs the cinematic theory of Eisenstein and Greenaway to explore personal interactions and also the visual and phenomenological experiences of commuters on the train.

Specifically, in considering relationships and adjacencies an analysis of several artworks is undertaken according to Eisenstein's categories of art. From this analysis, a series of abstract 3D analogues were constructed as figures that would later guide the design.

\subsection{Story Line/Narrative}

\subsubsection{Video Study}

The short movie consists of a multi-layered screen, representing the experience of train commuters to show how this project can be imagined and used. The three major perspectives that different people experience during a train ride are thus combined (see fig. 1) 


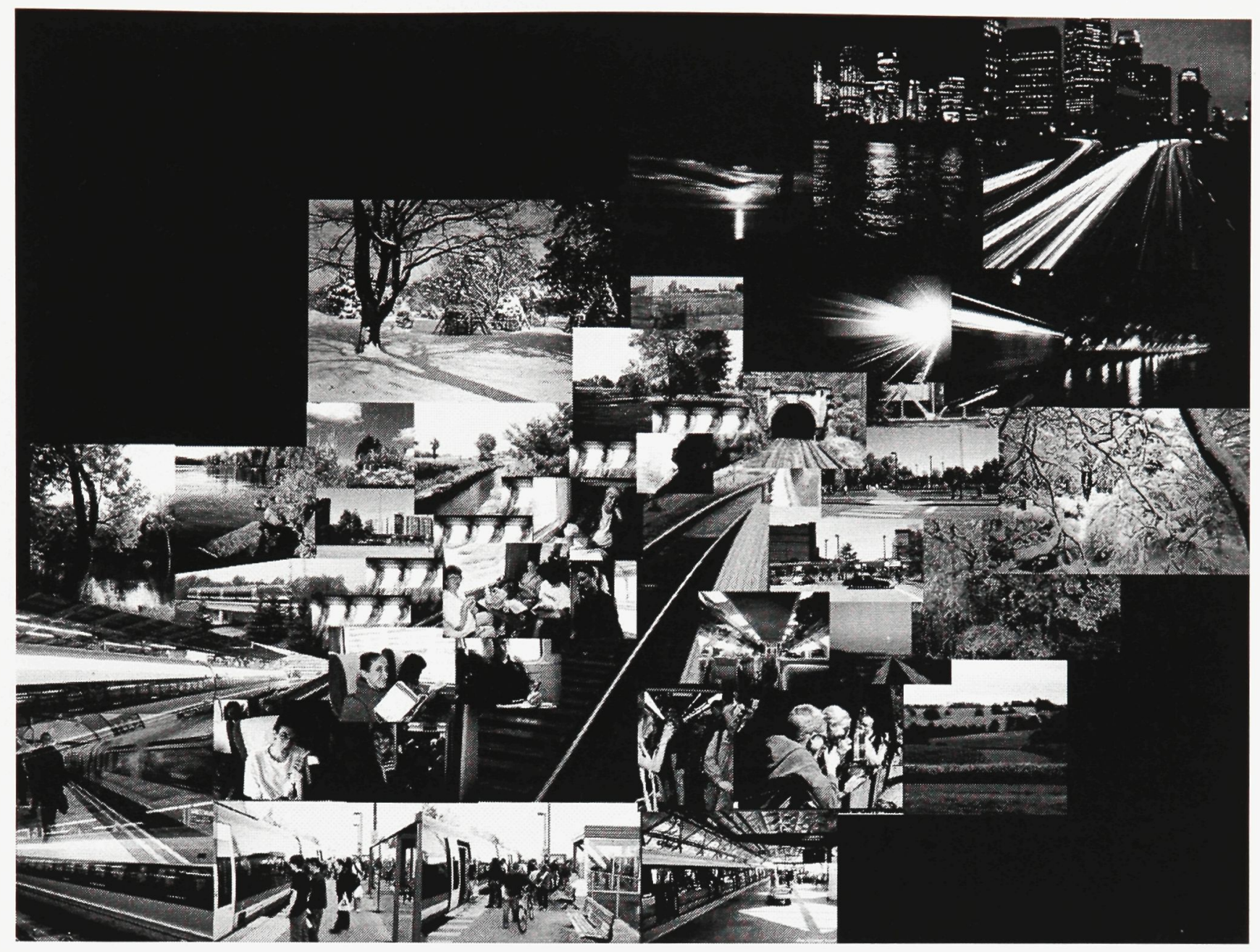

Fig. 1- collage showing the experiential axes around the train line

a) The first experiential axis is the environment and interaction inside the train. There are commuters listening to music, engaged in conversation, contemplating, resting, reading, etc.

b) The second axis (looking through the window) consists of a sequence of collective events, images, and scenes. Here, the emphasis is on the interaction between the ephemeral external world and the subject in motion.

c) The third axis is the exterior point of reference taken from the point of view of a passive participant seeing the train from the outside. This condition is especially 
important to the architectural programming whereby certain spaces lend themselves to more inactive aspects of the communal program while being juxtaposed against more active ones. A dynamic and layered effect can be promoted for example between the rush of trains and commuters against a backdrop of a reading room or café. The further juxtaposition of these three perspectives highlights the phenomenological interaction of a variety of subject positions in the environment. These possibilities will be subsequently concretized using Eisenstein's visual theory and adapted to an architectural proposition.
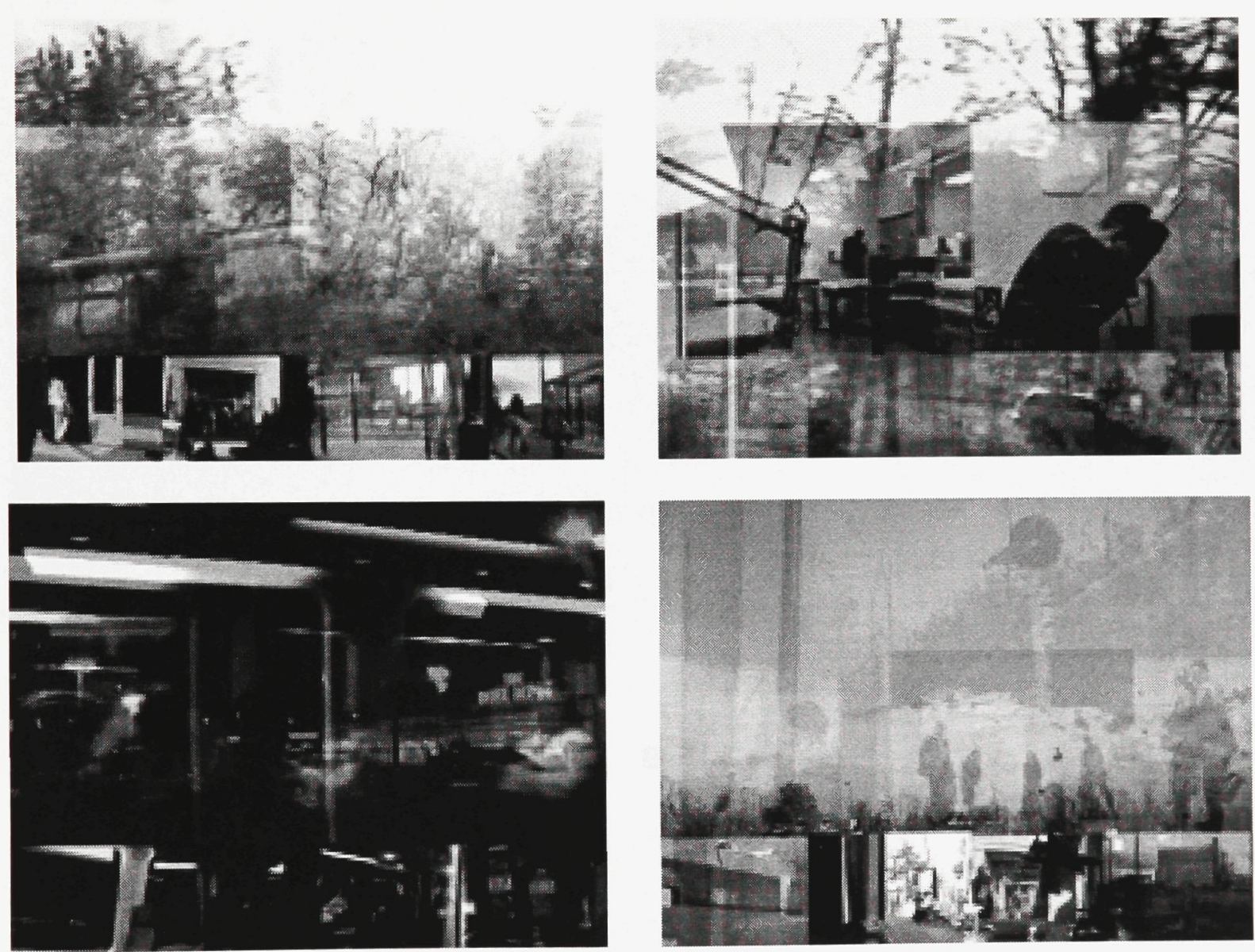

Fig. 2-3-4-5 still images from the digital representation 


\subsection{Display Cabinet}

The display cabinet (fig. 6) consists of three horizontal strips and it is based on a physical interpretation of the digital exploration. The cabinet is set on a sequential frame to permit the viewer an engagement with the contents of the display while in motion. The bottom strip relates to the commuters physical print when approaching the train, evidence of the trace, presence and memories of the commuters as they enter and exit the train. The middle strip refers to mechanical parts of the train, in stark contrast to the sensitive and fragile parts of the human body. The top strip unfolds like a theatrical sequence of a movie strip and each stage projects an event or an experience centred around the train line.

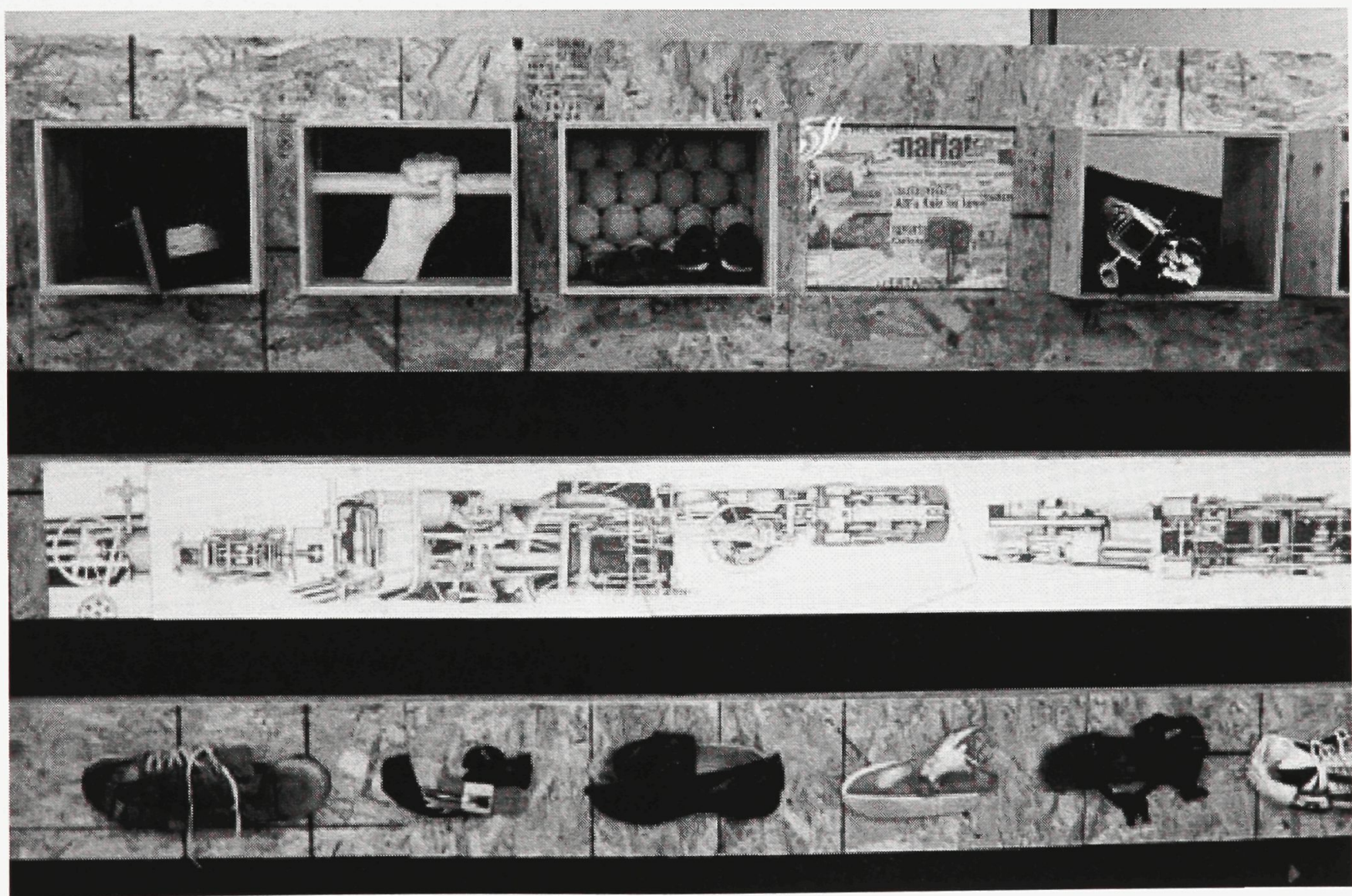

Fig. 6 Display Cabinet 


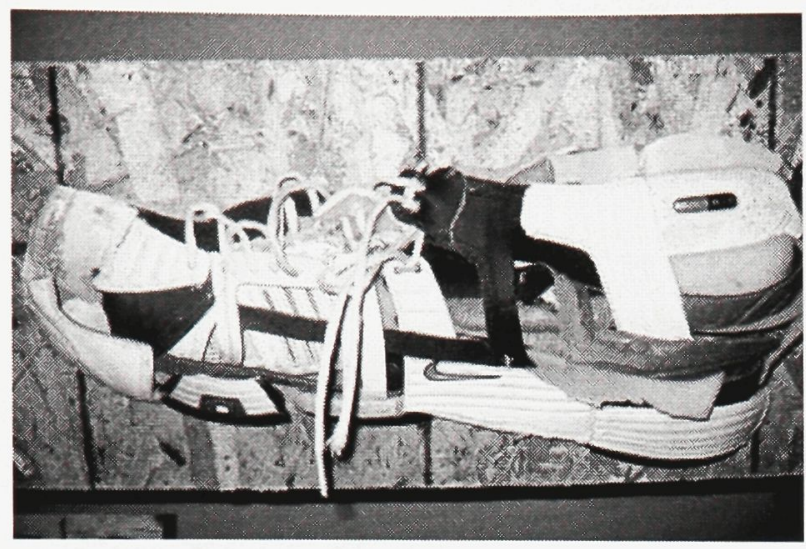

Fig. 7- Detail from the display cabinet

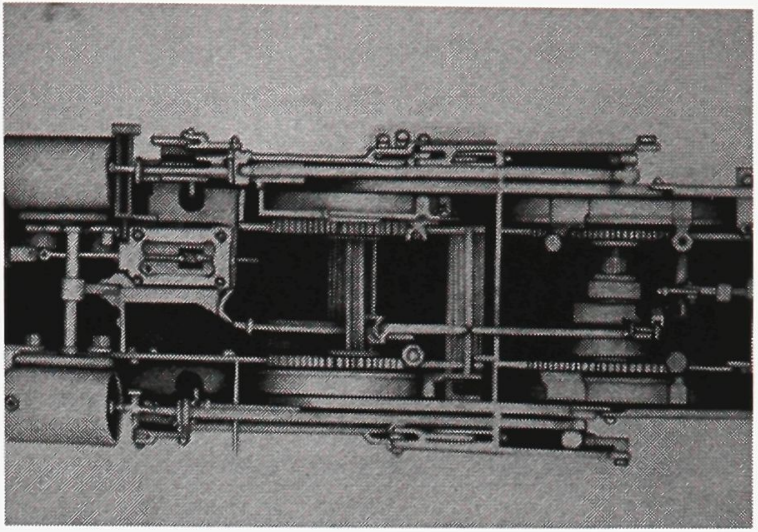

Fig. 8- Detail from the display cabinet

\subsection{Greenaway and Narrative}

Both of these early explorations, the video and the cabinet were inspired by Peter Greenaway's film Prospero's Book. Greenaway's work is representative of the (post)modern use of multi-dimensional spatial concepts and categories through the incorporation of varied and sometimes unexpected media. An analysis of his work can clarify how cinematic and multi-dimensional spaces are able to communicate symbolic and emotional content.

Amy Lawrence talks about the coexistence of a number of 'parallel universes' in the films of Peter Greenaway:

“Greenway's films are marked by an astonishing proliferation of detail and a remarkable breadth of reference... As his movies unfold, the attention shifts from one of these universes to another through the organization of the visual composition development over time. This makes, at certain moments, the perception of one of these parallel spaces to grow stronger in relation to the others. The presence of numerous visual 
citations never lets the viewer to be fully immersed in any one of the parallel spaces without perceiving, through various referents, the existence of the others". ${ }^{2}$

Nothing is clarified as the connections increase, though the possibility for connection and cohesion is enhanced. This produces "a special kind of interactive medium" as each viewer uniquely experiences the film depending on previous experiences, making decisions from the variety of paths presented throughout the film.

Thus, the film and display cabinet offer simultaneous and multi-dimensional representations of the train station that mimic the complexity of the transportation hub, and offer guidance to the design process. The design of the station is thus based on these parallel, diverging and converging narratives that are dependent on the individual experiences and choices of the commuter-subject. This plethora of paths mirrors the general economy of transportation, as people are literally choosing paths into and through the city.

\subsection{Eisenstein and Montage}

Prior to Greenaway, Sergei Eisenstein was experimenting with film technique, and his work provides a key direction to design strategy. Eisenstein defined montage as a 'juxtaposition of different points of view'3 , a definition that allowed him to compare cinematic montage with the construction of other visual representations, such as realist paintings. Eisenstein considered montage as a sequence of segments presented in their

\footnotetext{
${ }^{2}$ Amy Lawrence, The Films of Peter Greenaway (New York: Cambridge University Press, 1997), 1.

${ }^{3}$ Sergei Eisenstein, Nonindifferent Nature, (Cambridge University Press, 1987), viii.
} 
simultaneity: in the consciousness of the perceiver. Each segment is piled on each other, and the incongruence of colour, lighting, outline scale, movement, etc, are the elements that give a sense of dynamic thrust and impulse while generating a sense of movement, ranging from the perception of purely physical movement to the most complex forms of intra-conceptual movement ${ }^{4}$, (e.g. when we are dealing with a montage that juxtaposes metaphors, images or concepts). Eisenstein was fascinated by the 'decomposition' of reality into independent visual and aural signs and their free recombination. Eisenstein consequently emphasized the collision of disparate and conflicting elements in his montages in order to produce, in the synthesis, new concepts and emotions ${ }^{5}$.

Eisenstein identified specific artworks that project movement in an effective way, such as Serov's portrait of Yermolova, Velázquez' Las Meninas, Piranesi’s etchings, etc. For these pieces and others, Eisenstein established a diagrammatic breakdown (fig.20-21-22) to analyze the distinctive features of the composition and to identify the system of expression. He then employed exactly the same means to create the basic effect of dynamism in cinematography. This thesis follows Eisenstein's method of compositional configuration as a design strategy to guide the project.

For example, Serov's portrait of Yermelova (Fig. 9) was achieved through the application of a truly unusual means of compositional expression. One of the most distinguishing elements that Eisenstein identified is the way in which the painting can be seen from different points of view. Thus we see in the painting four theoretical 'shots' of our

\footnotetext{
${ }^{4}$ Eisenstein, ix.

${ }^{5}$ Eisenstein, viii
} 
sequence different from each other not only in the scale of what they depict but in the displacement of the set-up (the point from which the object is viewed). However, by connecting the four viewpoints in a montage sequence, a sense of dynamic movement is conveyed. Exactly the same means are employed to create the basic effect of dynamism in cinematography ${ }^{6}$.

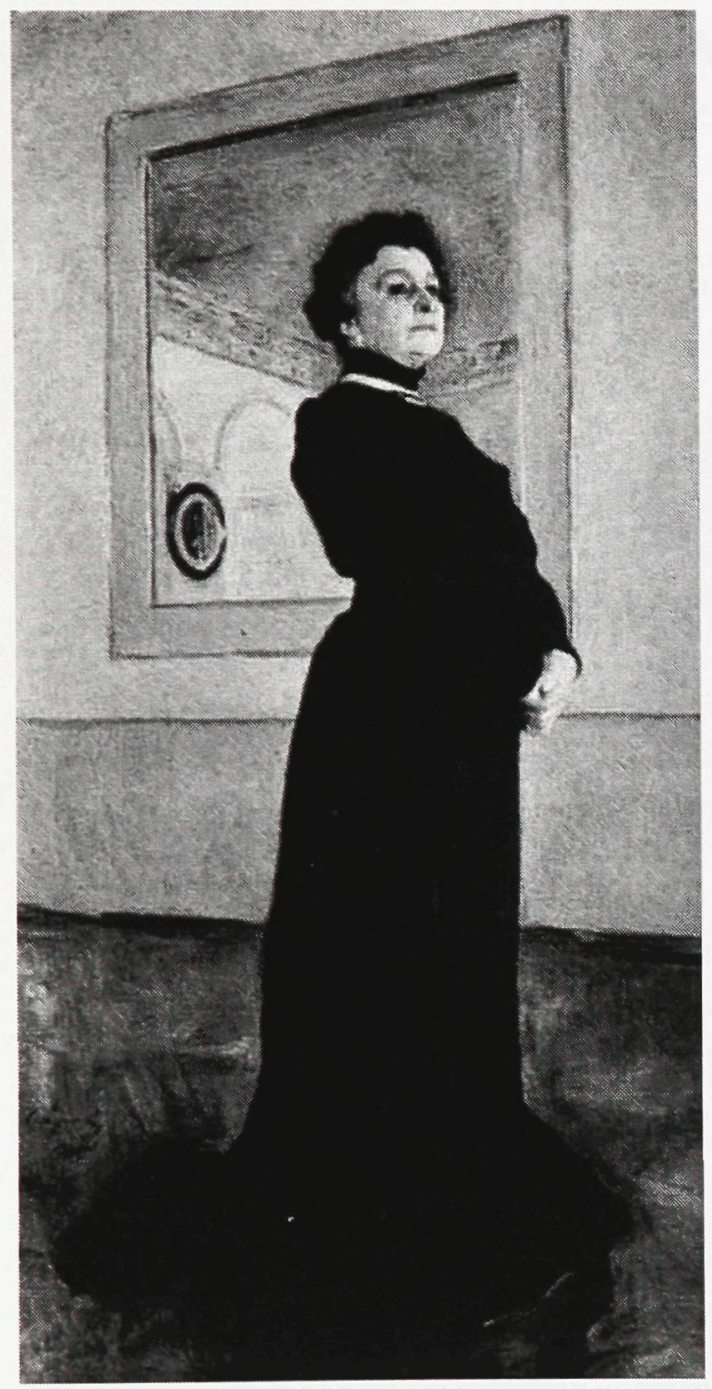

Fig. 9 Yermolova

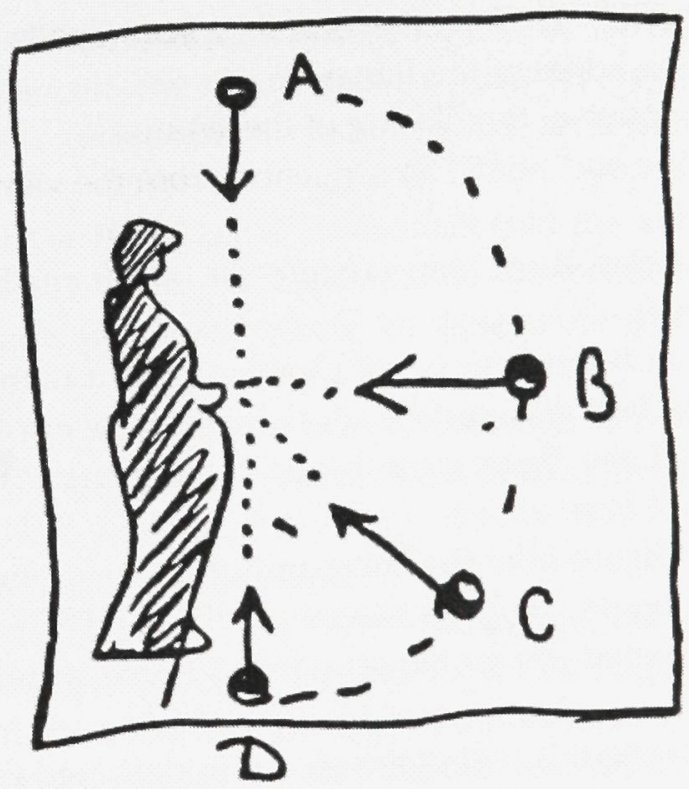

fig. 10 A diagrammatic breakdown sketch by Eisenstein showing the four view points

\footnotetext{
${ }^{6}$ Alla Efimova and Lev Manovich, Tekstura (Chicago: The University of Chicago Press, 1993), 17-21.
} 


\subsection{From Montage to Architectural Principles of Form}

The design strategy for this project begins with the translation of the graphical composition into an architectural spatial form. This architectural-spatial strategy is based on Eisenstein's theoretical interpretation of artworks. Thus, the contextual information provides the basis for understanding the abstract meaning articulated by a series of $3 \mathrm{D}$ analogues, which offer potential forms based on complexly interweaving narratives (following Greenaway) and montage perspective (following Eisenstein) (fig. 11-12-13).

The objective is to examine these dynamic explorations from various angles and points of view, and in various contexts.

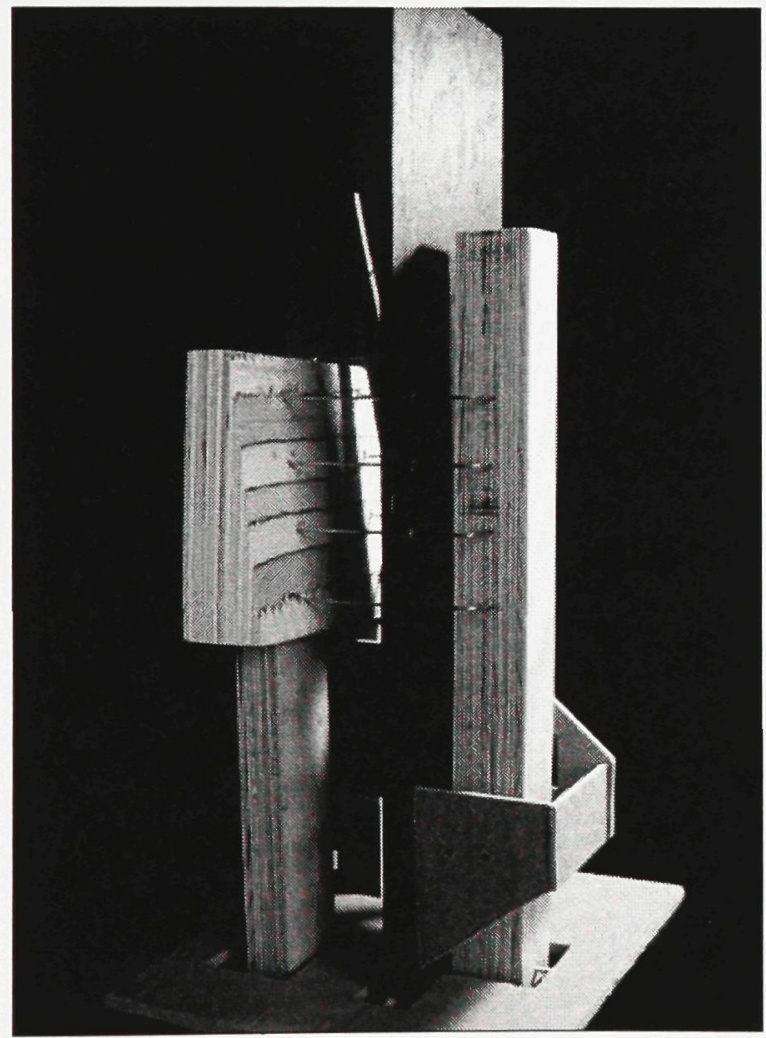

Fig. 11 3-D Analogues

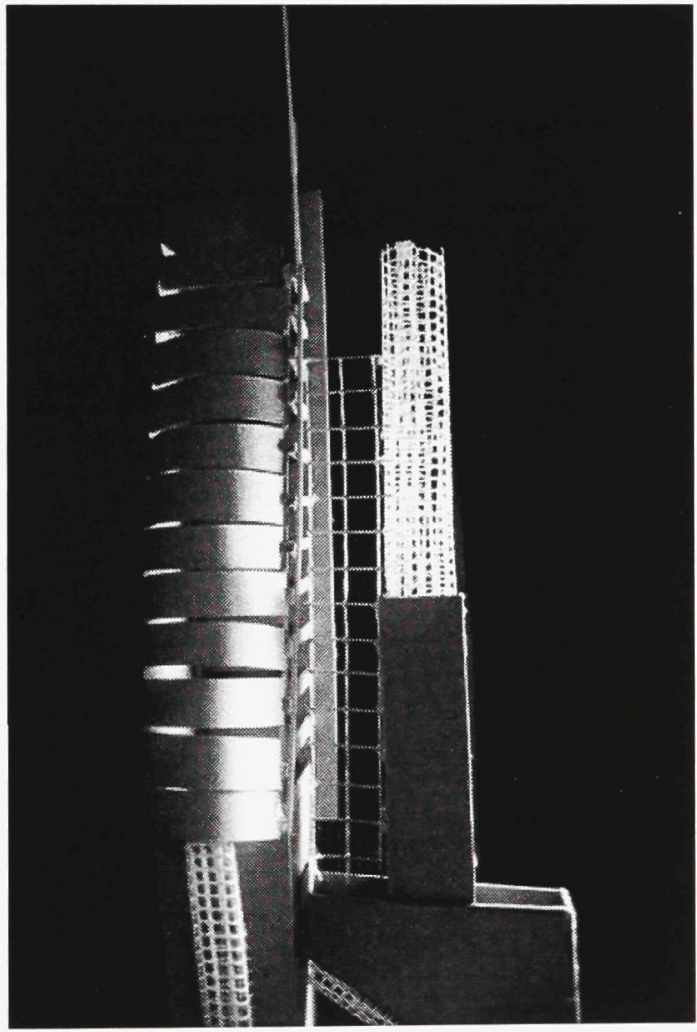

Fig. 12 3-D Analogues 


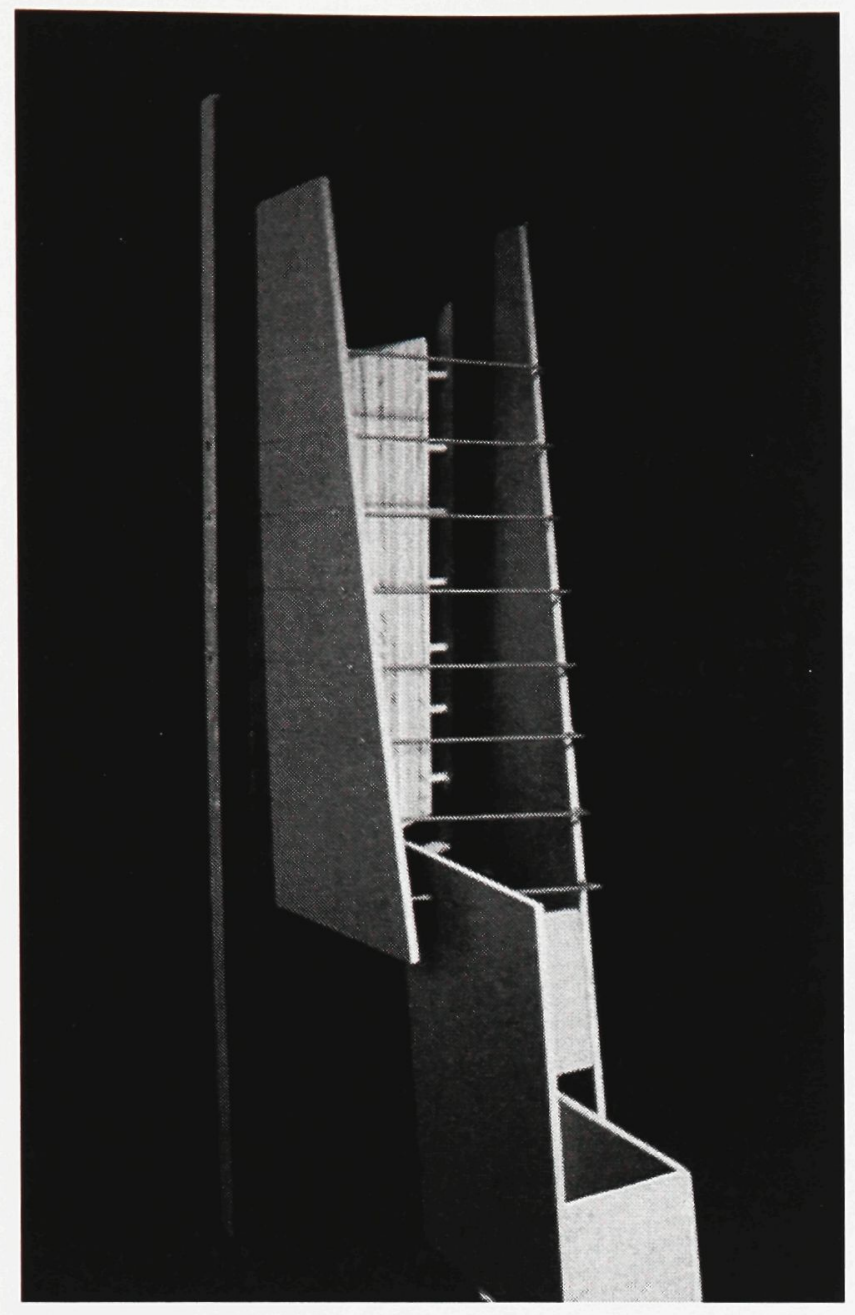

Fig. 13 3-D analogues

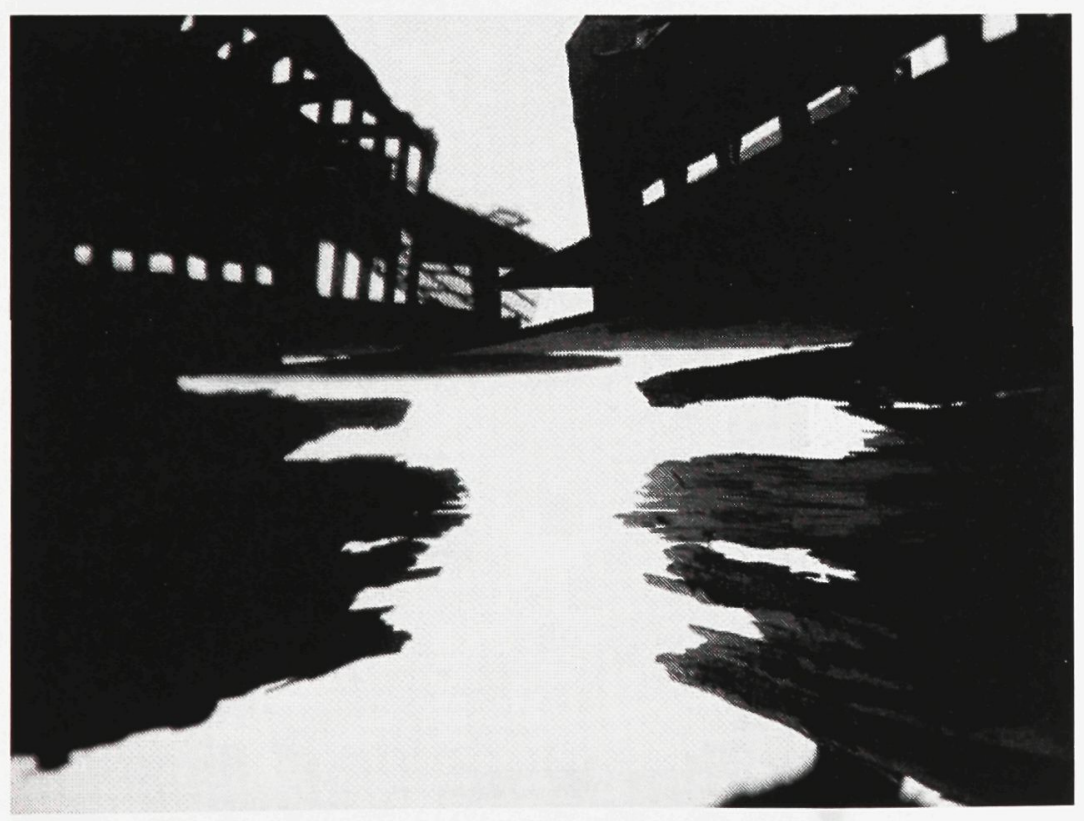

Fig. 14 image generated from 3-D Analogues 

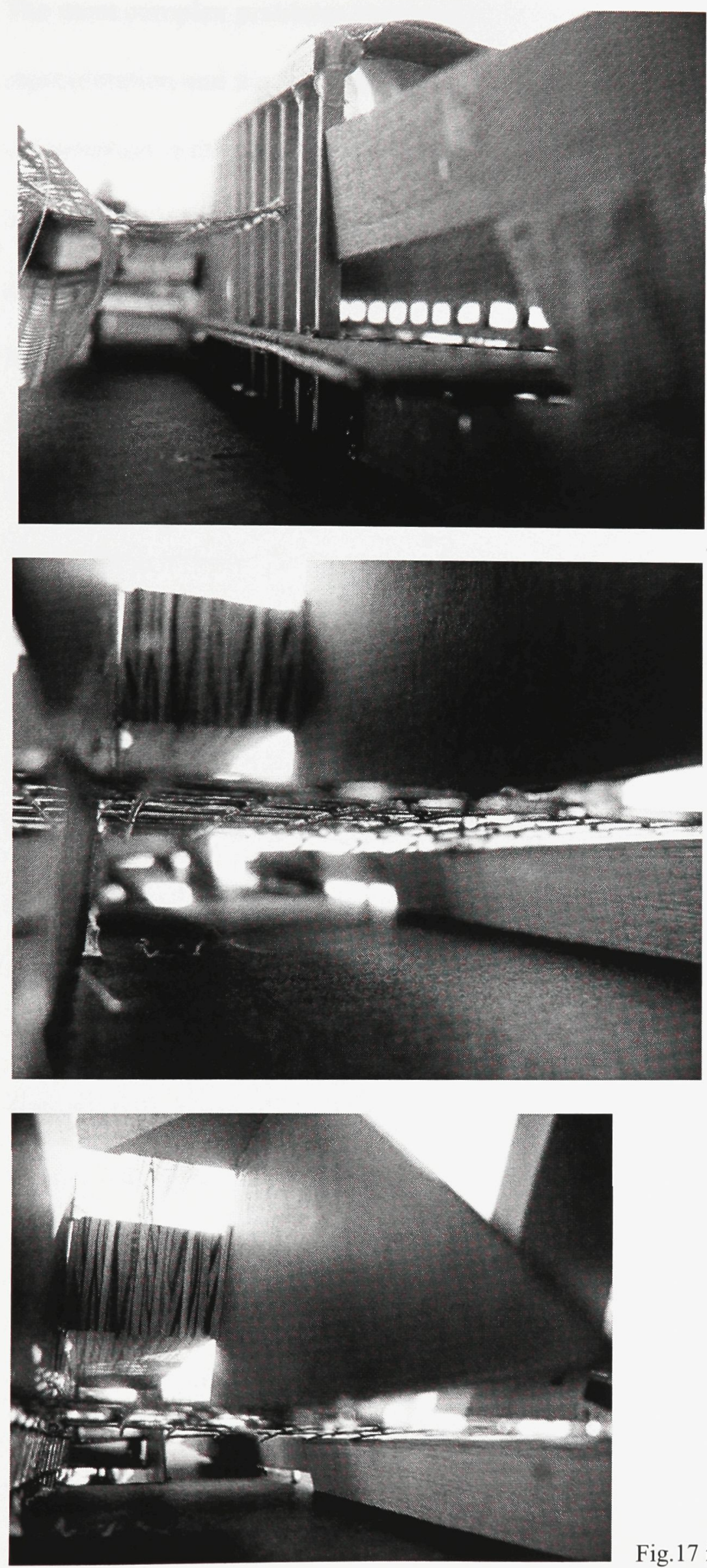

Fig. 15 image generated from 3-D Analogues

Fig. 16 image generated from 3-D Analogues

Fig. 17 image generated from 3-D analogues 
The most complex problems surrounding the structure of a work of art are the representation and the relationship to what is being represented. For Eisenstein, composition is the most effective means of expressing this relationship. The relationship to what is represented is achieved by the manner in which this representation is presented $^{7}$. There is always a relationship between what is shown, how the author relates to it, and how the author wishes the viewers to perceive, feel, and sense what he is representing. In fact, Eisenstein's focus on the intermediate position of theatre between the moving, continuous, real world and the still, discrete world of visual arts, expresses the dynamic between perception and the physical work of art.

Eisenstein's multi-dimensional approach to filmmaking thus provides the process of objectification and formalization of the language of spatial exploration pertinent to the current project. Eisenstein's theory is rooted in the interpretation of art in general, and film in particular, as structured around a dynamic concept of permanent interaction between the characteristic dimensions of the medium. In Eisenstein's theory, the construction of film is operated by controlling and relating the changes developed over time through the various dimensions of cinema. Eisenstein, as an architect and film maker, was obsessed by the symbolic meaning of architectural form ${ }^{8}$. He compares physical architecture to architectural composition in cinematic montages, as for instance, in Gothic churches and in Piranesi's work. He once wrote that: "architecture speaks in the strongest figurative rhetoric of its epoch... of its system or of its inner aspiration".9

Eisenstein's own personal ecstasy over Piranesi's work is expressed not only in structural

\footnotetext{
${ }^{7}$ Eisenstein, 3 .

${ }^{8}$ Eisenstein, viii.

${ }^{9}$ Eisenstein, viii.
} 
diagrams of the spatial and graphic explosions, but also in the poetic and metaphorical quality of Eisenstein prose.

Eisenstein thus proposed a set of dimensions and defined a number of principles for controlling the development of details in different dimensions, which can be understood as one of the basic mechanism of film making. The revolutionary set of visual dimensions proposed by Eisenstein included, angle of view, juxtaposition, volumes, depth, texture, light, colour, sound, time, movement etc. the principle of counter point provides the basis for controlling changes in various filmic dimension. A growing conflict in one dimension shifts the focus toward details in the respective dimension and it is operated by means of montage ${ }^{10}$. These concepts can be equally applied to an architectural context, and they will provide the thesis with a conceptual framework to tie together everyday experience, visual culture and built form, through the analysis and design of space- time relationships. These can be elaborated as follows:

\subsubsection{Movement}

The experience of movement can be expressed through a projection of axes. This underlying grid of repetitive vertical and horizontal axes is mostly carried by the outline of the model. These repeated verticals and horizontals emphasize the dynamic character of a vibrant community and reflect the dynamics of life in the city. These can be perceived as physical elements incorporating the suggestion of movement with a sense of direction. In addition, the dynamics of the visual experience can be explored throughout the building by emphasizing vectors of movement and the dynamics of form. Through

\footnotetext{
${ }^{10}$ Sergei Eisenstein, Film Form (New York: Meridian books, 1957), 39.
} 
the combination of complex and intersecting lines and forms, the eye is rapidly drawn from one detail to another. There is no stagnation; there is only a constant motion. The exploration of space in the design phase is thus organized around the main compositional lines of force in an attempt to highlight the paths of movement and capture the dynamics of the architectural space. Inherent in this is the shift from vertical conditions to horizontal features as well as the linear progression of spaces along paths. For example, the Bus/Train Stop (fig. 18-19) is extended vertically to accommodate not only the difference in the elevation but to allow commuters a better view the city. Similarly, (the same can be applied to each building).

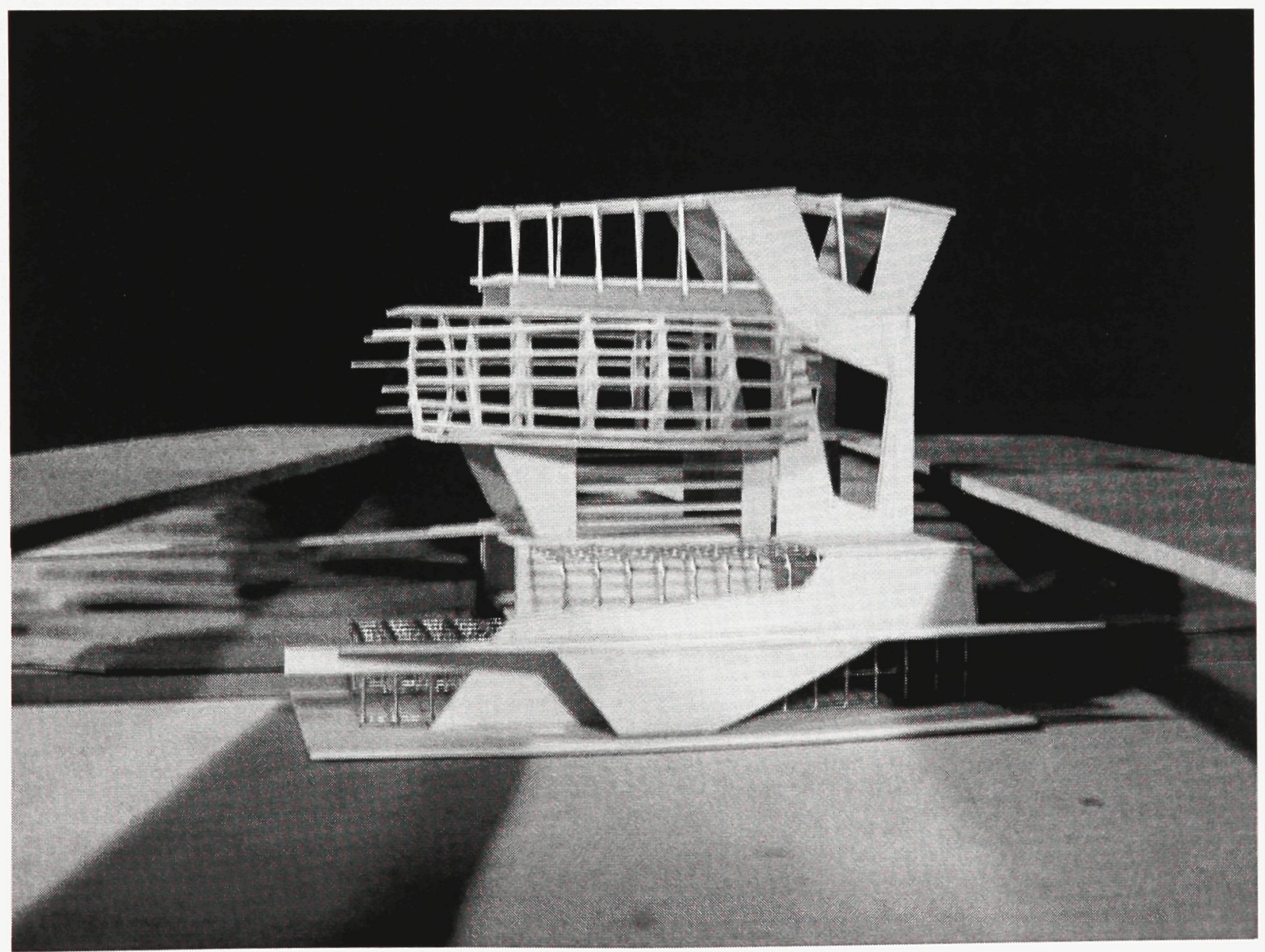

Fig. 18 Bus/Train Stop 


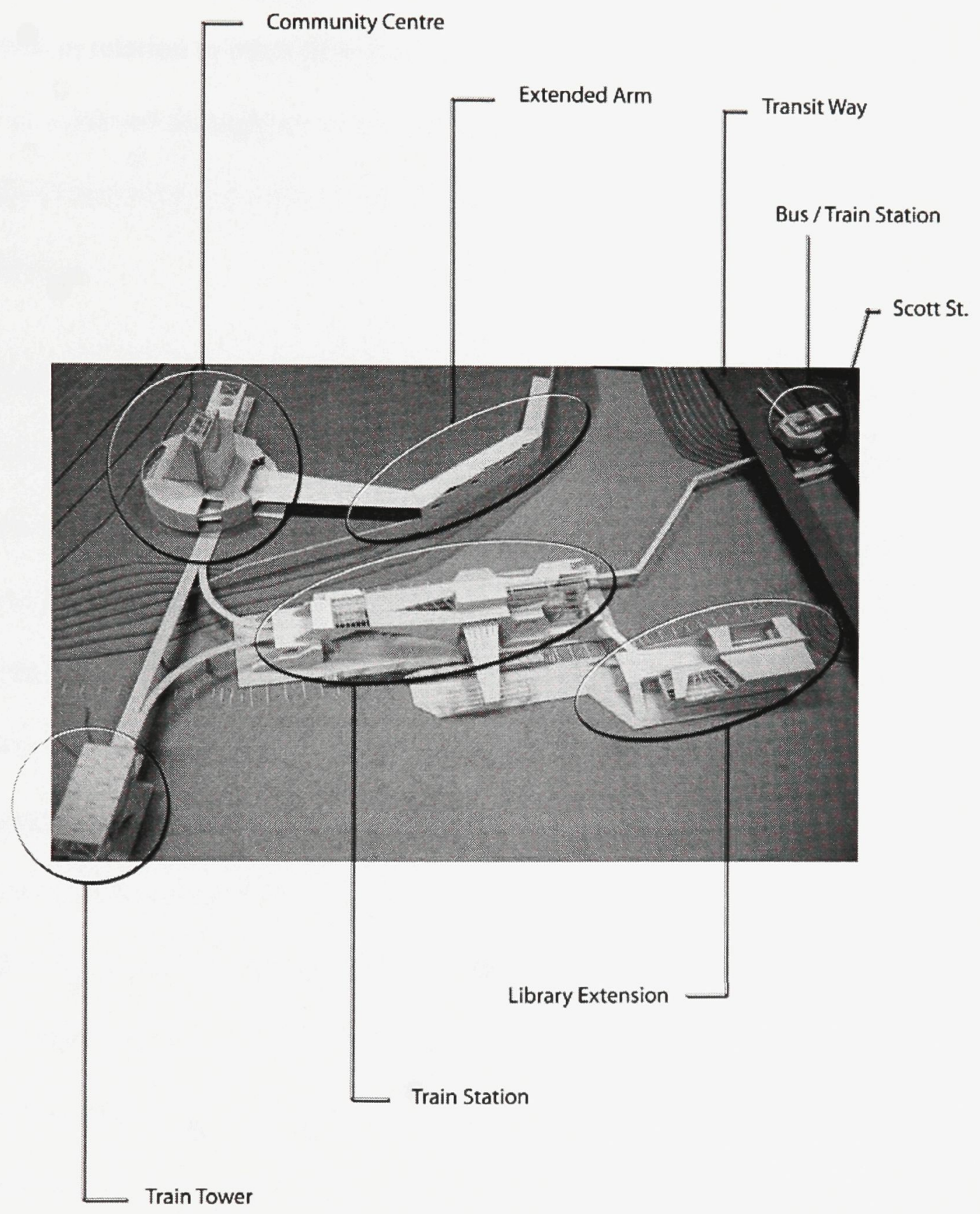

Fig. 19 project overview 


\subsubsection{Depth}

The element of depth plays an important role in Eisenstein's theory in reference to the manipulation of the angle of view. Depth helps establish the spatial relationship between elements (objects) in a composition. It is achieved by using light, colour, and texture and is important in relation to other specific dimensions of the composition. Architecturally, this will be achieved through the subtle modulation of surfaces to suggest the nonuniformity of materials and emphasize the temporal transformation of material by erosion and oxidation.

\subsubsection{Light}

Light is the 'materia' of the cinematic medium, and its manipulation is crucial in order to obtain desired effects; without it no shapes or forms can be perceived. Architecturally, any spatial experience is intimately connected with the experience of light. The range of lighting effects enhances the range of psychological experiences, gives a building form, and defines spaces. Furthermore, light engages and transforms material and space emphasizing depth and movement. Greenaway is especially adept in exploring the possibilities of light, using sun-light, moon-light, florescent lights, car-head-lamps, the light from a TV set, and in one incredible scene, the reflected light from a rainbow. This not only creates certain moods, but points back to light itself and demonstrates the range of possibilities that can be achieved. Similarly, built forms with a complex and varied use of light will add to over changing lived experience of the building. 


\subsubsection{Narrative}

Traditional film-making considers narration as an essential element in cinema. The narrative dimension is also a key element in the design process because it carries the same function that narration has in the traditional film. Narrative makes use of the structures and techniques of architectural framing to open up the possibilities of the architectural experience over time. From Eisenstein, the purpose of an (architectural) narrative is to convey abstract meaning in the process of an exploration that follows the paths suggested in the art work (architecture, painting, etc.) The intention is to carry the same experience when gazing through paintings (and in this context, through spatial sequencing) and to convey potential new meanings, and different perceptions of the essential truths that govern our lives.

\subsubsection{Positioning (metaphor of pose and gesture)}

Objects and elements in a painting should be in complete compositional harmony. The pose of a model, for example, should be a total, generalizing image of the multiplicity of positions and movements that are characteristic of the model's real behaviour. In the case of cinema, this would include the actor's behaviour, gestures and voice. Each of these aspects derives inseparably from the other, and, taken together, they both derive from the idea, theme, and content of the screenplay. Similarly, the intention of the architect is to question how architecture's spatial forms are actualized by parallel strategies and means. 


\subsubsection{Collage (Superimposition and juxtaposition)}

Collage was used effectively by both Eisenstein and Greenaway, and is an effective way to organize a complex building program. Rather than 'collage,' Eisenstein used the term "montage' to indicate the process of superposition and integration of the various structural levels of cinema: landscape and scenery, mise-en-scene, enjambment, gesture, music, lighting, and colour ${ }^{11}$. Also, Eisenstein claimed that all of these levels should reflect the dominance of a unifying theme, one which governs all of the choices in all participating 'lines': "The juxtaposition of these partial details in a given montage construction calls to life and forces into the light that general quality in which each detail has participated and which binds together all the details into a whole, namely into that generalized artistic image, wherein the creator, followed by the spectator, experiences the theme". ${ }^{12}$ A Collage method, specifically the juxtaposition of partial details, is a highly effective means to emphasize the movement and force inherent in architectural representations.

Similar to Eisenstein, the most powerful impact of Greenaway's films comes from the remediation of the specific means of expression from graphics, painting, and photography into the film medium, based on collage techniques. The combination of unrelated objects into a unifying visual composition, which, in subtle ways, still reminds the view of the individual parts, transforms the scene into a dynamic collage of emerging and receding

\footnotetext{
${ }^{11}$ Eisenstein, Nonindifferent, xv.

${ }^{12}$ Eisenstein, the Film Sense, 11.
} 
worlds. Almost every one of Greenaway's important shot sequences suggests a complex collage as a container of multiple meanings ${ }^{13}$.

\subsubsection{Subject/Object Relationship}

The analysis of possible gazes between the subject and the object points to particular sites where this dialectic is encountered - representational painting, fiction films, or architecture - and makes the relationship between the viewer and the viewed explicit. The identification of subject matter does not come from looking at what is familiar in the art work, but instead comes from an artist's ability to show us something that we do not know of the subject/object depicted - the something that is unknown, yet still recognizable as an attribute belonging to the subject captured. A degree of recognition in the composition is still acknowledged, but it does not exclusively occur through the representation of physical traits ${ }^{14}$.

Another quality inherent in the creation of paintings and film is the notion of transaction. Within any artwork there is always a connection between the artist and the viewer. The creative process is the translation of the artist's own subjectivities and interpretation of the composition onto the canvas. Thus, each viewer lends his/her own subjectivity to the interpretation of the $\operatorname{artwork}^{15}$. The transaction inherent in works such as Las Meninas, as discussed by Michel Foucault (fig 20), cannot be simply symbolized by a meeting of

\footnotetext{
${ }^{13}$ Willoquet-Maricondi Paula and Mary Alemany-Galway. Peter Greenaway's Postmodern/Poststructuralist Cinema, (Lanham, Md.: Scarecrow Press, 2001), 90.

${ }^{14}$ Michel Foucault, the Order of Things, (New York: Pantheon Books, 1970.). 10.

${ }^{15}$ Foucault, 10.
} 
subject and object because it is unclear where the subjectivities of artist, sitter and viewer can be determined. Thus, using the above concepts of movement, depth, light, narrative, positioning and collage, this final consideration, the emphasis of the subject/object relationship can be manifest architecturally. For example, as shown in the design, the provision of walkways for a variety of different purposes, both functional and nonfunctional, allows inhabitants to reconsider their relationship to the space and to others sharing that space. Also, through the manipulation of light and movement, large structural forms will be created that offer inhabitants a wide range of phenomenological possibilities.

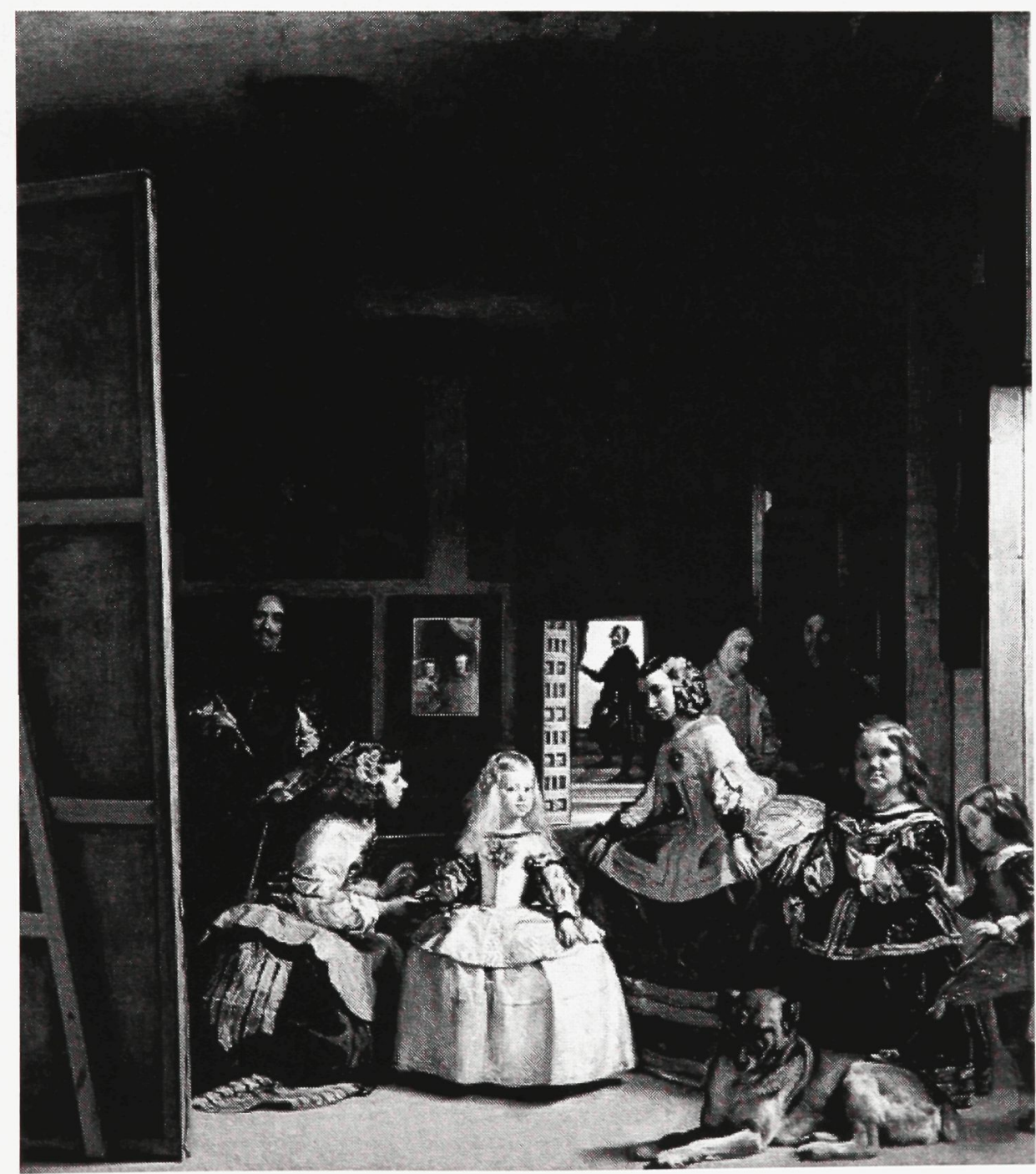

Fig. 20 ‘Las Meninas’ By Velazquez 


\subsection{Design Methodology - Employing the Visual Analysis of Paintings to Derive Architectural Relationships}

In order to develop a built form based on the multi-layered exploration of visual perception, Velázquez' Las Meninas was subjected to an Eisensteinian analysis. Using the above categories, a series of 3-D 'analogues' were generated (fig 11-12-13) to form the basis for the design, and to derive various perspectives and spatial relationships in a proposed reality. The direct information extends from the technical data extracted from the painting by focusing on composition, dynamism, atmosphere and the abstract meanings conveyed. Also considered are observable phenomenon such as layering, framing, reflections and point of view. This derived data is important for the attainment of the correct proportional relationships between the architectural forms as well as in the creation envisioned by the observer (architect). The visual analysis provides information about the dynamics of the graphical composition, specific atmosphere conveyed, and symbolic meaning. The diagrammatic breakdown (fig. 22-23-24-25) allowed Eisenstein to establish and analyze the distinctive features of the compositional art work and to identify the system of expression ${ }^{16}$. Thus, the thesis aims to abstract Eisenstein's analysis into 3D spatial forms and experiences.

${ }^{16}$ Alla Efimova, 17. 


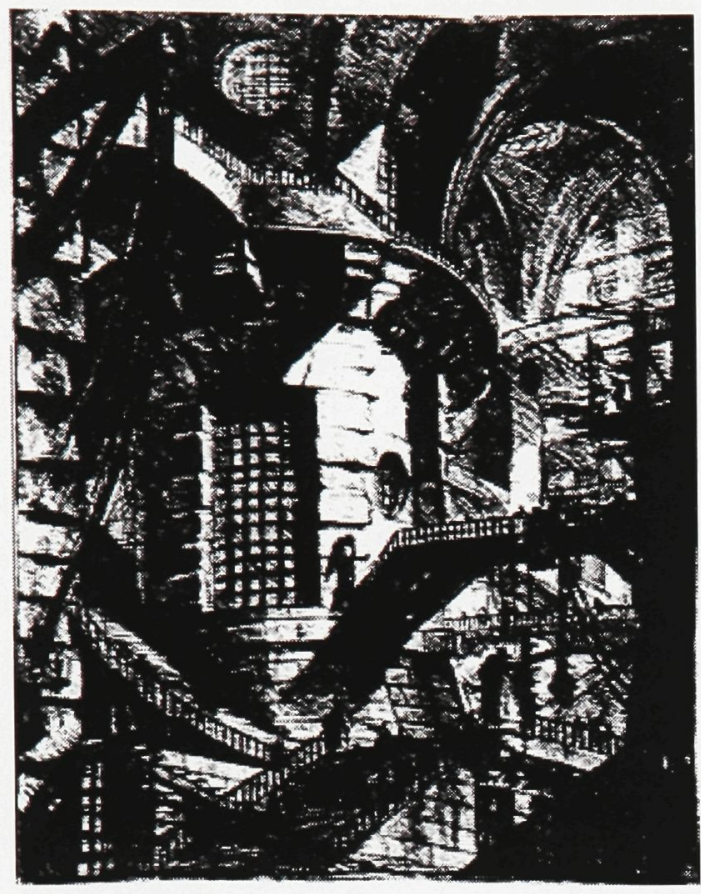

Fig. 21 Dark Dungeon (or Dark Prison) By G. B. Piranesi, 1743
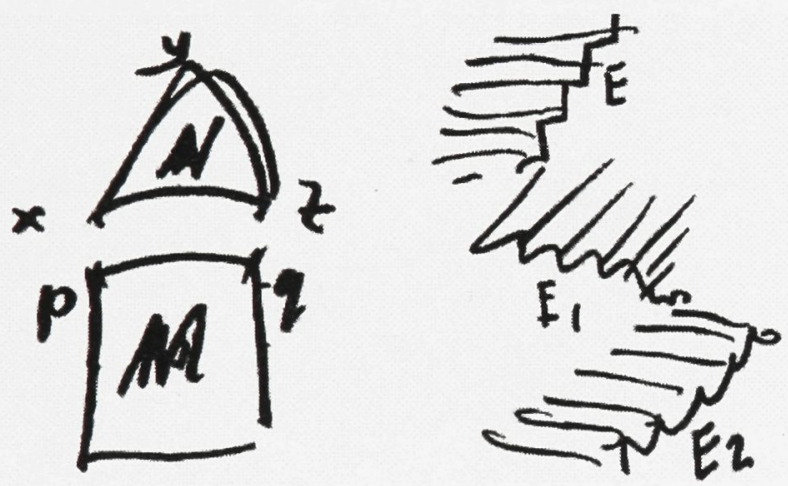

Fig. 23

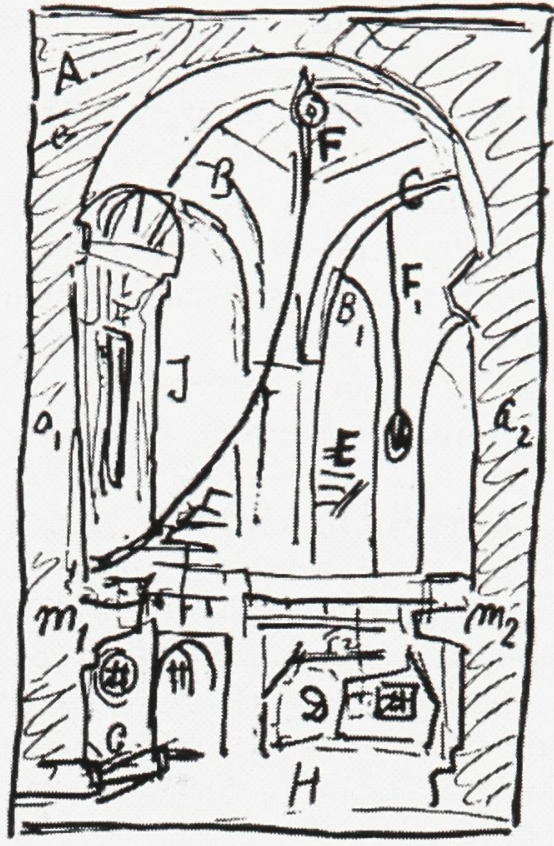

Fig. 22 Eisenstein Diagrammatic sketch for Piranesi's etching

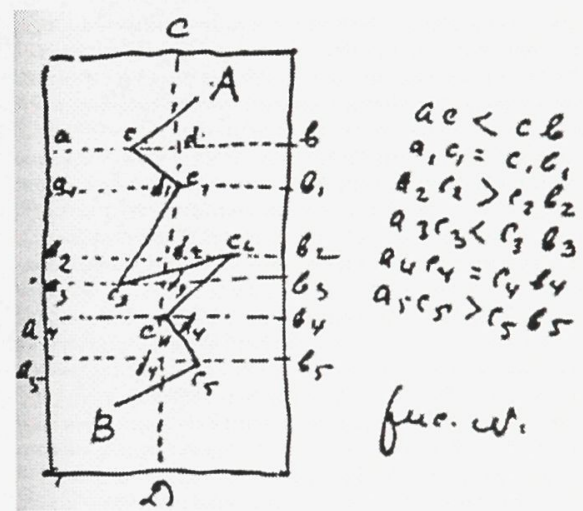

Fig. 24
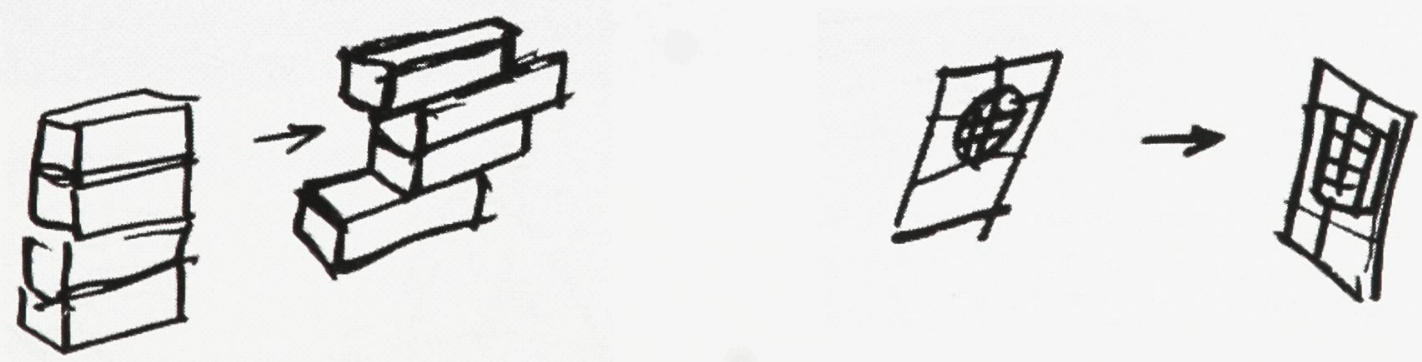

Fig. 22-23-24 and 25 Eisenstein analyzing Piranesi's etching 
The abstracted 3D analogues are to be considered as instruments to investigate specific physical and spatial conditions of the site (fig. 26-27-28). For example, they are used to explore the vertical and the horizontal axes of the site, as the viewer engages in various types of activities in the surrounding environment. As one moves around in space, many different views reveal the vast programmatic and spatial variety that surrounds and encompasses the site. Thus, these analogues help in the creation of the spaces that would allow commuters to experience the building and its context from multiple points of view while elaborating their dynamic characteristics.

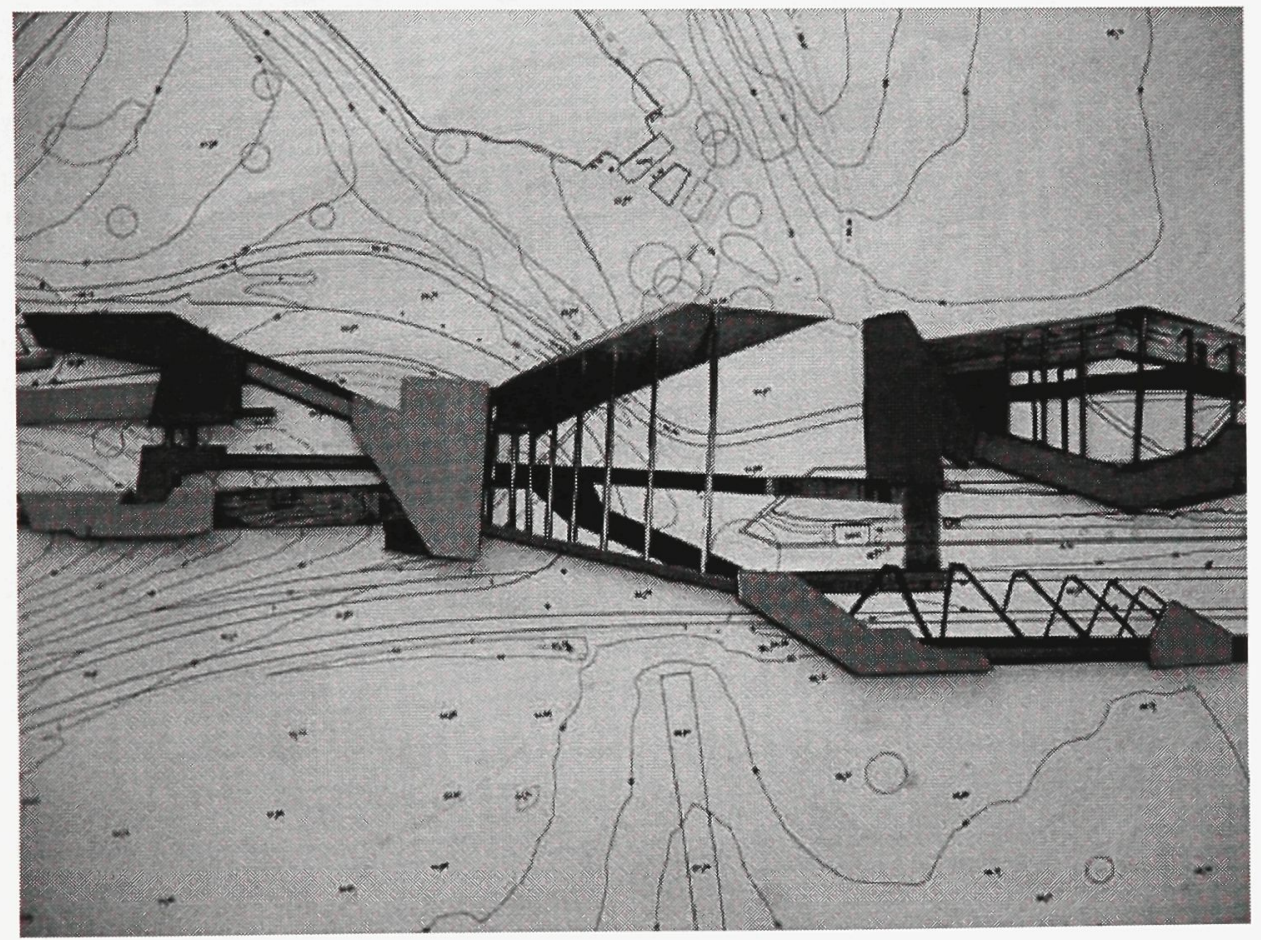

Fig. 26 Exploration of the abstracted 3-D analogues on Bayview site 


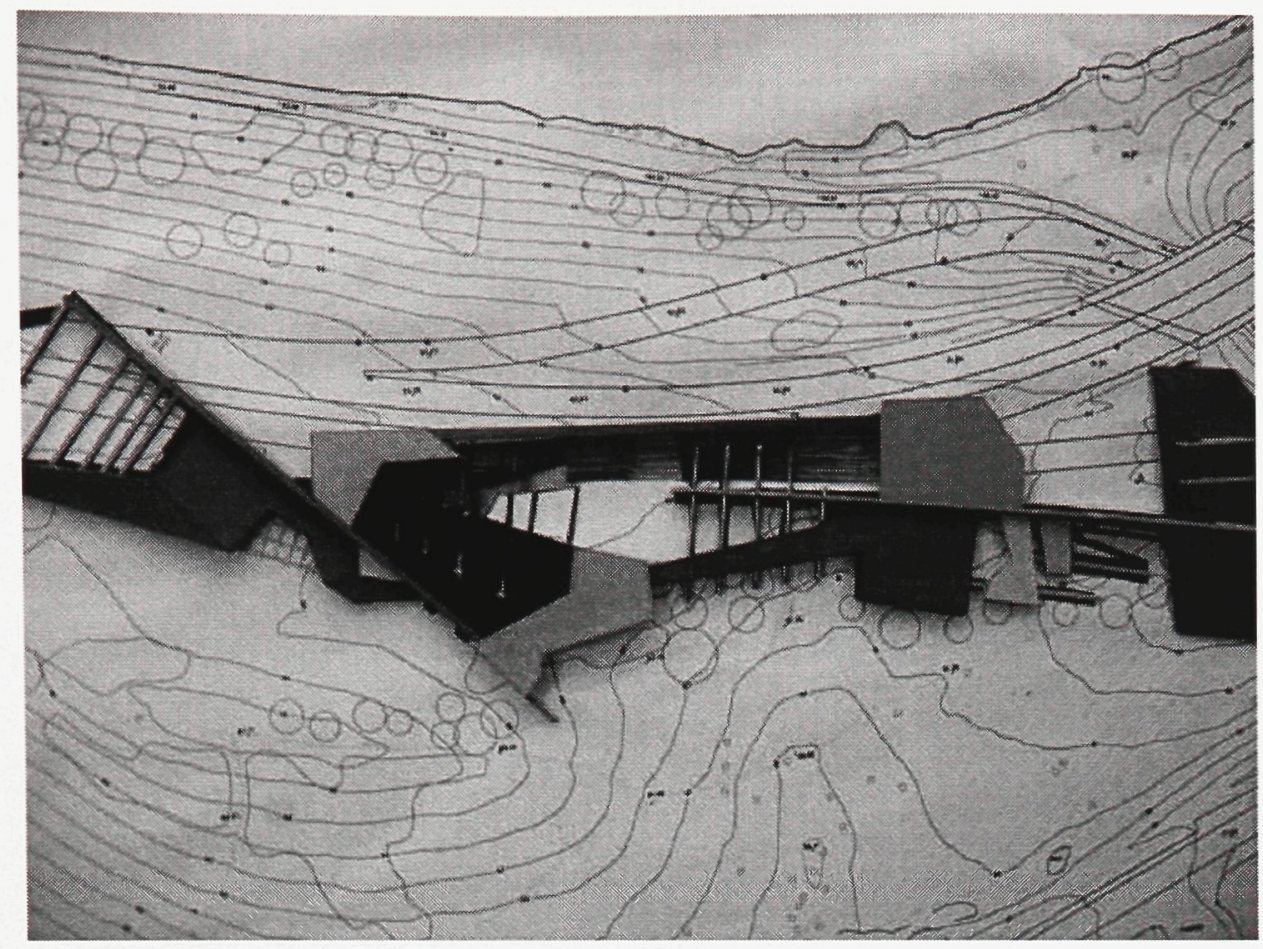

Fig. 27 Exploration of the abstracted 3-D analogues on Bayview site

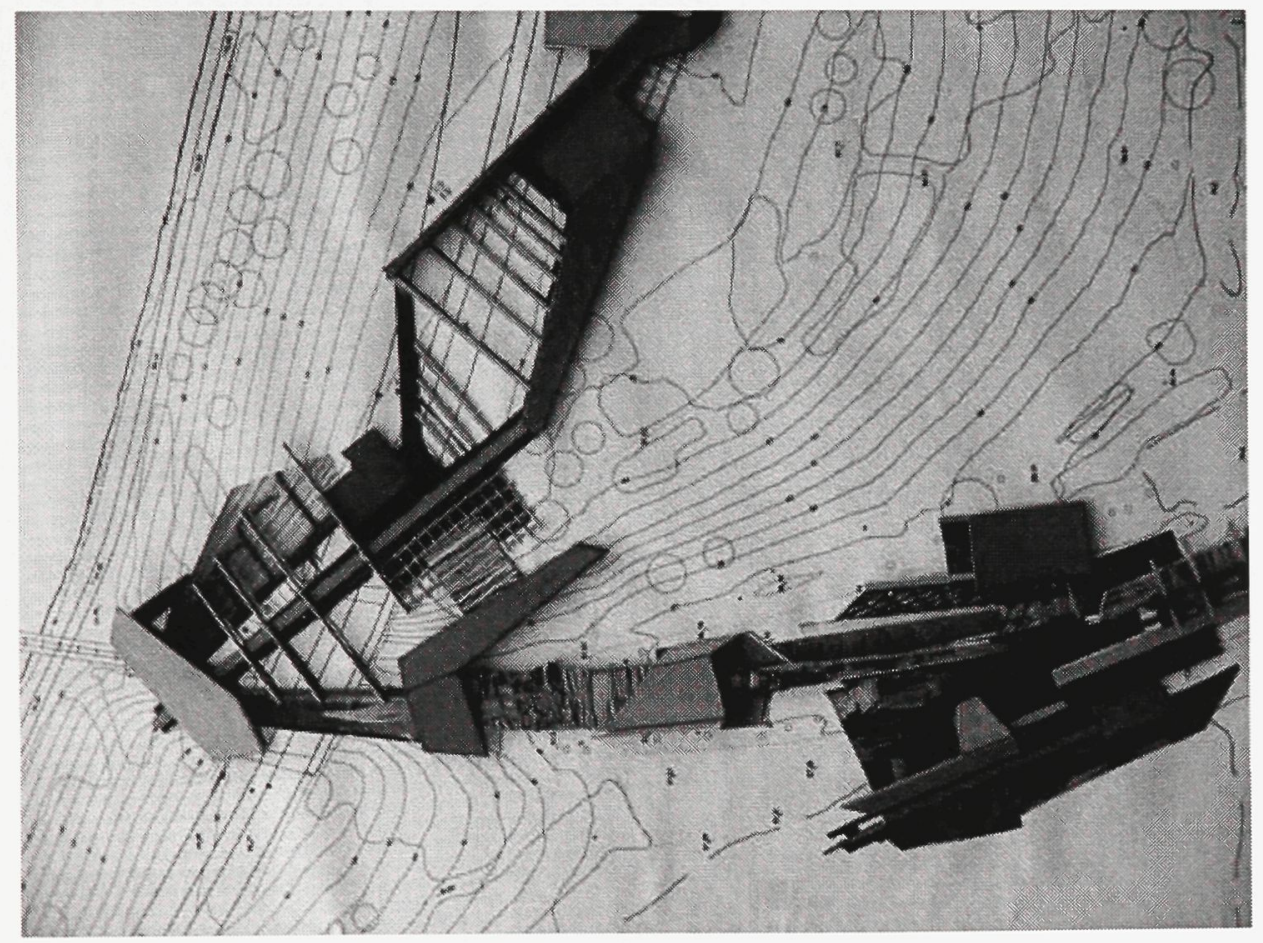

Fig. 28 Exploration of the abstracted 3-D analogues on Bayview site

Many factors exert significant influences upon the project's design decisions, whether aesthetic, technological or otherwise. Some of these include physical site constraints such as topography, orientation and climate. These conditions, however, also allow the poetic 
articulation of architectural space as a reconstruction of the visual experience inspired by paintings. Material, light, shadow, juxtaposition, depth, etc. are all tools in the digital environment to create space that awakens the senses. Light, for example, can be manipulated to influence the perception of objects, space, and specific atmosphere in accordance with the multidimensional design, architectural program and the physical constraints of the site.

This design strategy focuses on the challenge of finding certain design guidelines that allow the analogues to communicate and integrate with each other. For example, these analogues were superimposed or put into the context of the surrounding site to help locate optimal or interesting positions of the buildings. Moreover, to solve the issue of the contour/elevation of the site, the same analogues were explored vertically to help bridge or link the different areas of the site. However, these analogues, while somewhat elementary, do not merely play on the surface; they penetrate transparently and spatially with each other in accordance to the nature of the site (as shown in plate 1). As with montages, the analogues acquire a 'plastic' effect while being integrated with the architecture, depending on their placement in the sequence of movement in relation to the site conditions. As one walks within the space, certain elements of the composition become visible and concrete while others remain elusive, and others vanish altogether. They are to be seen as fragments of a montage combined as a narrative in such a way that they promote possible emotions and experiences such as joy or sorrow, calmness or anxiety. These emotional states in turn stimulate the imagination by evoking innumerable emotional responses in different time sequences without a beginning or end. 
Plate 1. showing different stages in the design

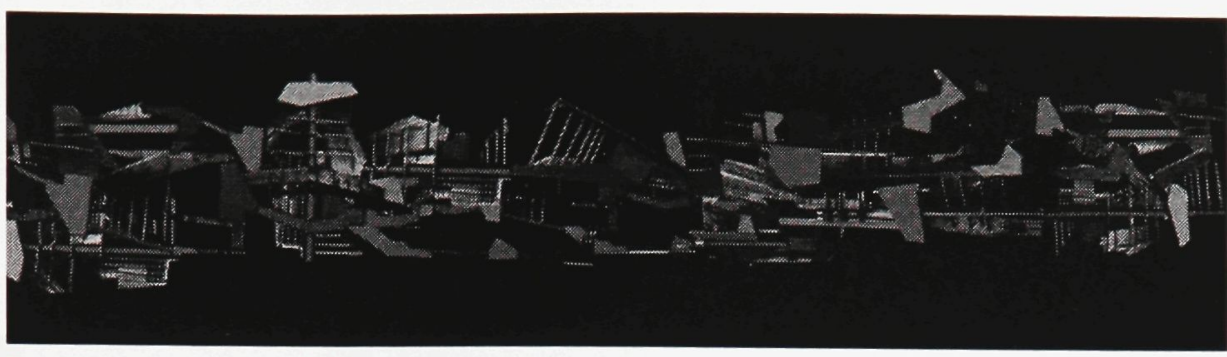

Fig. 29 juxtaposition of the abstracted 3-D analogues

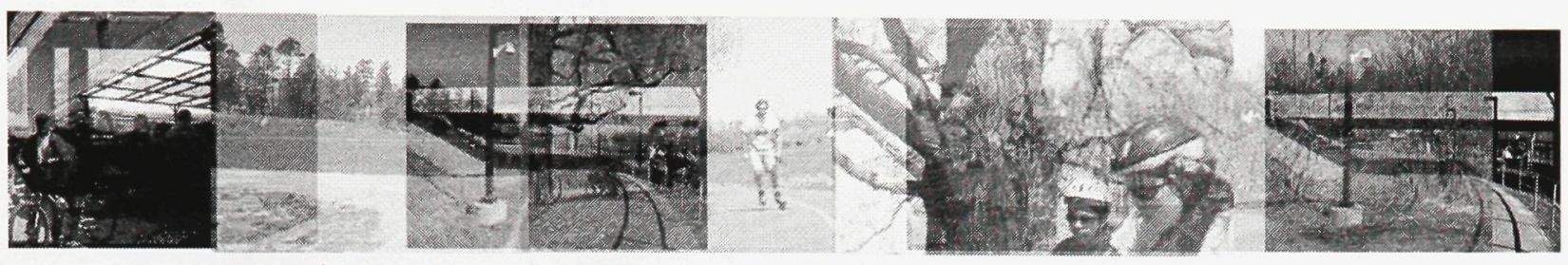

ig. 30 exploration of site conditions, program and narrative

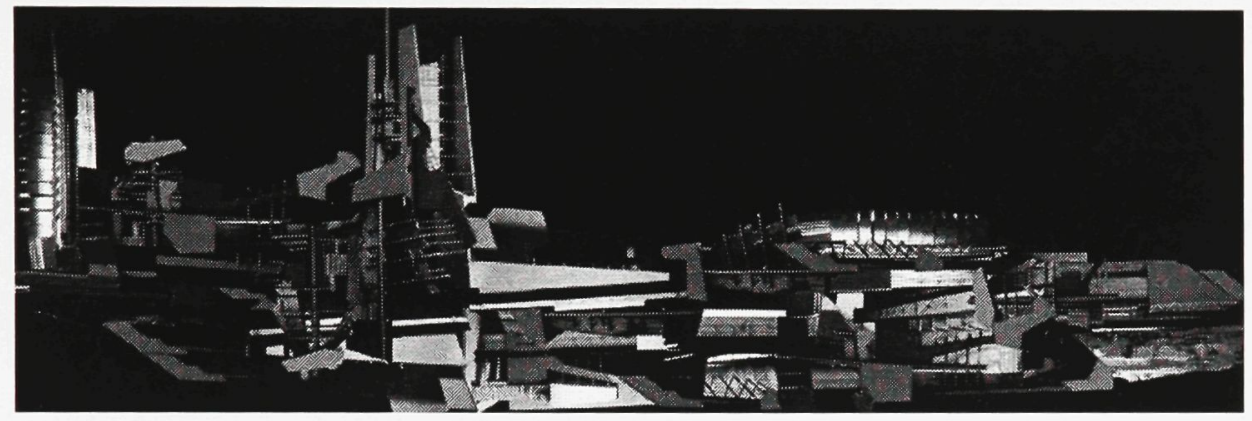

Fig. 31 juxtaposition of the abstracted 3-D analogues

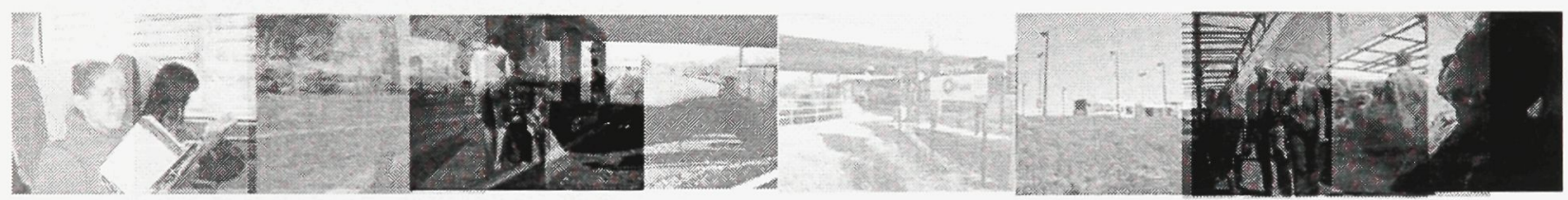

Fig. 32 exploration of site conditions, program and narrative

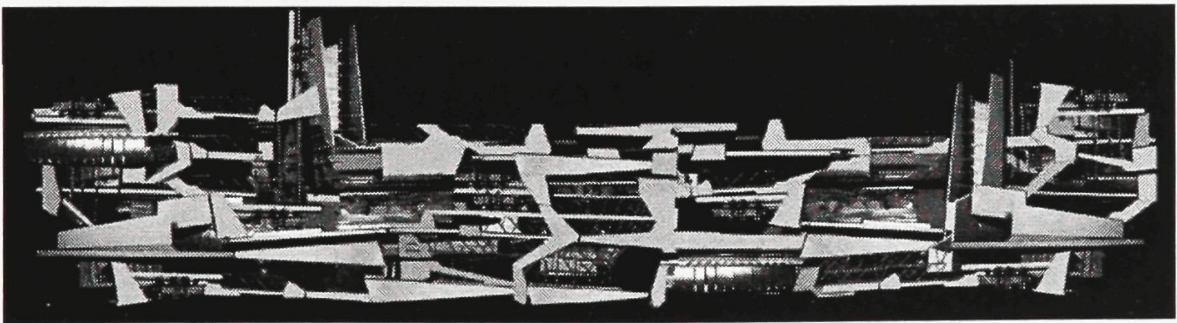

Fig. 33 juxtaposition of the abstracted 3-D analogues 
In this way, the architect is like a film director assembling different materials through narratives, which are programmed through particular activities taking place within indeterminate and fluctuating boundaries. The experience of the station is thus analogous to the experience of a film montage. The audience is invited to participate creatively in the reconstruction of the tactile space suggested by the montage. As Sergei Eisenstein writes:

"The power of montage resides in that it includes in the creative process the emotions and mind of the spectator. The spectator is compelled to proceed along that same creative road that the author travelled in creating the image. The spectator not only sees the represented element of the finished work, but also experiences the dynamic process of the emergence and assembly of the image just as it was experienced by the author"17.

Architecture and cinema have more in common in the cross-translation of two-dimensional and three-dimensional space since they share the desire to give the living feelings of the human being their proper place in a constructed world. As one walks within the station, he/she becomes a co-author; the movement and engagement of the observer is indispensable for the meaning of the images and spaces. Certain elements of the composition become visible while other vanish, as a dialectic of revealing and concealing operates spontaneously in the field of the observer's space. Based on the analogy with the cinematic montage, this thesis introduces temporality and the necessity for the viewer/visitor to participate in the visual experiences within the station. A

${ }^{17}$ Eisenstein, the Film Sense, 37. 
distance is created for self-conscious interpretation, a distance that Nietzsche believed to be important to learning to see, "habituating the eye to repose, to patience, to letting things come to it [...] the essence of it is precisely not to 'will', the ability to defer decision"18 The space ideally helps the inhabitant to experience an embodied, subjective spatiality through both active and passive mechanisms.

One of the key issues addressed in this thesis is how the process of taking details from reality or from already deformed representations of reality, (drawings, photographs, etchings, etc,) stresses dynamism and includes the creative role of the spectator or viewer, or user, depending on the representational medium. Experiments with the power of individual interpretation used by Piranesi and later by Eisenstein, become even more significant through the use of new media. The new medium of digital image manipulation, for example, has the potential of undertaking Eisenstein's experiments by investigating the architectural space through a succession of events over time while allowing for the interaction of these events with each other to connect and bring new meaning to the architectural composition ${ }^{19}$. Based on Eisenstein's theoretical analysis through diagrams on generating ideas and set up the stage; the thesis aims to explore these diagrams in three dimensional forms, or analogues.

All the elements of these analogues are fragmented, juxtaposed and reconciled according to the ideas of collage. Essentially, these 3-D analogues are fragments laid out on the site

\footnotetext{
${ }^{18}$ Albert Gomez and Louise Pelletier, Architecture representation and the Perspective Hinge, (Cambridge: MIT Press, 1997)

${ }^{19}$ Eisenstein, Nonindifferent Nature, 127.
} 
and transformed to become the physical components of the proposed complex of buildings (Fig.26-27-28). The intention here is to bring a new and unpredictable meaning to the design process, but still in keeping with the overall governing idea of movement and transportation in a key urban site that combines a variety of uses, a strong community and the natural surroundings.

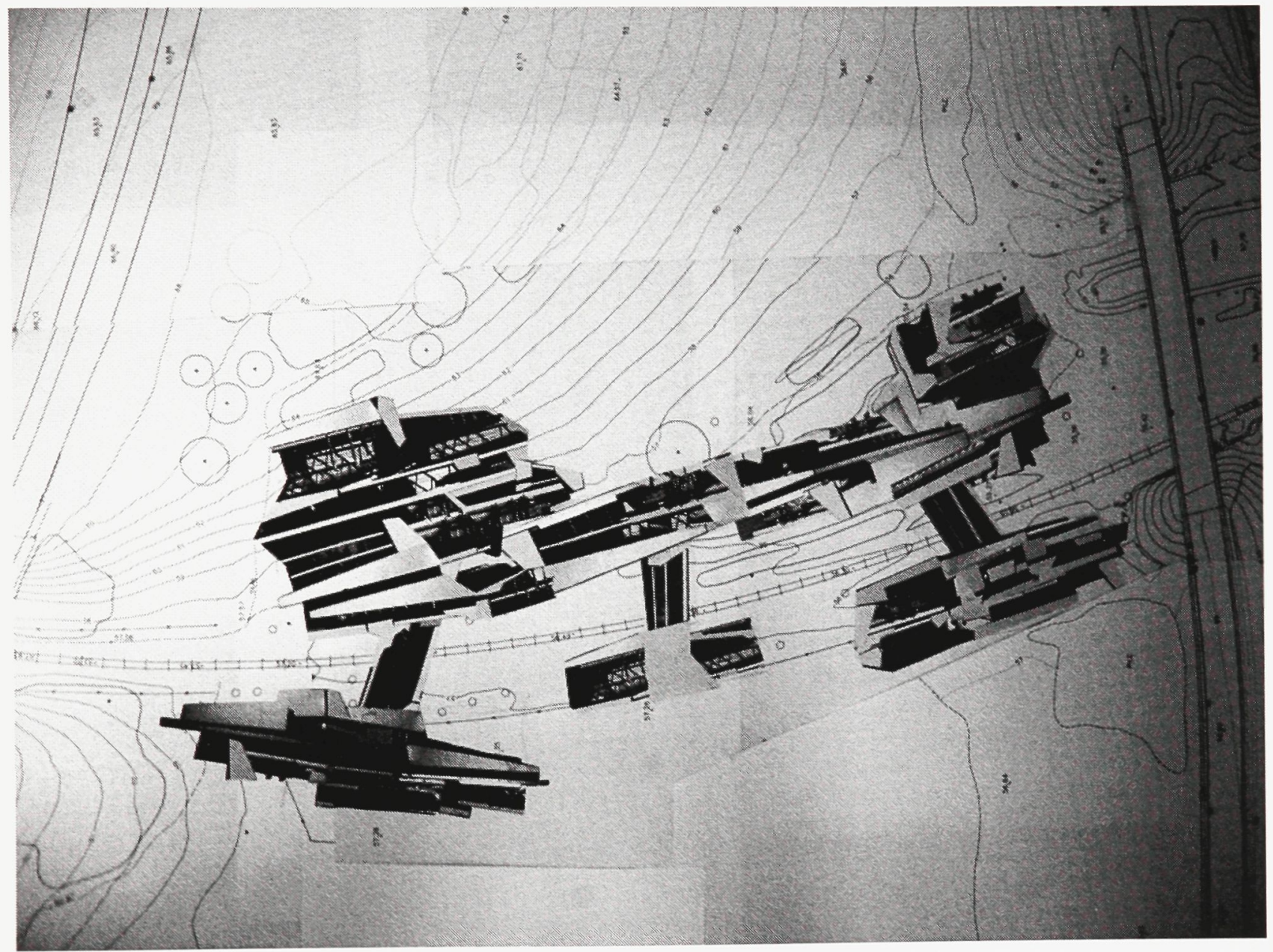

Fig. 34 collage showing the last stage of design exploration 


\section{Chapter 3}

\subsection{The Site and its current development context}

Lebreton Flats is currently surrounded by three major communities: Mechanicsville, Hintonburg and Somerset Heights. In accordance with current urban development proposals, the flats are divided into a variety of uses and functions (fig 35-36). The National Capital Commission (NCC) has a plan for a few thousand residential units. Office and retail space will also be included to provide a completely self-sustaining neighbourhood. Similarly, the City of Ottawa has a proposal for approximately 1,700 residential units and 3,200 square meters of retail space in the Bayview area. As part of the proposal, a major civic facility is planned along the transit way (plate 2). The content of the building is yet to be determined, (one of the proposals, supported by this thesis, is the relocation of the public library from the downtown core to the Bayview area). It will also contain mixed-use functional programming with a commercial ground floor and residential units located above. Both the Bayview and Lebreton plans share a common building type consisting of mid to high-rise apartment complexes, many of which will face inner courtyards and will have retail facilities at street-level. Figure (40) demonstrates how this context will likely appear over time ${ }^{20}$.

${ }^{20}$ NCC Web Site, Planning the Capital Region <http://www.canadascapital.gc.ca/ 


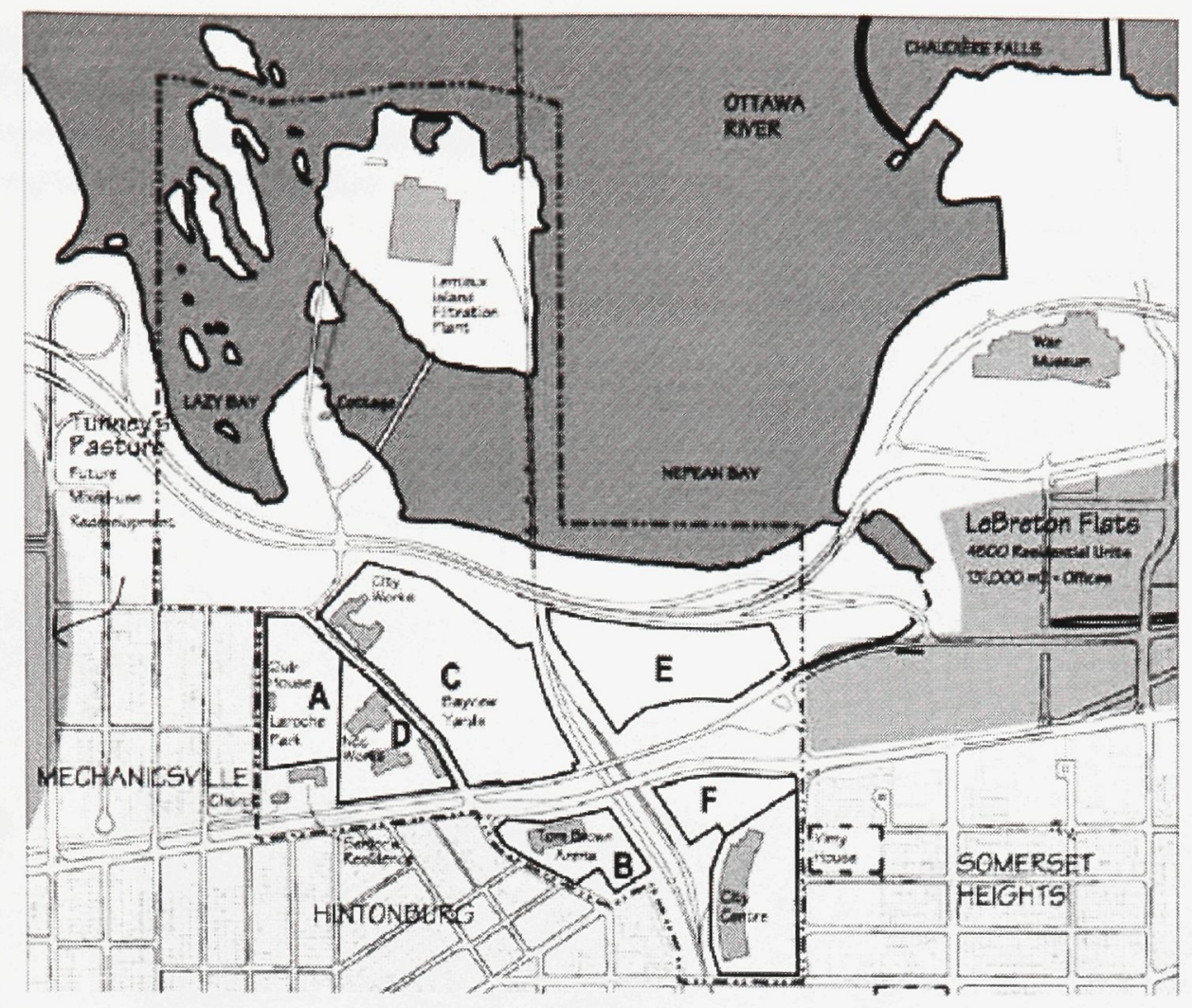

Fig. 35 Urban Master Plan development Context, Significant Building and Structure

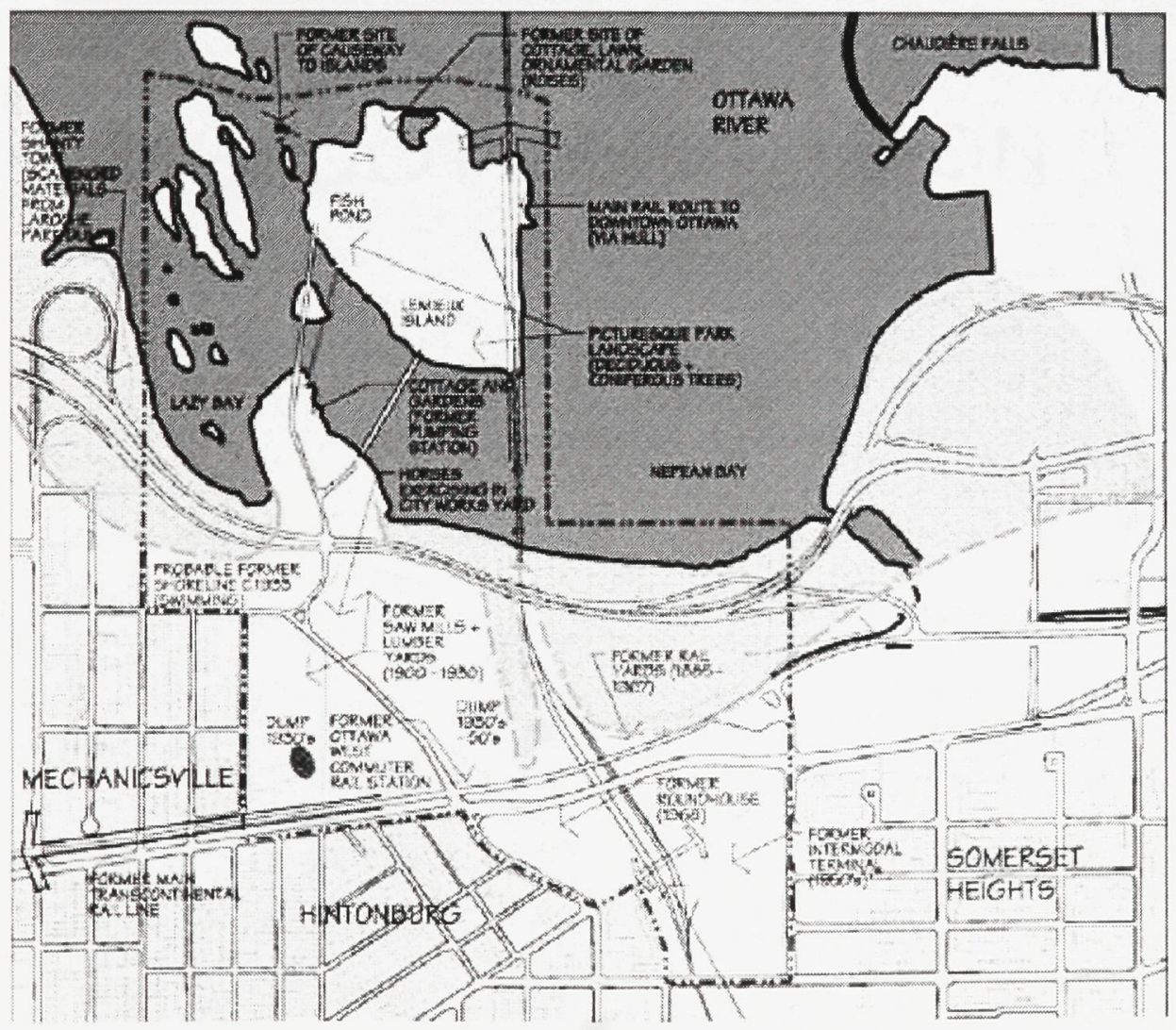

Fig. 36 Urban Master Heritage 
Plate 2

Urban Master Plan-

Expected Development (massing) of Neighbouring Communities
Fig. 37 Proposed Developmant for LeQvetan Flats sita from NCC

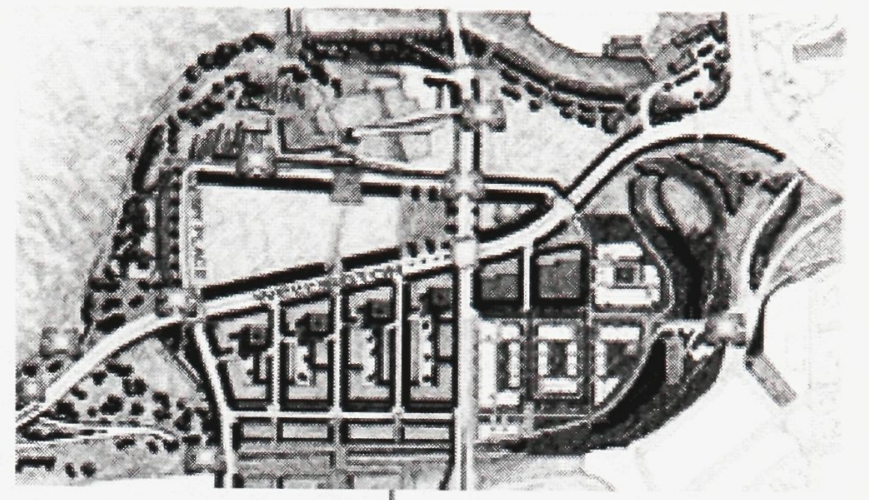

Probable future Residantial Development Area (Zoning suggests High-Pise Aparments)

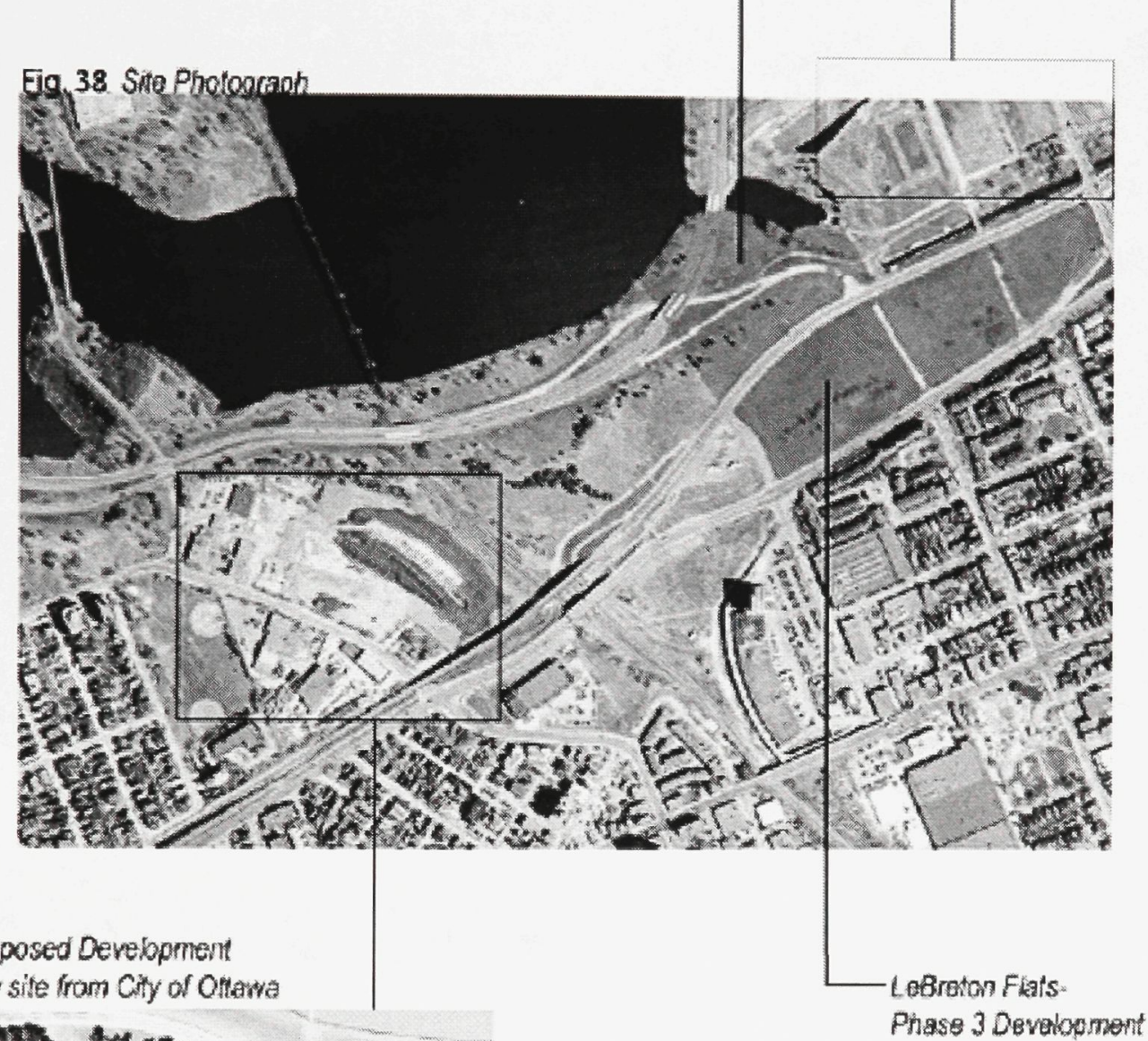

Fig. 39 Proposed Devebpment for Bayview sife from City of Othawa

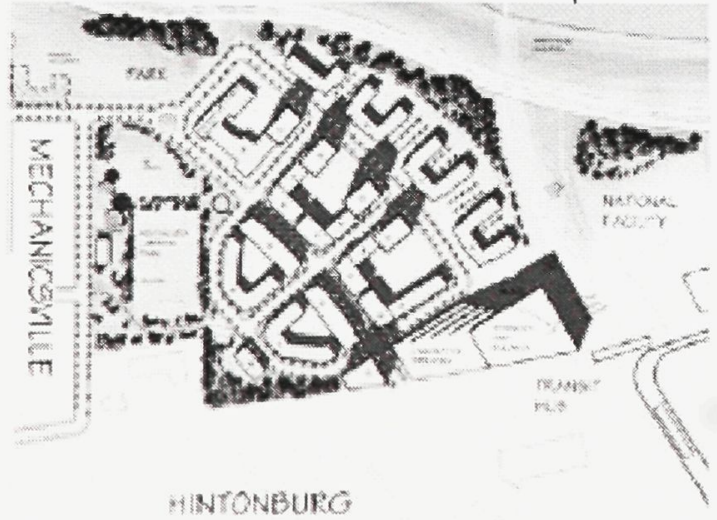

Phase 3 Development Area

(Scheme not yef propased) 
Fig. 40 Uiben Master Plan (Expected Future Context)

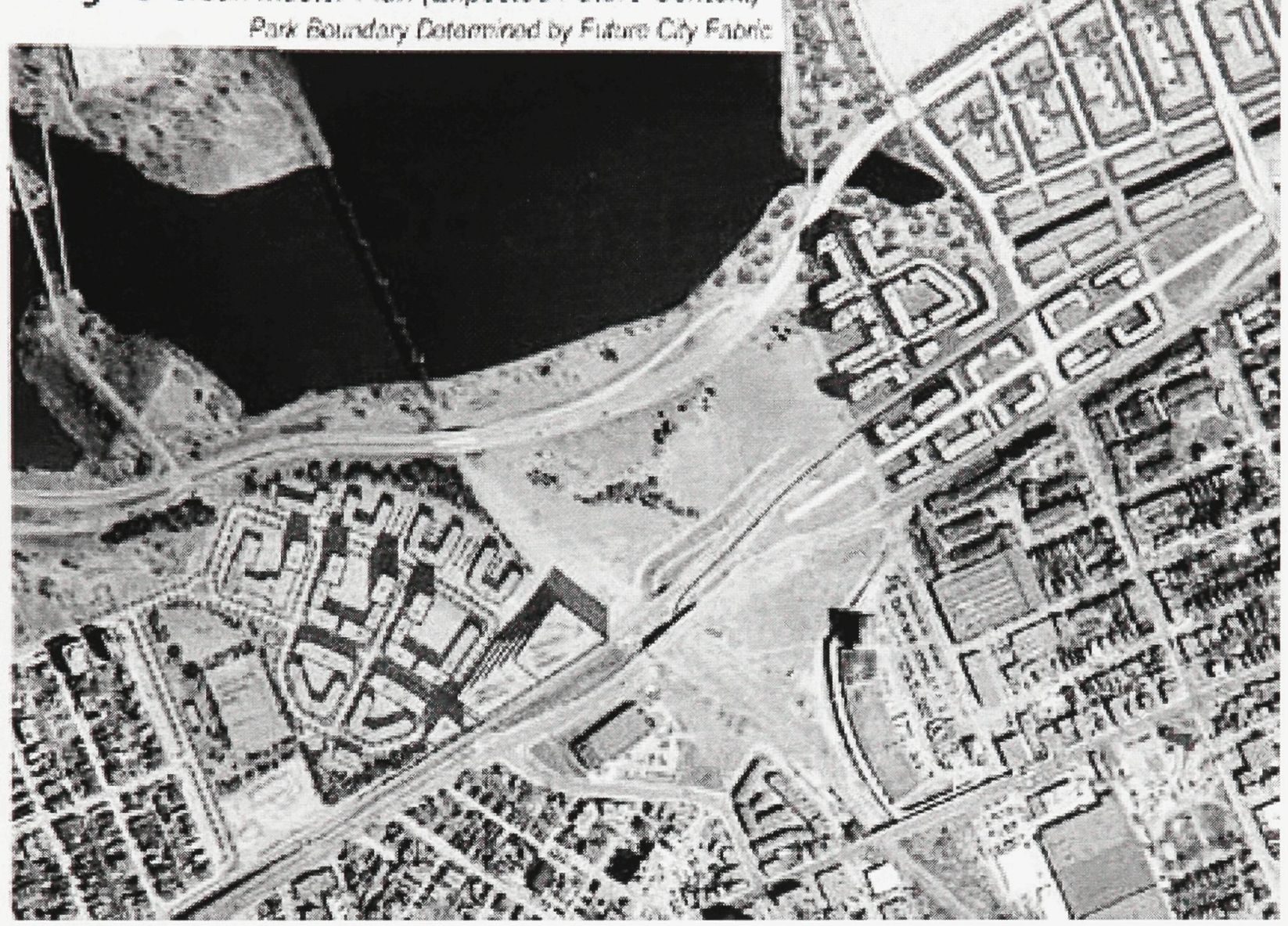

The station is orientated and organized to integrate with these plans and suit community needs. Four buildings are planned (proposed) with connections to the transit station. Each building is a link to different structures on the site. Thus the train station is conceived as a connector and mediator between several functional entities. 


\subsection{Design strategy}

The design responds to the master plan which structures and accommodates a mixture of several functions. Also, the site consists of a combination of natural landscape and urban interventions, which contribute to a unique and identifiable sense of place. Similarly, the proposed project focuses on expressing the vitality of the site while reinforcing the exchanges and links between the public and private aspects and functions of the site. Another key focus of the architectural scheme is to create a well-organized transport interchange that can simultaneously serve as a new gateway that becomes a critical zone of passage and link between the site and the surrounding districts of the city. This will partially be affected by providing an urbanized public link across the tracks. The task is to give expression to the imposition of a new through-station that can also act as the nucleus of a new proposed urban park linking the various surrounding facilities and functions. The project is intended to weave " light and movement" in an attempt to establish a "natural connection" among all parts of the site, and between the built elements and the surrounding environment (landscape/nature). The station would hover and extend over the park-land to move openly through the site alongside the tracks opening and connecting the site to both the surrounding landscape and the city centre. 
Fig. 41 Park Boundary Pian Existing Conditions

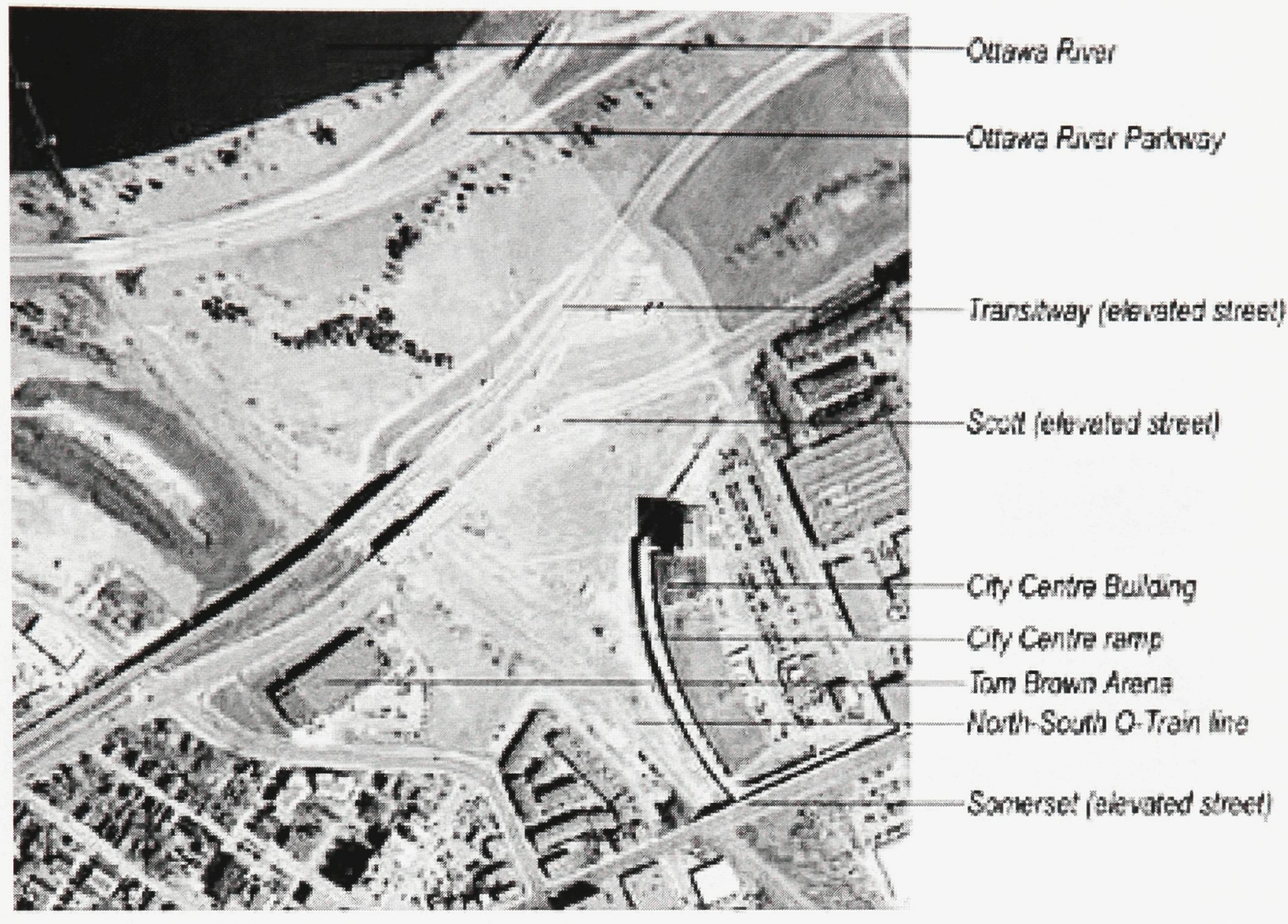


PLATE 3 - SITE OVERVIEW

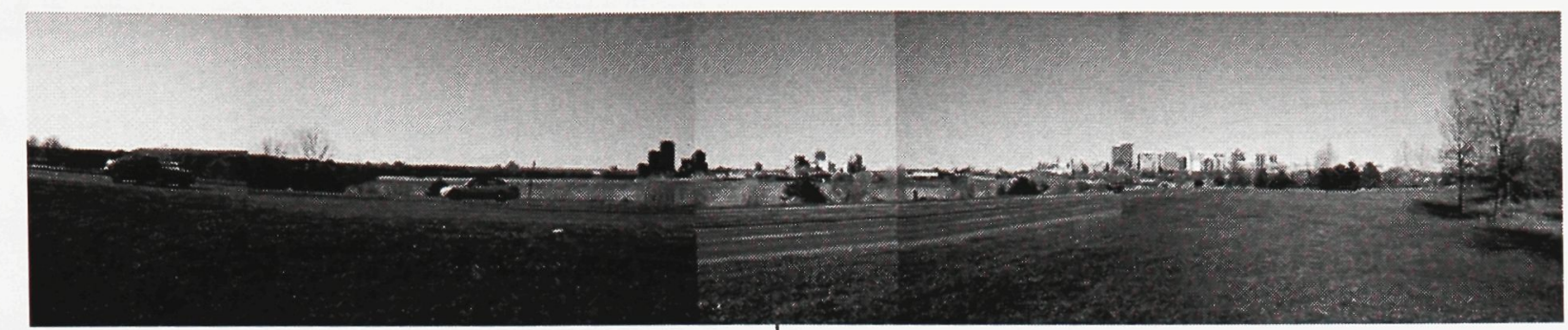

Looking North

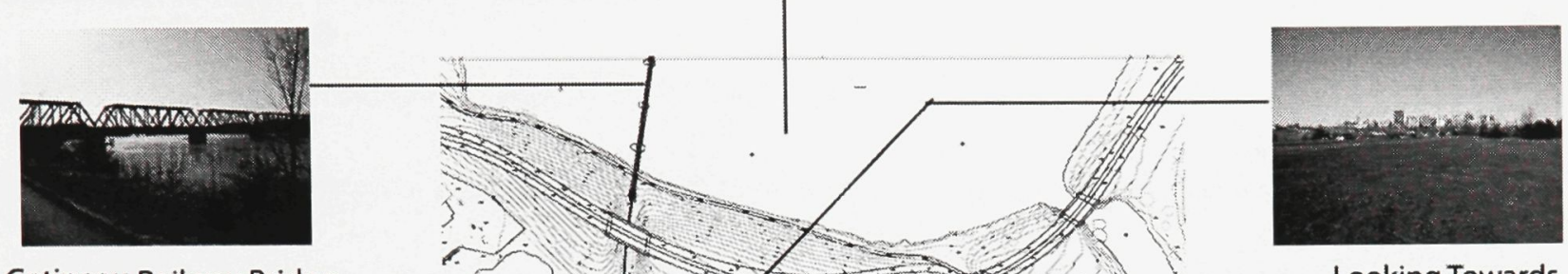

Gatineau Railway Bridge

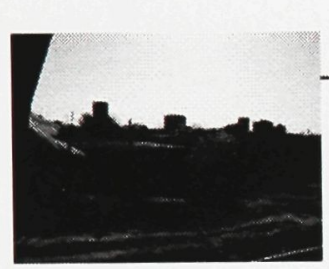

Looking West

ge

Looking Towards Centre Town

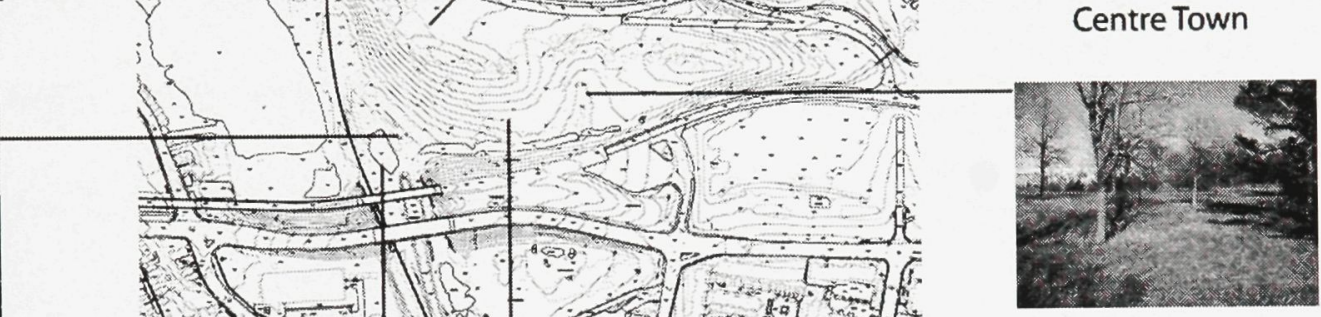

Bayview Park / Current Condition

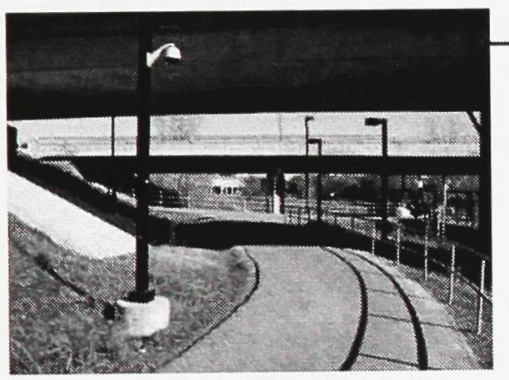

Bayview Rail Station / Current Condition

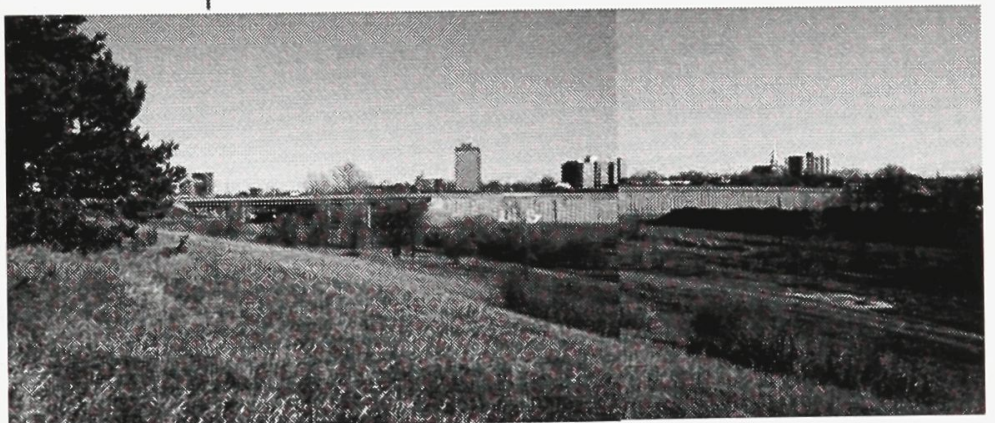

Looking South 


\subsection{The project concept}

\subsubsection{Narrative}

In contrast to the linearity of the cinematic experience in film, this station is intended to be a story line or narrative that unfolds many visual experiences and interactions which depend on the visitors and his/her own way of perceiving space. In other words, each scene has enough content to permit associations, experimentations and even a degree of distraction. These scenes consist of events and are populated by characters and places in the building that create a sense of engagement and maintain the visitor's interest throughout the entire experience of the building. This process may trigger memories of the past and encourage a sense of serenity and contemplation as well as opposite reactions of stimulation and excitement. Besides the architectural metaphors that govern the design process, the design is intended to emphasize the strategic location of the site at the threshold of two provinces. The powerful main axis of the station suggests not only the dynamic motion of the train but also a directional connector across the Ottawa River, which separates the two provinces.

\subsubsection{Movement}

The station is in a state of constant transition; it is never static and defined by constant movement and dynamic visual experiences. The architectural form will thus emphasize such dynamics in the building's multi-use functionality. A main challenge for the station is accommodating special events and the major transformations the region goes through during the year (climate trends, seasonal events and festivals, population trends, etc.) 
The flow of passengers and other movement animate the interior. By extension, the architecture will guide and let itself be guided by this dynamic. Passengers' routes will be directed using racing lines, and the architecture will be subsequently shaped by the movements of the people who use it, establishing a symbiotic relationship between architectural flow, vehicular movement and human motion.

\subsection{Overall composition and layout of the project}

Five Buildings - One Project

The sequence of buildings and walkways around the site is planned to maximize the number of potential connections on the site. It is set like a stage, open to a variety of rhythms and harmonies. The views constantly change as one moves about, and oppositional juxtaposition is exploited to create a series of framed pictorial compositions and figure/ground relationships. Also, the interpenetration of the walkways within the context of the buildings has been arranged in order to achieve a visual situation of multiple compositions, and to evoke a wide range of emotive responses.

The design exploits the site's natural beauty as a response to the lack of green spaces in the city core. With this in mind, the landscape is fully integrated into the site's transportation strategy in order to emphasize the intense linkage between nature and culture. This thesis specifically attempts a community-based program that is both functional and enjoyable. Indeed, this historical, vacant and valuable site should be programmed such that the community can integrate it into its daily life. The site will play a predominant role in the future of the city, providing residents and the general public 
with a place of relaxation and recreation within the mixed-used business and residential district. The program thus revolves primarily around the local cycle of daily life.

\subsection{Design Project: Scope and Program}

The project consists of a light rail train station and facilities for regional services that are spread over five major buildings. Building ' $\mathrm{A}$ ' is the main Station and spans along the rail line. From the east side of the main station Building 'B' (Bus/train stop) is situated between Scott St. and the Transit way. The North West end of the station is building 'C' which connects to the proposed Library and houses academic and cultural facilities. Building ' $\mathrm{D}$ ' is a proposed tower building, which is located at the north end of the station, and a recreational centre is located at the south end of the station. 


\subsubsection{Train Station Program (Building 'A')}

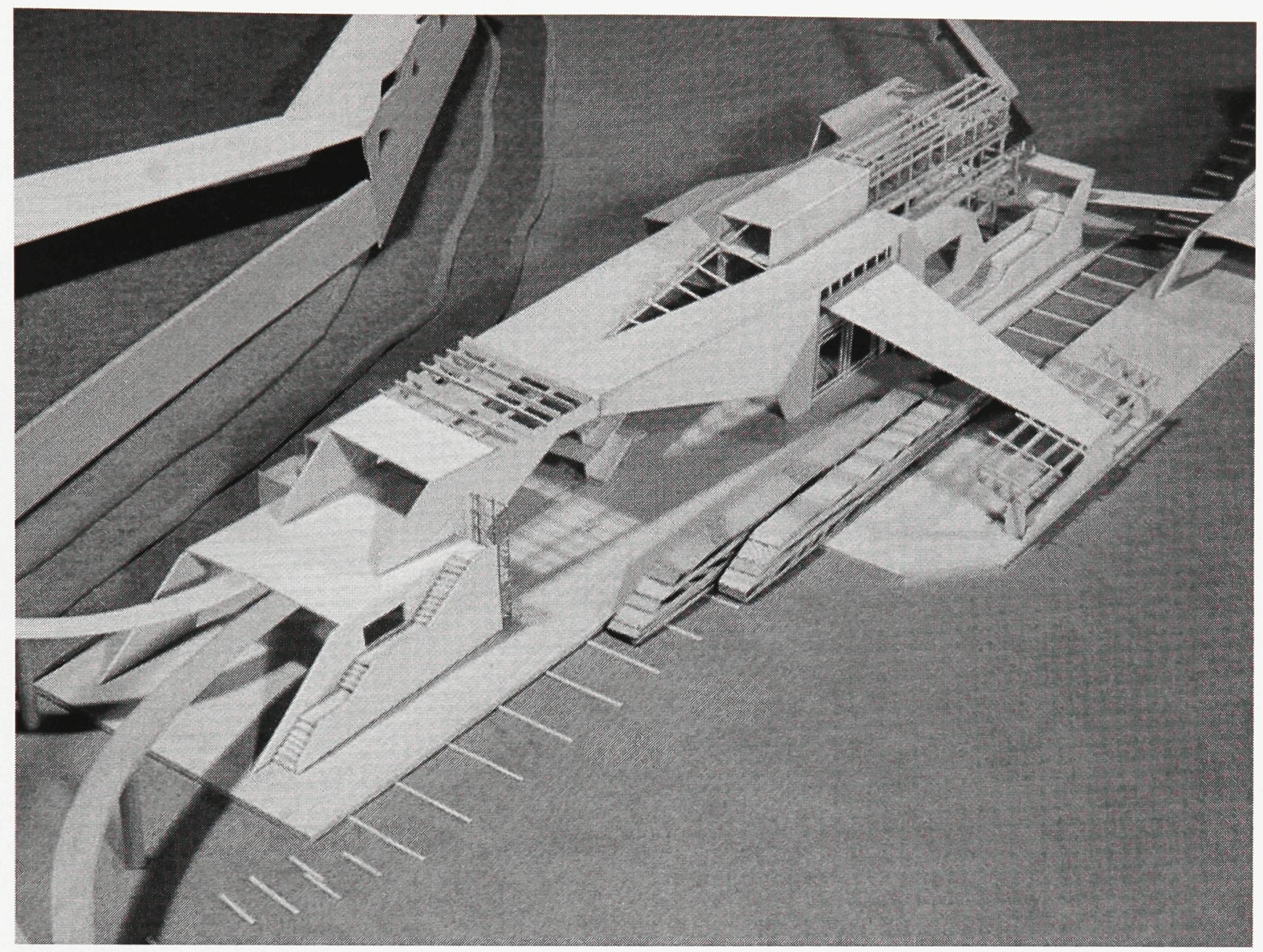

Fig. 42 Train Station

-Main Hall

-Info Centre

-Staff offices

-Food Court/ Shops

-Cyber Café

-Maintenance and building services

-Vertical circulation 
-Washrooms

-Garden space

-Parking

-Train platform

The station consists of a main axis that runs perpendicular to the dynamic motion of the train rail line. Thus, it is both physically integrated with the transit line, and also runs against the flow, creating a specific place in which daily life can flourish. As mentioned earlier, the station can be accessed from different locations on the site, in response to the various paths, directions and user intentions. The most dominant feature of the station is characterized by the subject's passage through the building, which involves a carefully orchestrated spatial journey. Visitors encounter a dramatic display of light and shadows depending on the time of day and the path they choose, and a variety of architectural features add to the spatial experience. The main hall acts as a hub of circulation and orientation at the heart of the station. The visitor is compelled to ascend or descend to various levels, experiencing the space through an array of walkways, ramps and escalators. The openness of the building offers easy access to other buildings on the site and the train platform itself.

The main hall also accommodates all features necessary for the visitors: information booths, a food court and garden. Specialty stores line some of the hallways, and there are a wide variety of refreshments available to visitors and commuters. The train docks along the main axis of the station at the core of the station where visitors are received into a monumental space. There are also ramps that lead up to the roof garden, offering access 
to a natural setting that is integrated into the building. The roof garden functions as a means to allow visitors to engage visually with the entire landscaped site. Also, the train station offers practical facilities for buses, taxis and car parking, in addition to rail administration, and emergency police and fire services.

\subsubsection{Building 'B' Train/Bus Stop Program}

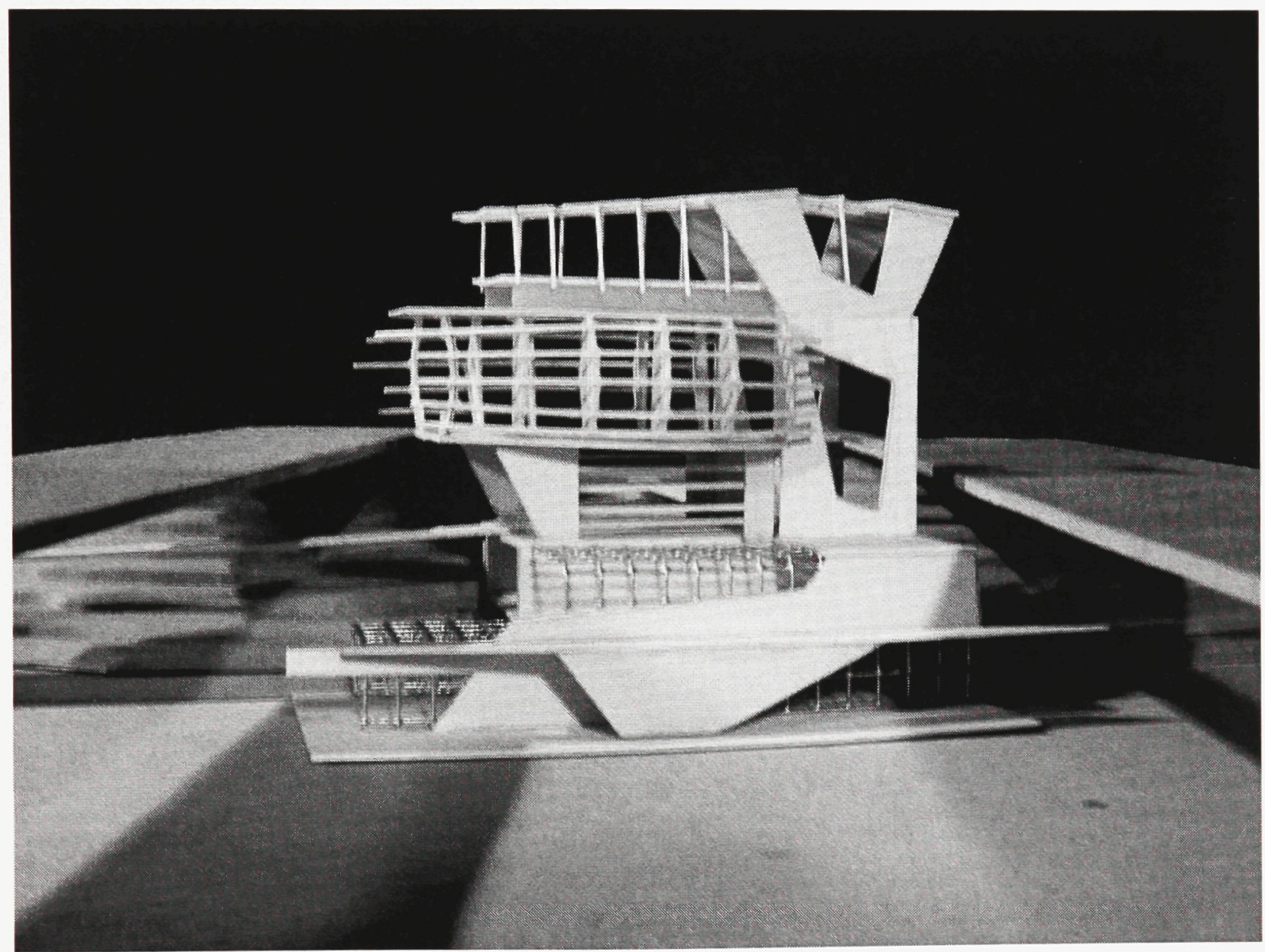

Fig. 43 Train/Bus Stop

-Coffee shop/Internet café

-Convenience store

-Washrooms 


\section{-Vertical circulation}

Building ' $\mathrm{B}$ ' is located at the east end of the station and between Scott Street and the Transit way. The building replaces the existing exposed ramp and offers a transitional route between the train and the bus. It is situated at a sloped/slanted ravine lot where the contours of the site are accommodated and emphasized. At this location, there is a sixmeter difference in elevation between the bus and the train platforms. Two means of access are provided for easy circulation: a bridge that connects to the station and a vertical circulation (Stairs and Elevator) that allows access to the outdoor walkway. The bus/train stop would host a coffee shop, convenience store and washrooms. The building is thus dominated by the vertical axis that emphasizes the contours of the site, and offers multiple paths. 


\subsubsection{Building ' $C$ ' Library Extension}

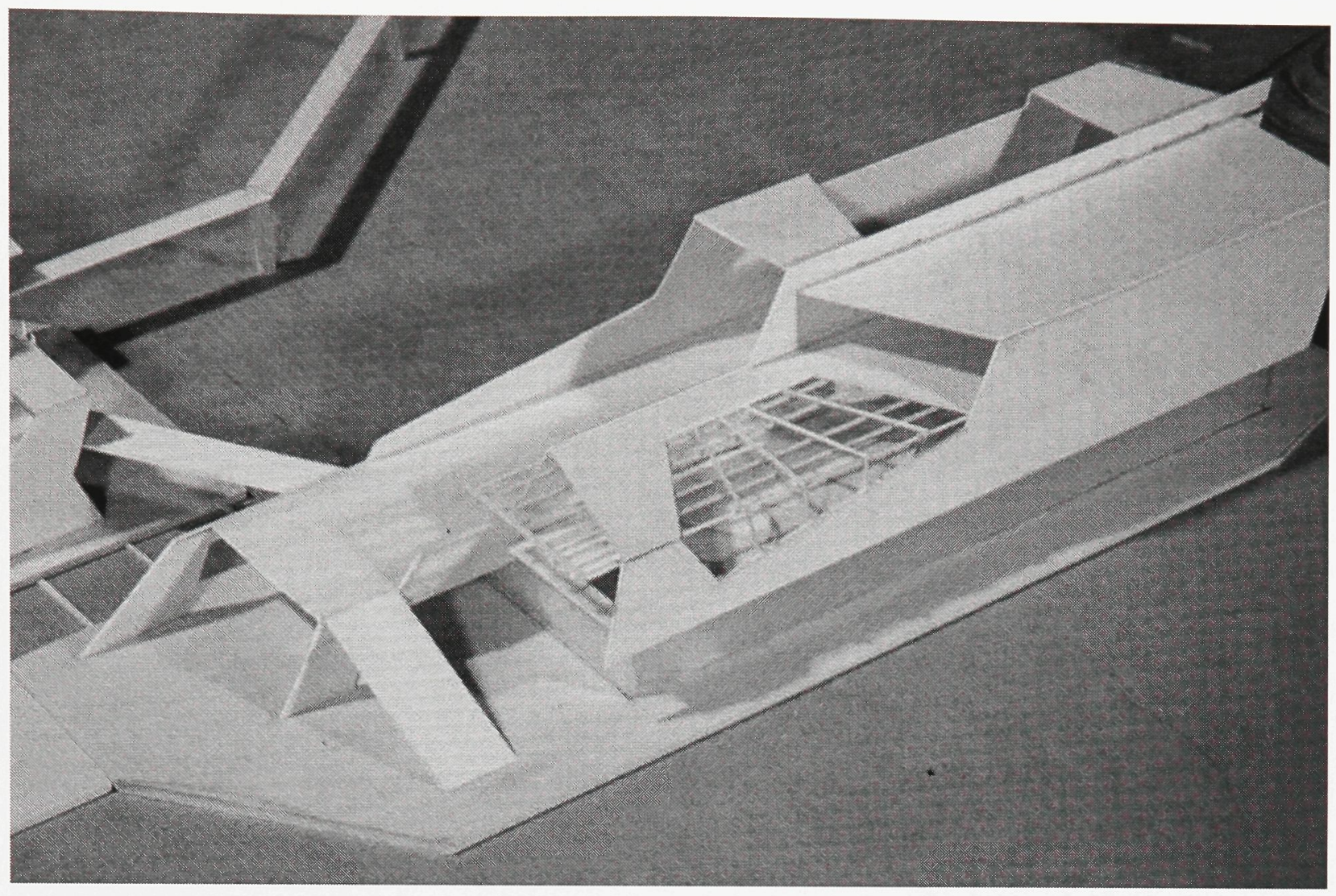

Fig. 44 Library Extension

-Exterior platform

-Main hall

-Lecture room

-Classrooms

-Computer room

-Information centre and Pub

While the main proposed library is for the general public, this building is dedicated to students and specifically, to the international student. The building's aim is to bridge the four major universities in the area, and allow students to communicate and exchange knowledge. In addition, the building would facilitate the life of international students by 
providing an information centre, computer rooms, and classrooms for equivalency courses in English and/or French, lecture halls, and a pub. The physical character of the building aims to connect with the horizontal layout of the site, and both contrast and connect to the other buildings. The library is raised above ground and is cantilevered and floated above the horizon. This horizontal extension creates a "suspended" dialogue between the building and the rest of the site.

\subsubsection{Building ' $D$ ' the Train Tower}

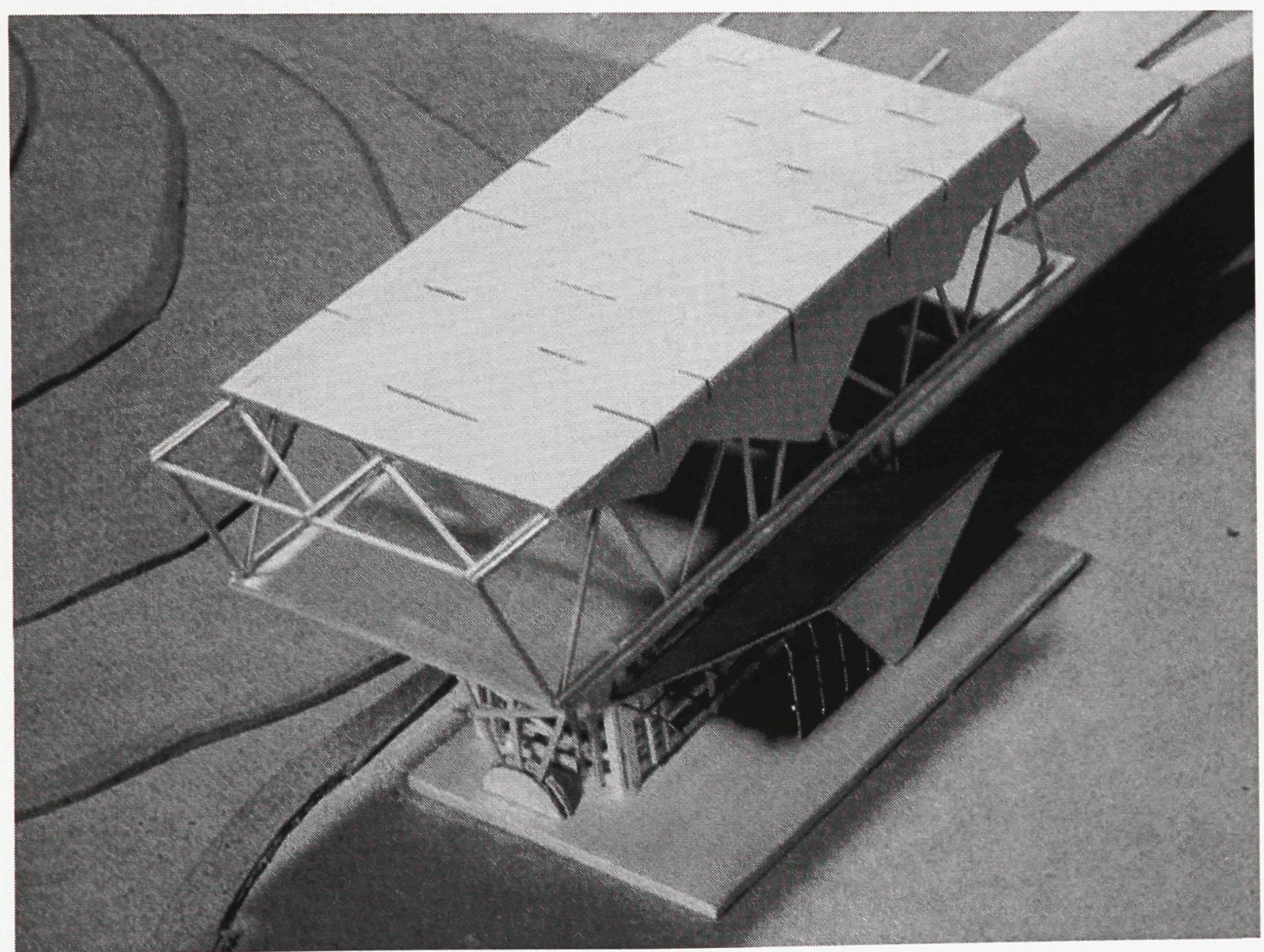

Fig. 45 Train Tower 
-Coffee shop/Deli

-Washrooms

\section{-Vertical circulation}

The train tower is situated at the north end of the station and has dual functions. First, the tower has a coffee shop and deli to cater the workers at the nearby light industry park.

Second, the tower functions as an observatory and is wrapped almost entirely with glass to allow visitors to enjoy the natural vistas of land, sky and the city beyond. Also, the tower is accessible from the ground or by a bridge that connects to both the recreational centre and the main station building.

\subsubsection{Recreational centre}

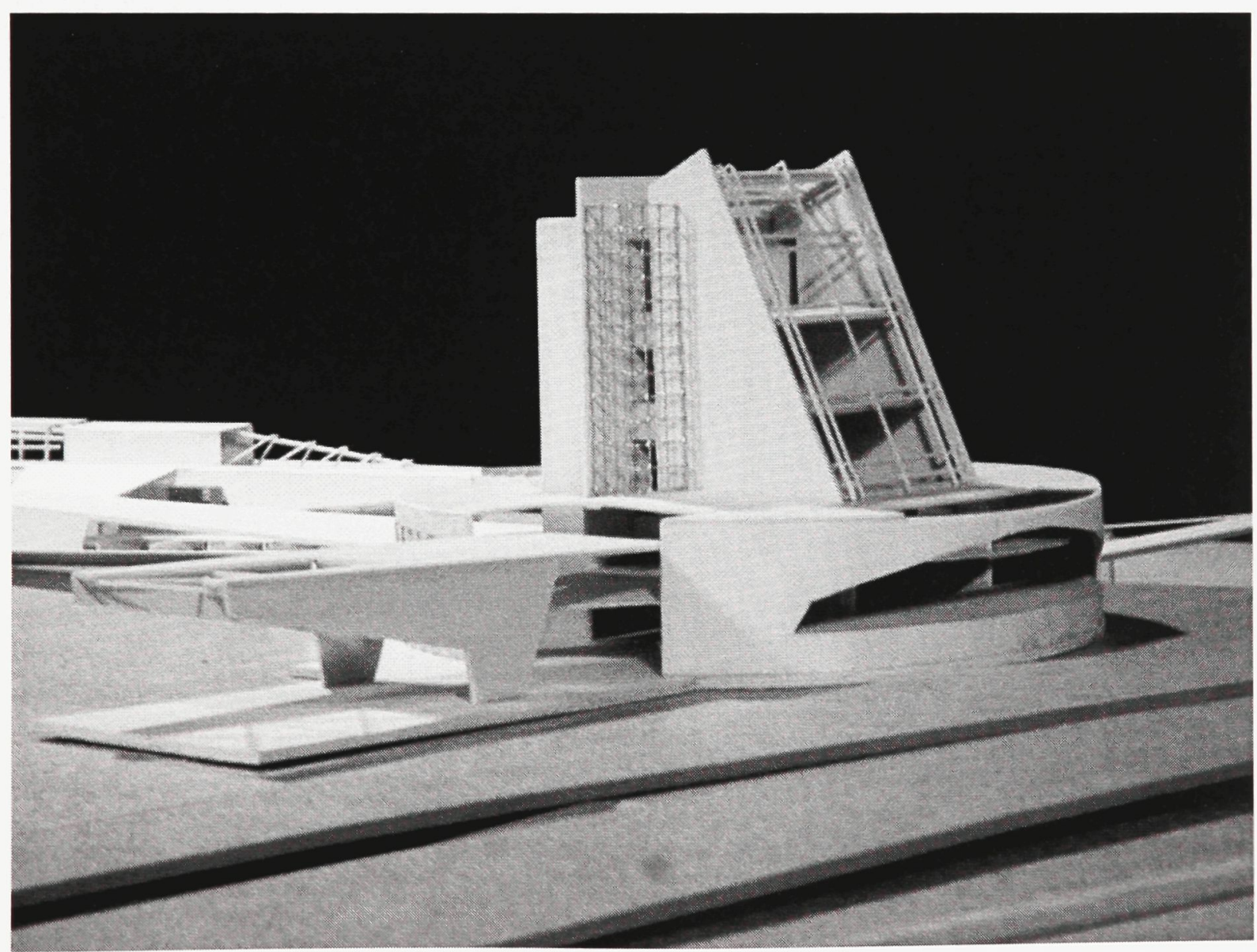

Fig. 46 Recreational Centre 
-Main Hall

-Day care

-Family restaurant

-Interior garden/Patio

-Play room

-Theatre/Auditorium

-Staff offices

-Washrooms

-Vertical circulation

The recreational centre spans the entire Western edge of the park and is connected to the east end of the station. It aims to bring the community together by offering a nearby refuge from the busy downtown district. A family restaurant will be available to host banquets and buffets, and a day-care will allow parents to drop their kids while going to work. Also, a theatre/auditorium is incorporated into the design to promote a dynamic and culturally active community.

The stretched arm section of the centre extends out of the west end of the recreational centre and embraces the topographical contours of the park. The arm is raised above ground and has a dual function. First, a series of spaces are proposed along the stretch of the arm to accommodate the seasonal activities in the park such as flea markets and outdoor market sales. Second, the arm is used as an entrance ramp into the tower building; as visitors walk along it, they can view all the activities and facilities in the park. 


\subsubsection{Walkways}

The intention of the design is the maximization of many, potential narrative-based journeys, which emphasize the interactive relationships between visitors and the surrounding area. The emphasis is on the explicit subjectivity of the experience as visitors are encouraged to discover the beauty of the site for themselves as they go about their daily lives. The architecturally-framed journey relates to Le Corbusier's notion of a reconciliation of man with architecture and nature, known as the 'Architectural Promenade'.

In order to create a spatial system of great visual complexity and variety, and achieve the effect of collecting a sequence of narratives, events and visual experiences, the walkways are highly emphasized and applied to set up a series of views and programs that cover the entire site. These passages function not only as connecting paths between the buildings on the site, but they also emphasize the potential syntheses produced by the movement of people and objects in the city. They open up possibilities for creating wholly new spatial experiences and atmospheric effects in addition to those already provided by the site. The covered walkways are intended to provide shelter from the Ottawa weather without detracting from the sensation of being connected to the landscape and the seasons while increasing the interpenetration among the spaces.

Through the exploitation of contrasts in lightness and darkness and the interplay of opposites such as horizon and the sky, the design opens up possibilities and stimulates visitors' senses and emotions. The visitor's sense of stability and certainty can be displaced by the dynamic characteristics of the space caused by the changing of weather 
and time, by the play of light, snow, rain, vegetation, movement and water. Thus, the journey would touch and evoke a wide range of emotive responses, and would give commuters an environment in which to be inspired or relaxed. The overall movement emphasized throughout the design brings the dynamic element of time into the project. The shifting horizontal and vertical perspectives allow the visitor to follow a variety of paths and narratives throughout the site and engage them in a constantly changing apprehension of the building and its numerous programs. 


\section{Conclusion}

The above paper has provided a framework for a viable train station/community complex in accordance with a theoretical focus on the combination of the language of visual perception and the production of open, creative spaces. The primary goal for this project is the creation of a healthy community integrated with the city as a whole. Accordingly, the five buildings on the site exhibit the entire range of local uses: a community centre, connection to the library, shopping facilities, recreation, all centred around the hub of the light-rail station. The station would be used as a meeting place, a place of interaction. The programmatic function of the station would encourage such meetings to take many forms, and these will in turn promote enhance daily life in the community.

The thesis also proposes an integrated environment to promote environmental responsibility and awareness and a healthy growing community, according to three main ideas: one aesthetic, one phenomenological and one social, though all working towards the same goals of a vibrant community space:

1) The execution of the design was not necessarily seeking concretized forms of expression, but instead articulating a range of potential narrative projections, to promote visual, emotional and experiential reactions in the final work. Importantly, space over form is highly emphasised during the design process to allow visitor to commute, engage and interact with the proposed settings. 
2) Phenomenologically, the objective of the proposed project is to engage commuters in a journey which is different from that of their ordinary journeys. There exists many crossings of time and space boundaries. By crossing from one space to another, the individual carries on the continuous action of externalizing and internalizing spaces. With such a constant physical movement, the individual is part of many spaces throughout the site, and the internal subjectivity mingles with the more objective setting.

3) The design process attempts to take full advantage of the natural virtues of the site (historical, environmental and situational) to create a dynamic dialogue that merges all proposed buildings to achieve a powerful ensemble of architecture, landscape and urban infrastructures. The objective is to create an urban setting to bring people together and share cultural experiences; the project would thus attract a wide range of consumers, local residents and workers, visitors and foreign tourists.

The site has been designed in accordance with the above to promote cultural harmony. Architecture has the capacity to define new ideas and to convey new meanings. Thus the objective here is to promote multiple, creative and harmonious relationships as commuters and members of the community interact with natural settings while using the transportation system. 


\section{Bibliography}

Efimova, Alla and Mavovich Lev. Tekstura, Russian Essays on Visual Culture. the Chicago: University of Chicago Press, 1993.

Eisenstein, Sergei. Film Sense. Edited and translated by Jay Leyda. New York: Meridian Books Edition, 1958.

Eisenstein, Sergei. Film Form. Edited and translated by Jay Leyda. New York: Meridian Books Edition, 1958.

Eisenstein, Sergei. Nonindifferent Nature. Translated by Herbet Marshall. New York: Cambridge University Press, 1987.

Elliot, Bridget and Anthony Purdy. Architecture and Allegory. Academy Editions, 1997.

Foucault, Michel. The Order of things: An Archaeology of the Human Sciences. New York: Pantheon Books, 1970.

Hacker, Jonathan and Price David. Take Ten, Contemporary British film directors. New York: Oxford University Press, 1991.

Lawrence, Amy, The films of Peter Greenaway. New York: Cambridge University Press, 1997.

Manovich, Lev. The Language of the New Media. Cambridge: MIT Press, 2001.

Perez, Gomez, Alberto and Louise Pelletier. Architectural representation and the perspective hinge. Cambridge: MIT Press, 1997.

Willoquet-Maricondi Paula and Mary Alemany-Galway. Peter Greenaway's Postmodern/Poststructuralist Cinema, Lanham, Md.: Scarecrow Press, 2001. 


\section{Web Sited}

City of Ottawa - Ottawa 20/20

http://www.ottawa.ca/city_services/planningzoning/2020/index en.shtml

Luksch, Manu. Interview with Peter Greenaway, 1/97: "The Medium is the Message" http://www.heise.de/tp/r4/artikel/6/6112/1.html

Planning the Capital Region. National Capitol Commission Web Site <http://www.canadascapital.gc.ca/ 


\section{Project Photographs}

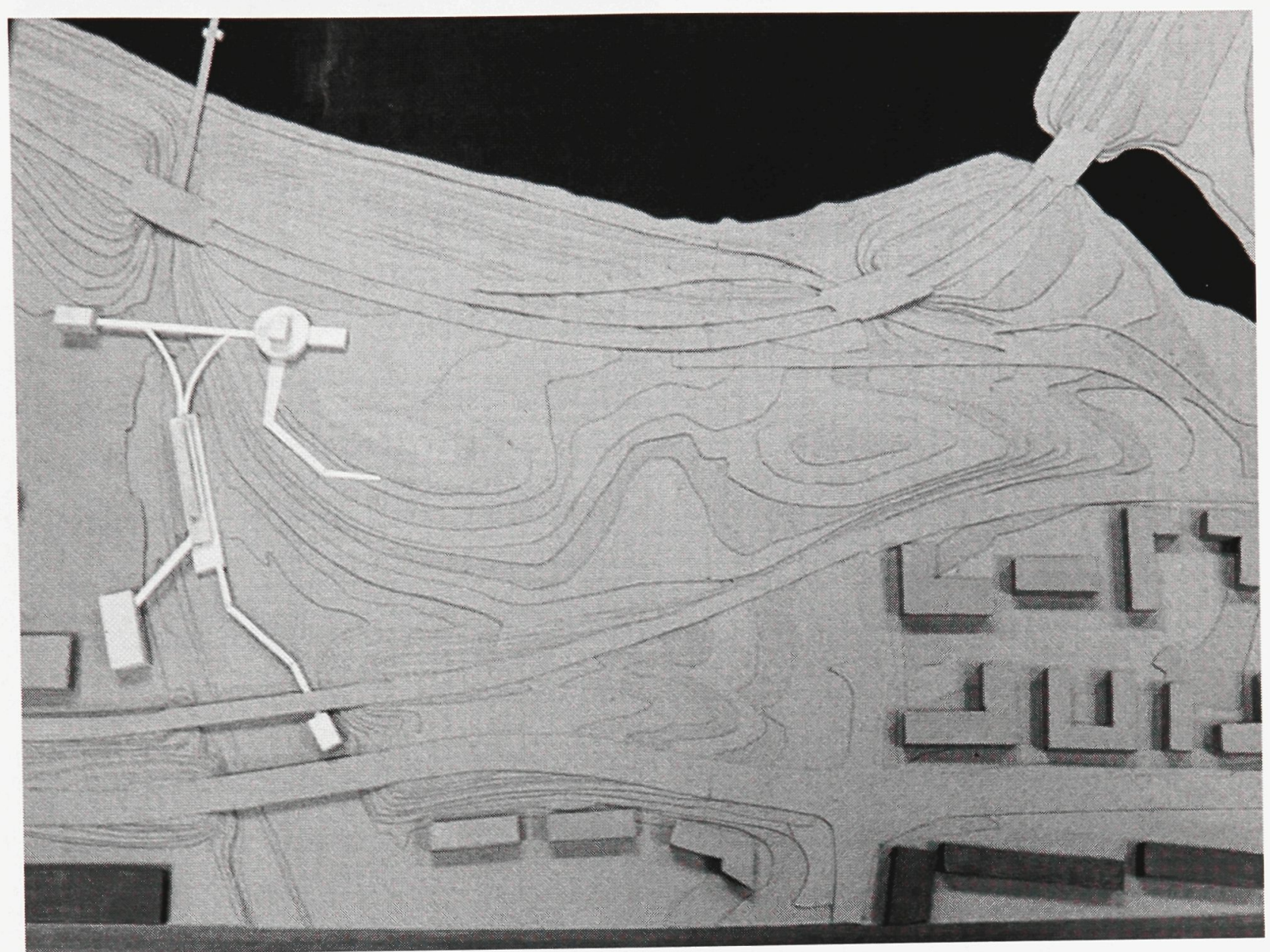

Fig. 47 Project 3-D site Plan - Bird View 


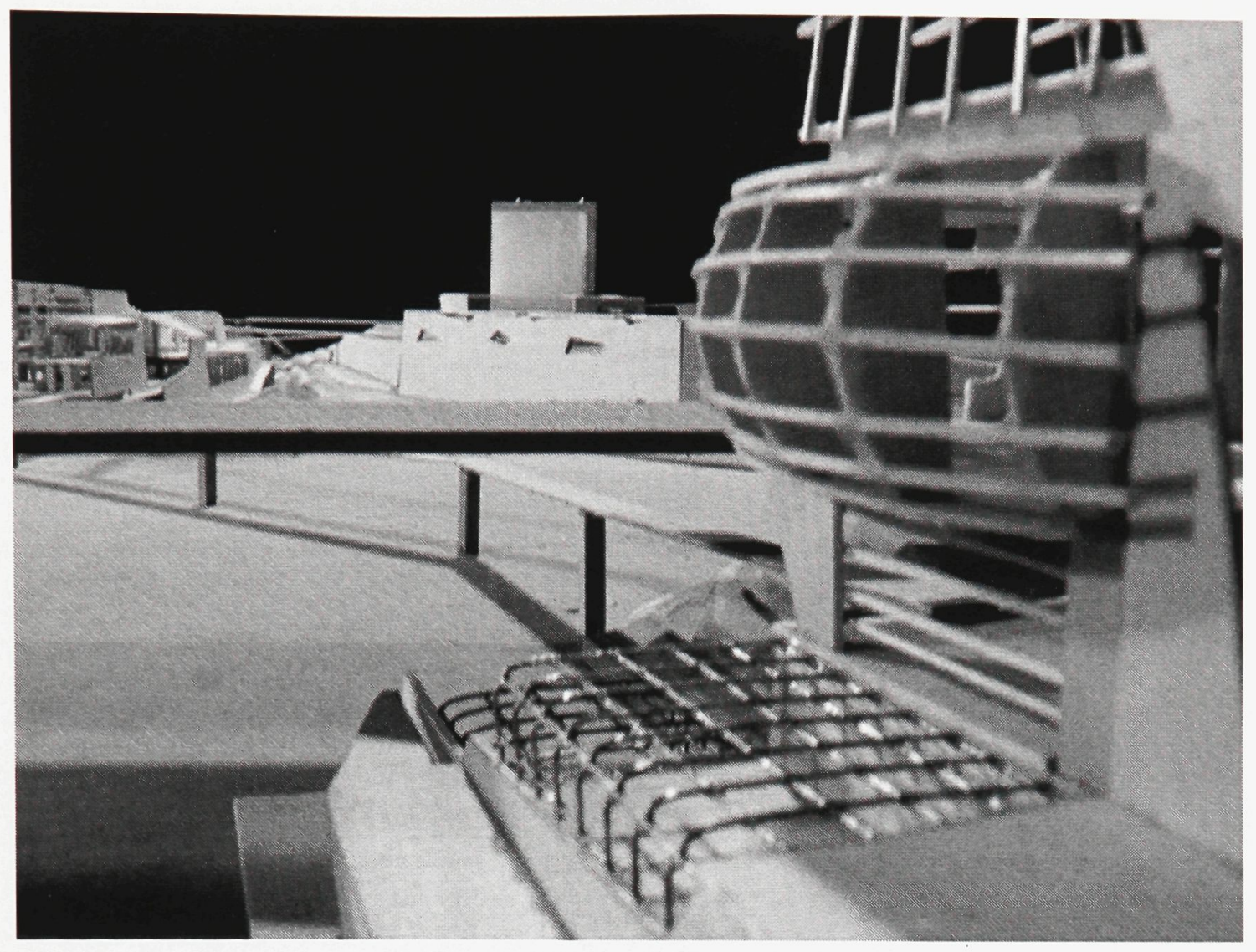

Fig. 48- 3-D Model - looking from the Bus/Train Stop towards the Station

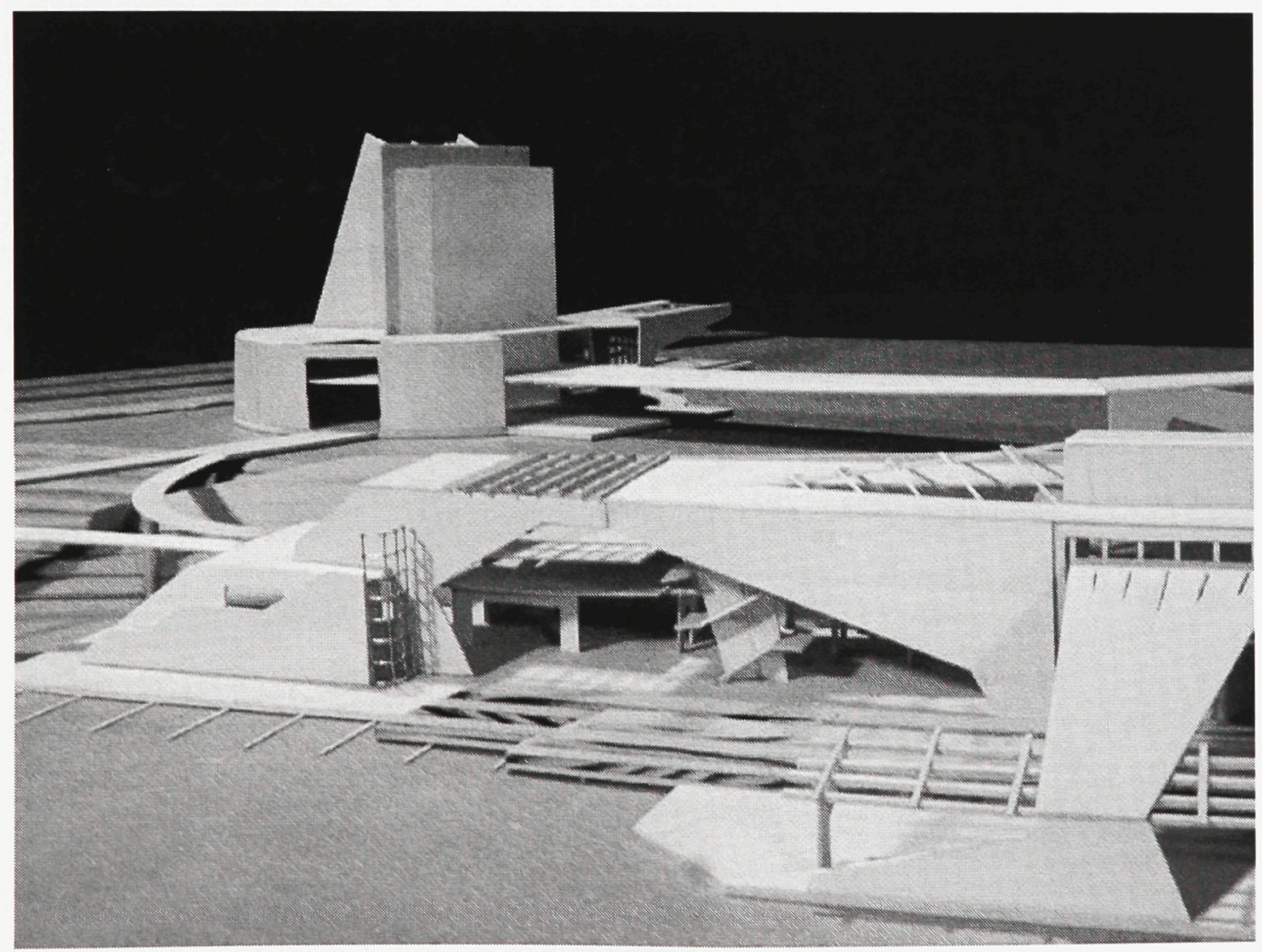

Fig. 49- 3-D Model showing connection between Train Station and community Centre - Looking east 


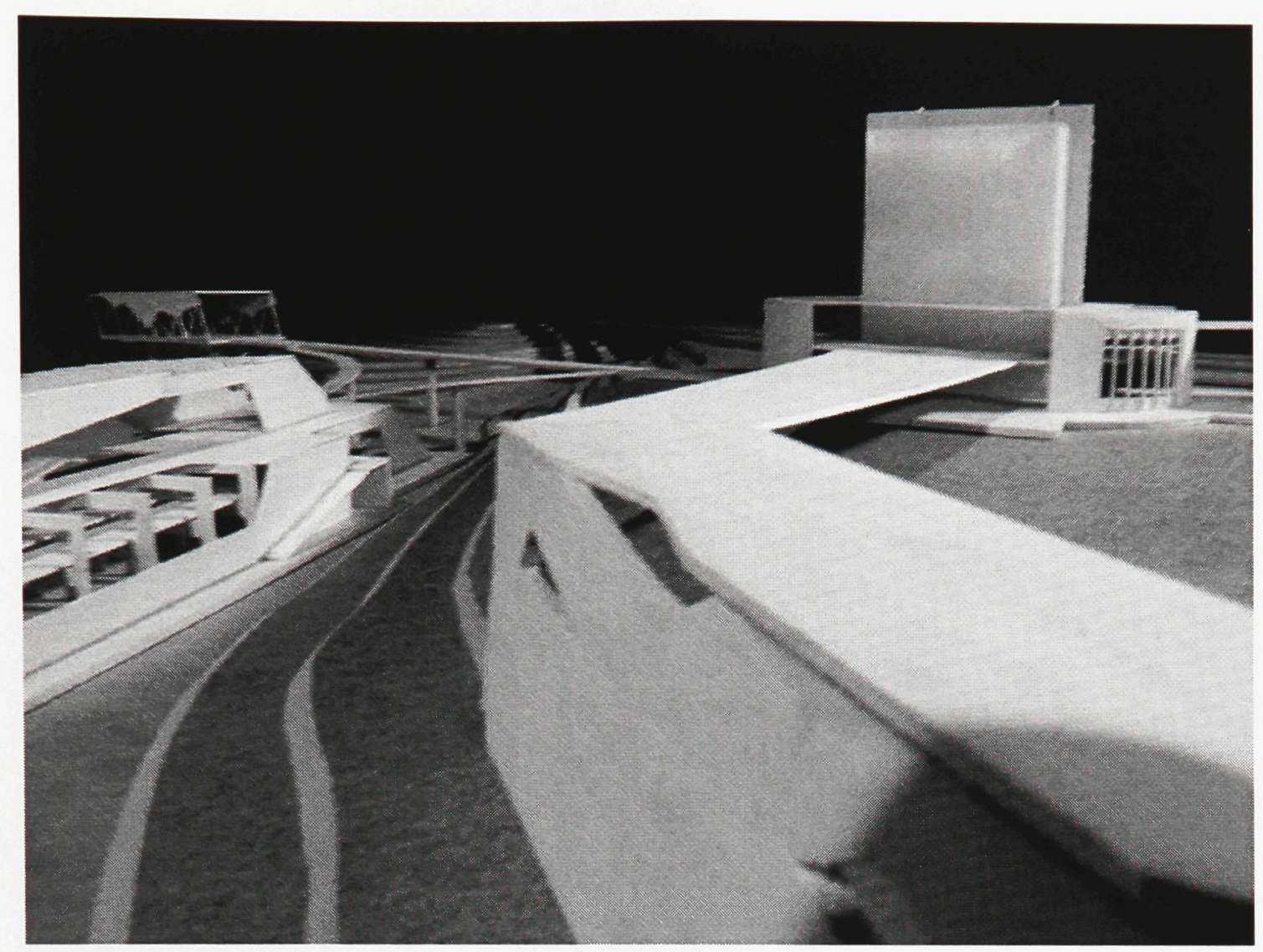

Fig. 50- 3-D Model showing project over view - looking north

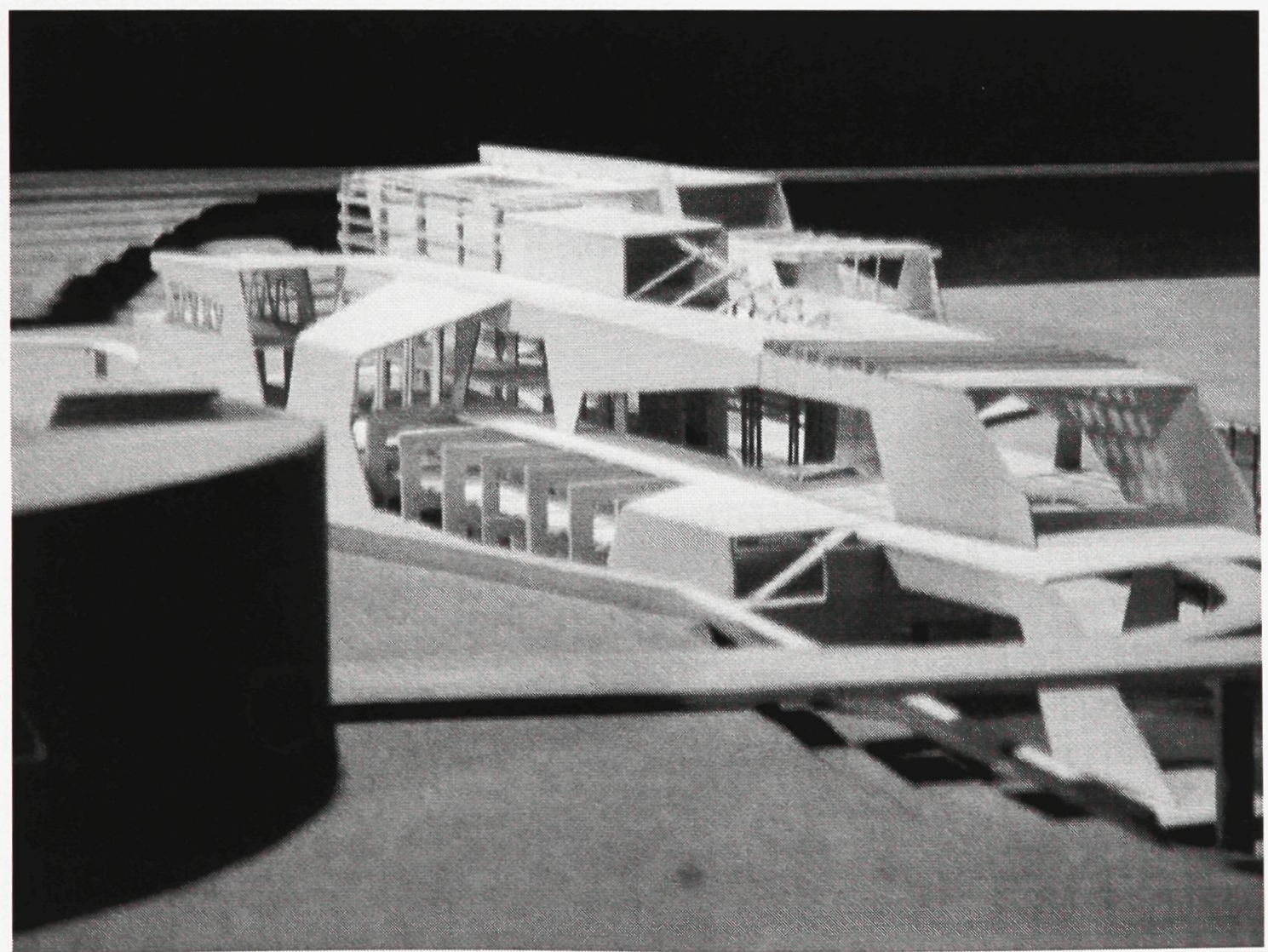

Fig. 51-3-D Model showing Train Station and Library 


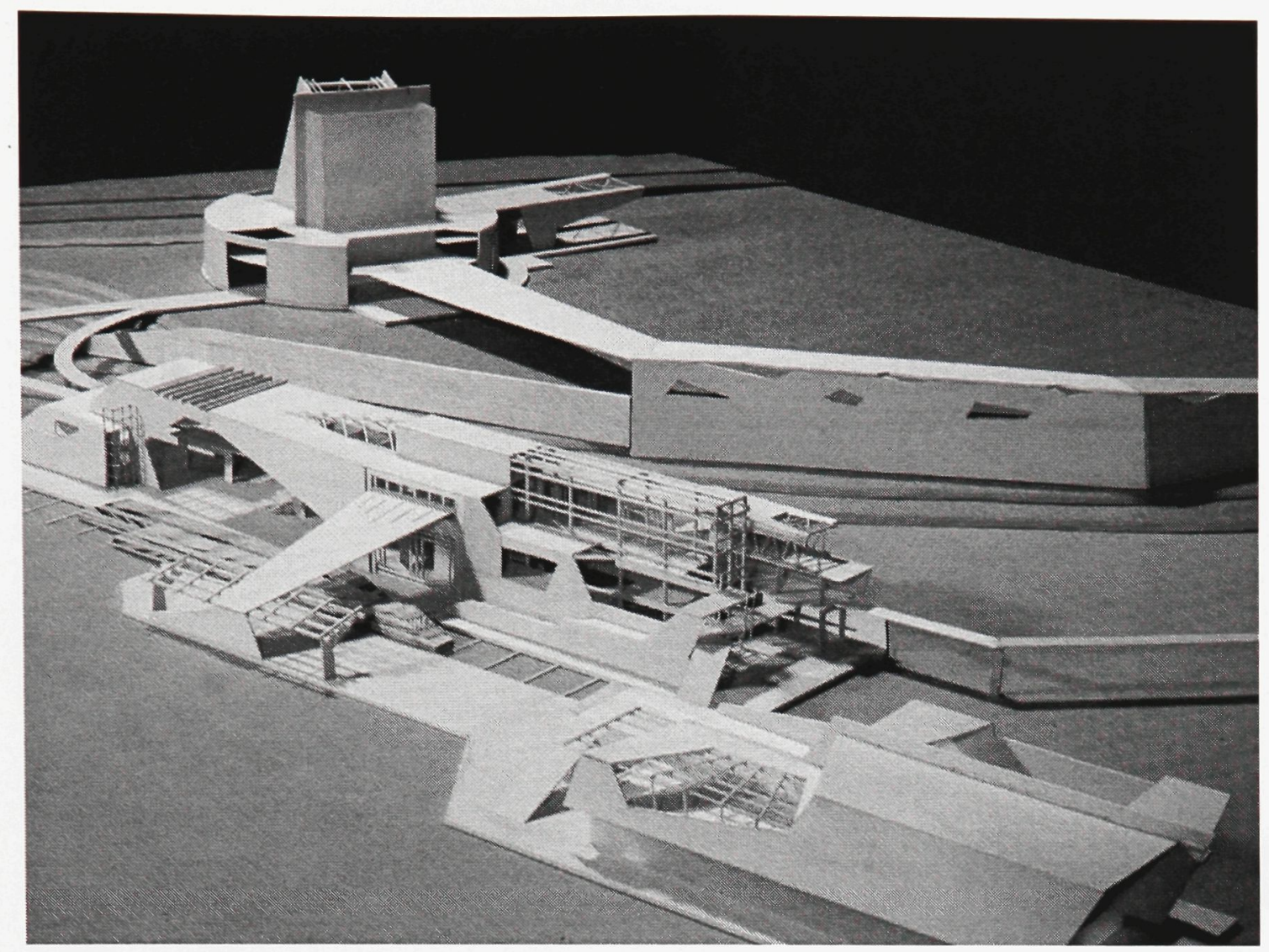

Fig. 52- 3-D Model showing project overview - looking northeast

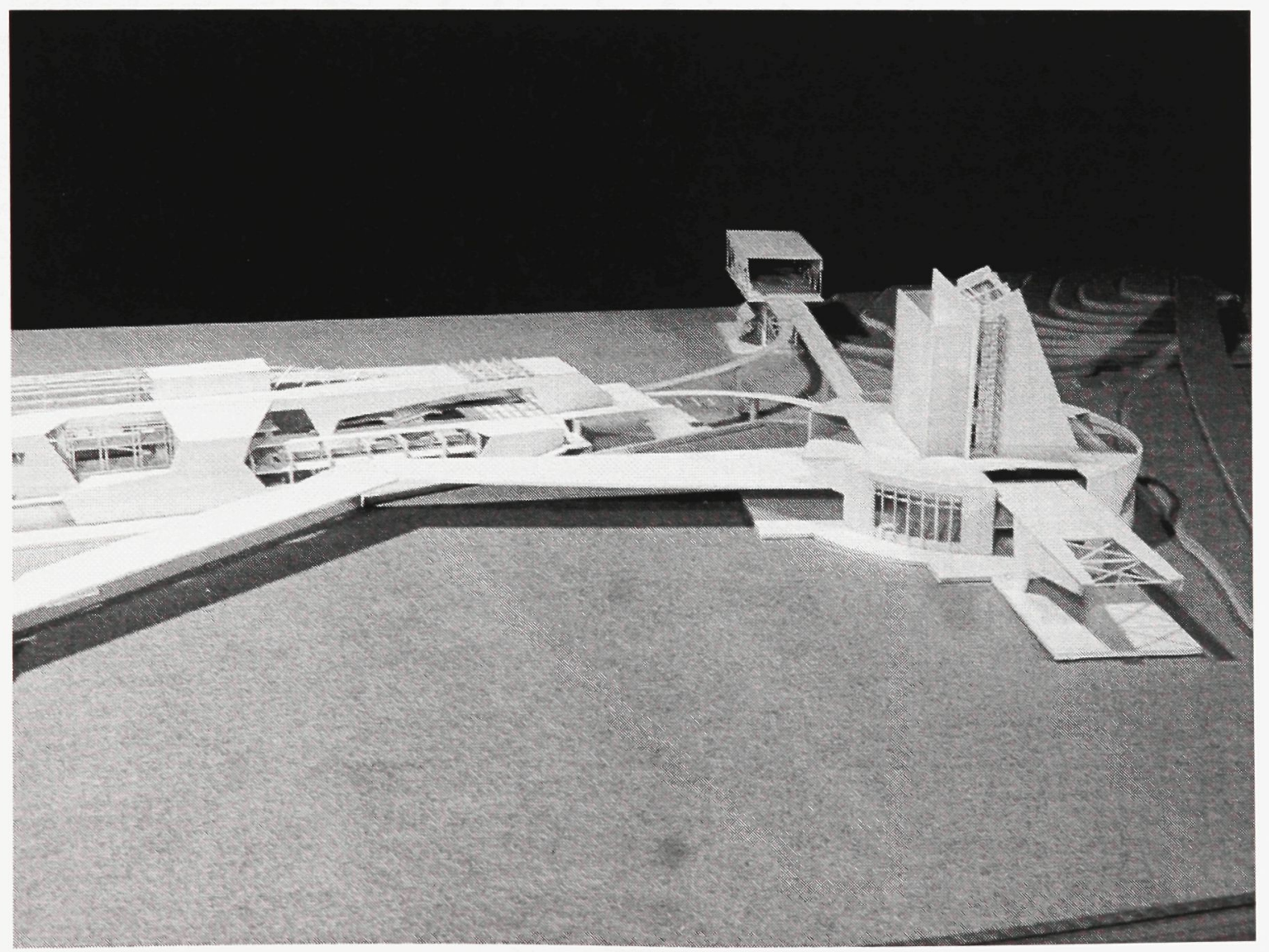

Fig. 53-3-D Model showing project overview - looking north 


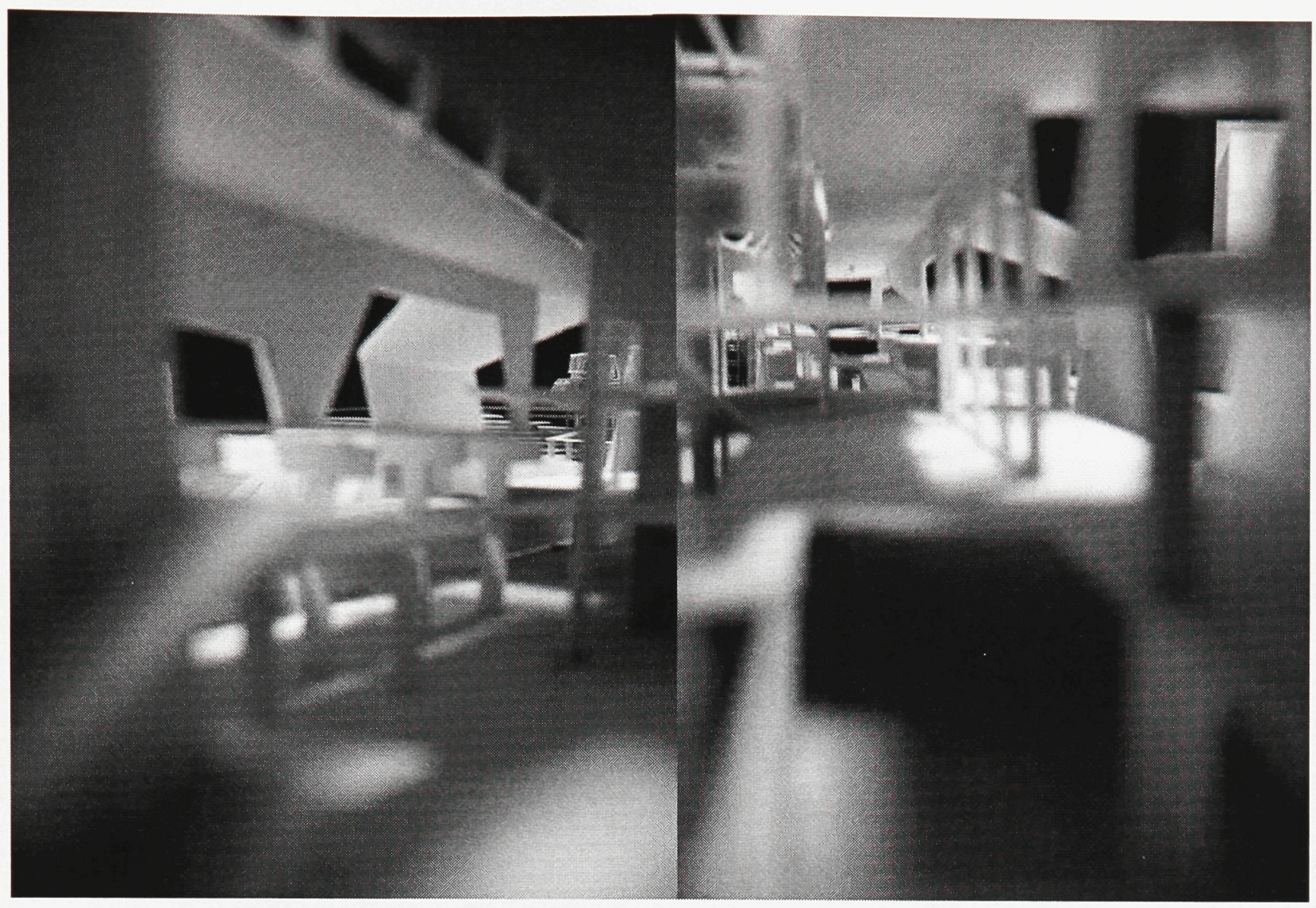

Fig. 54 Train Station - Interior 


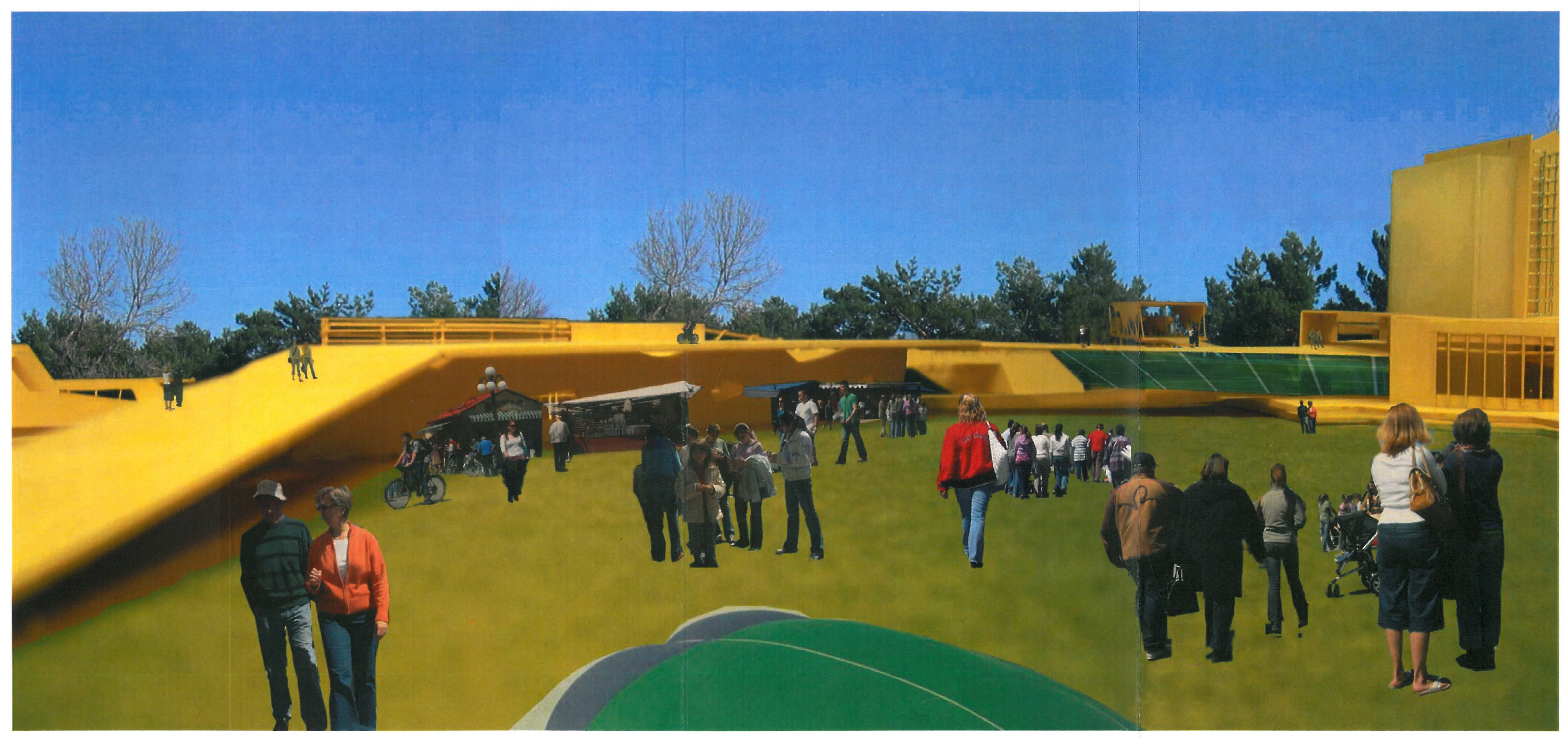

Fig. 55 Bayview Park 


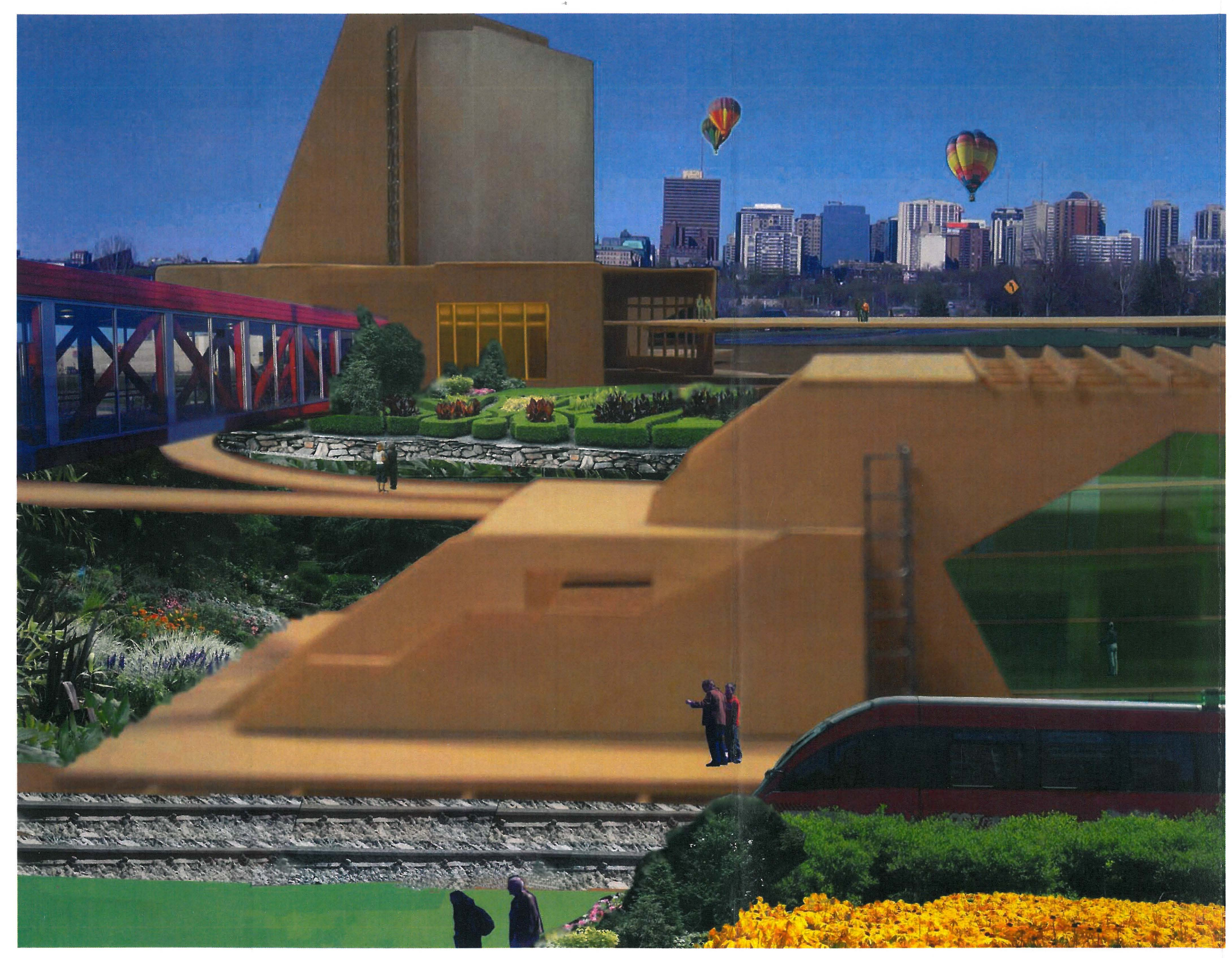




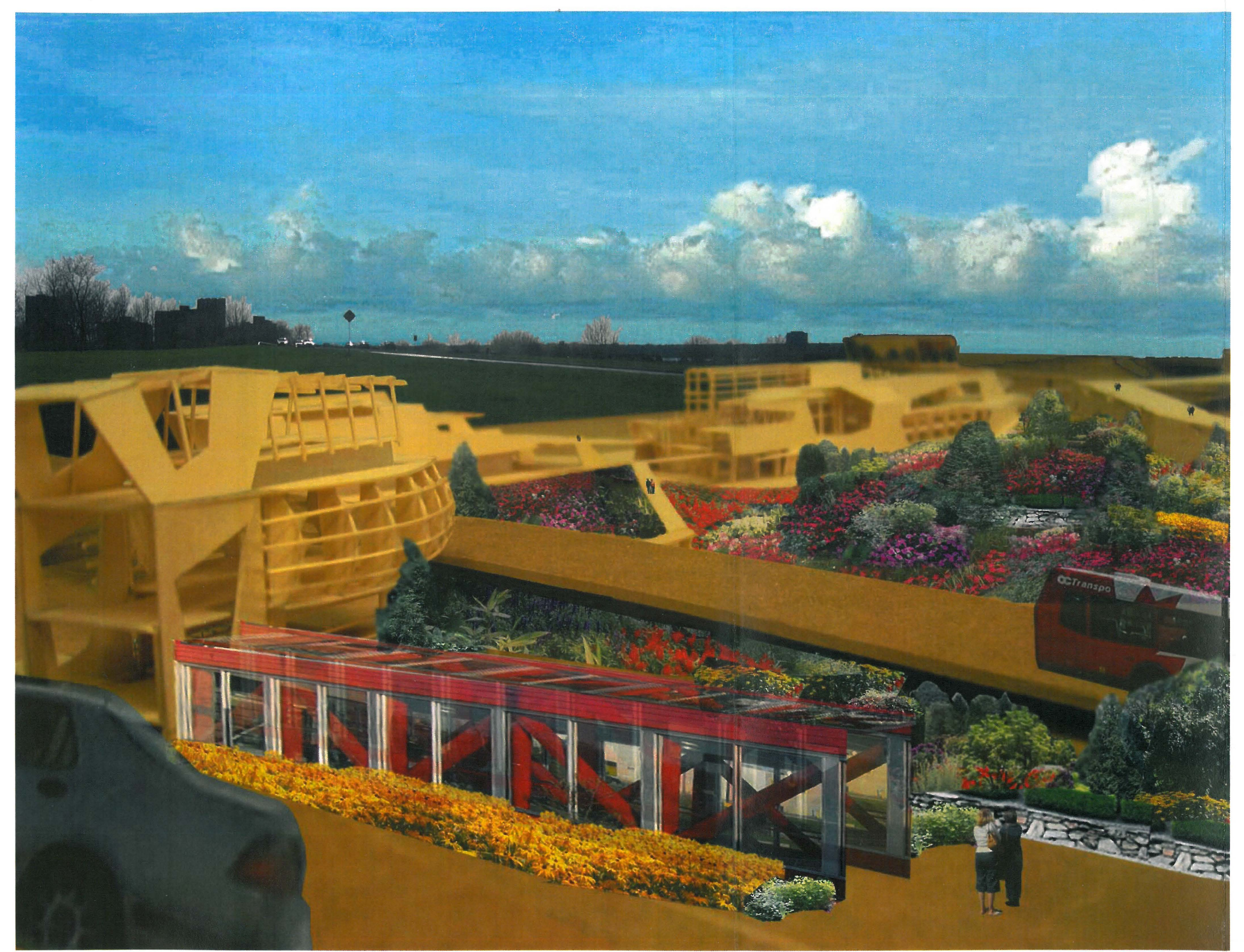




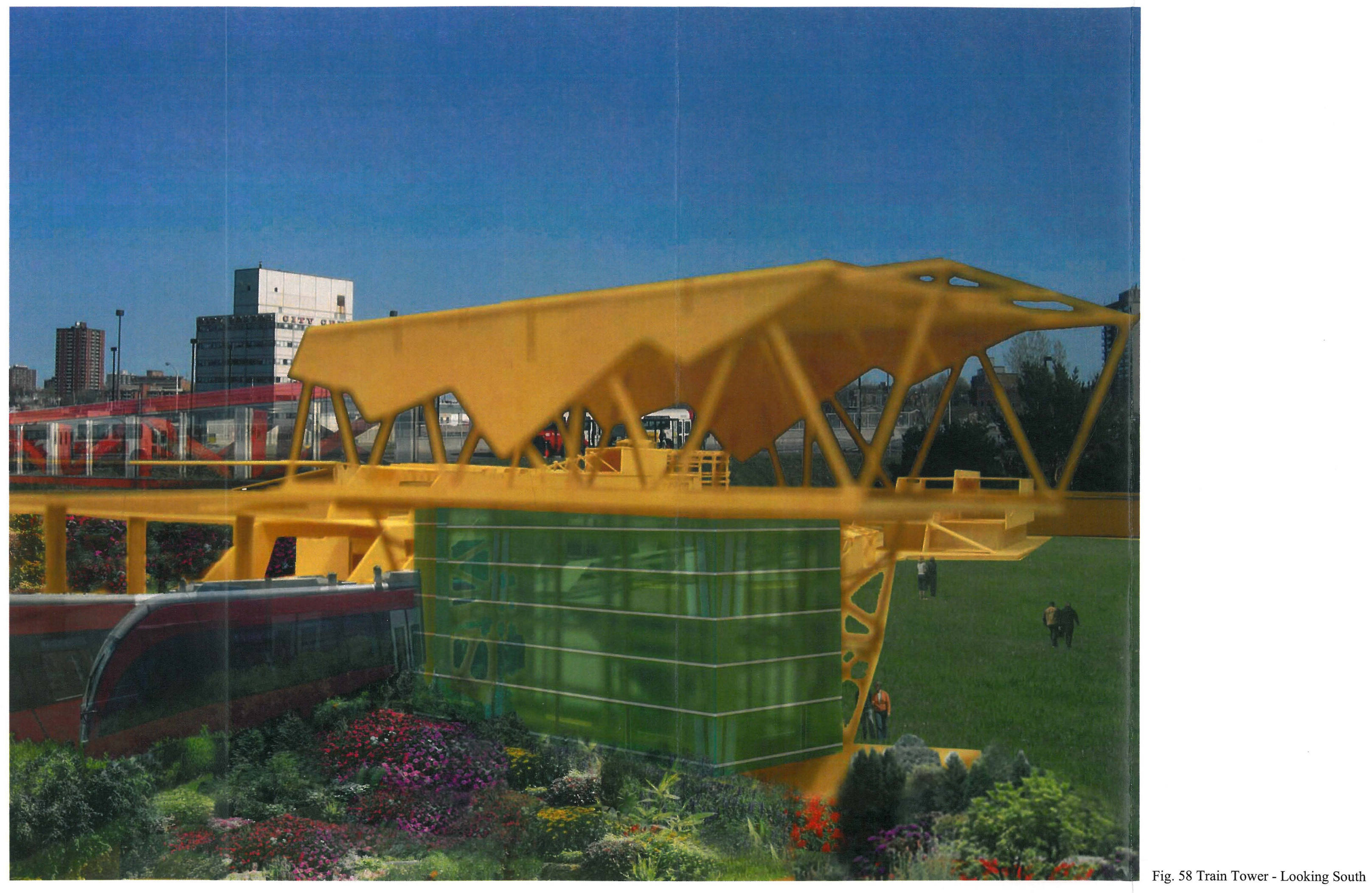




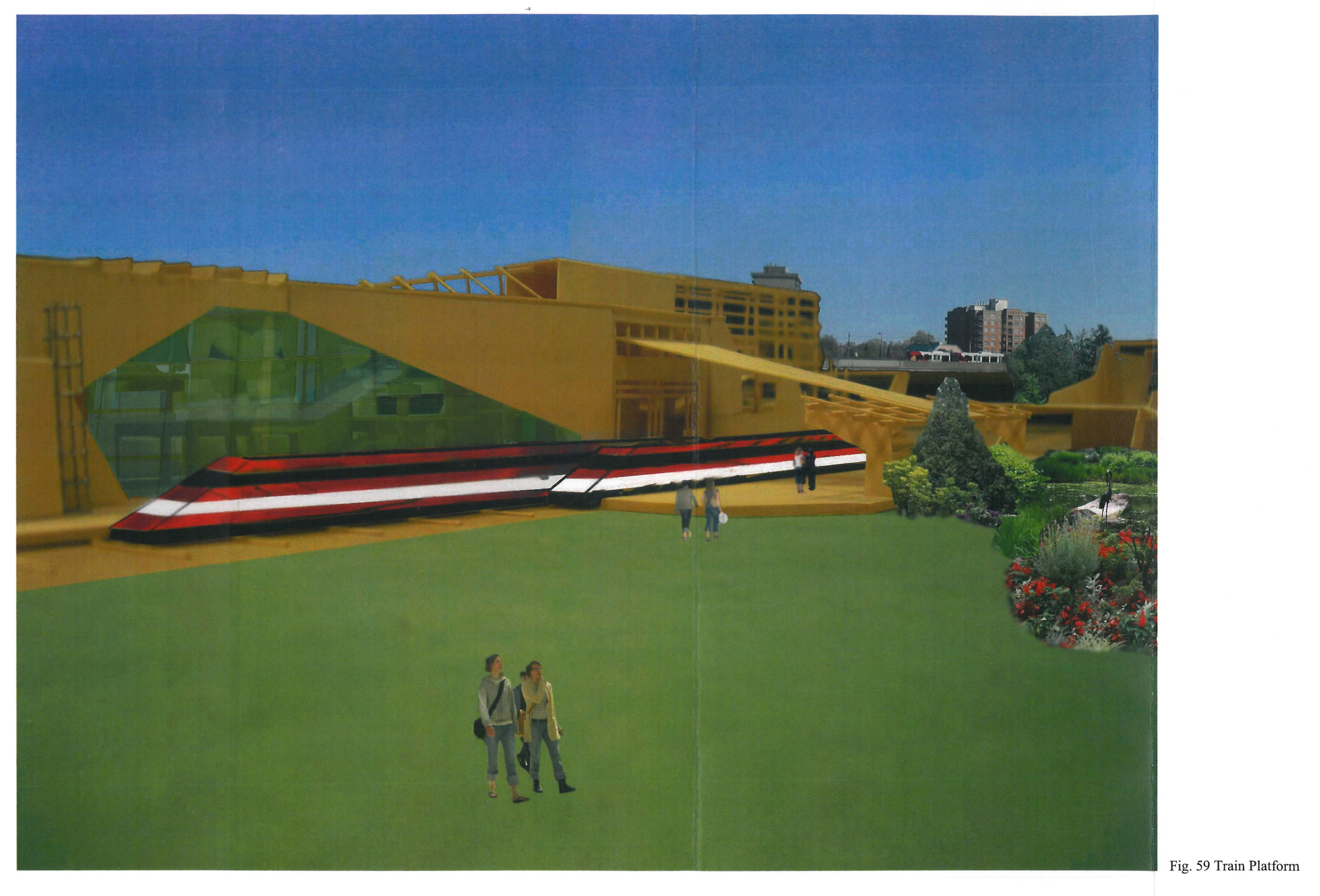




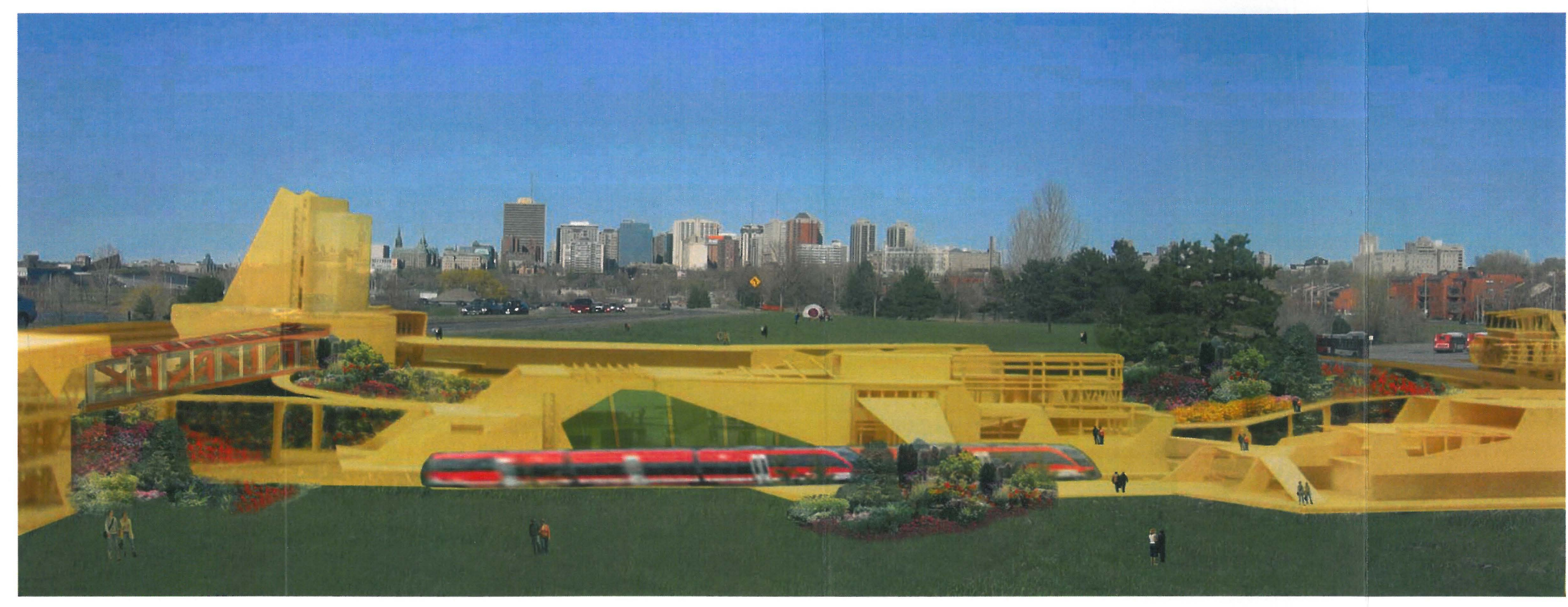

Fig. 60 Project Perspective - Looking East 


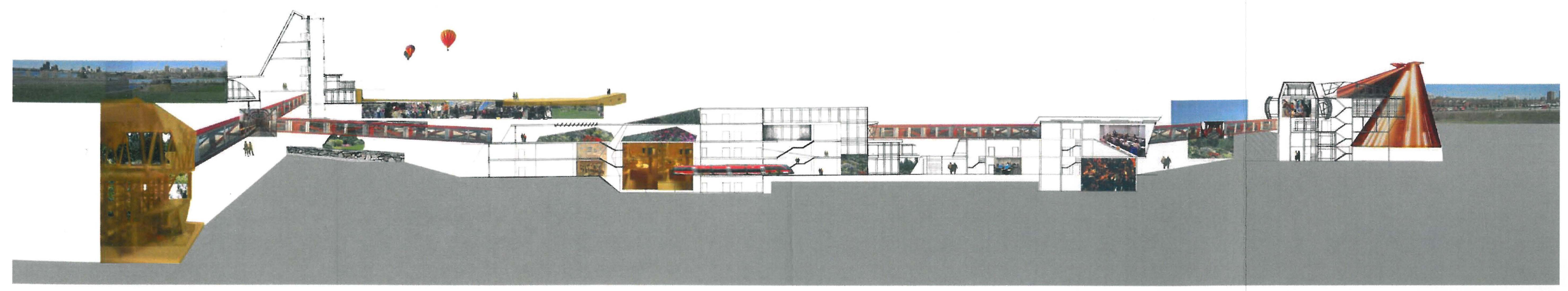

Fig. 61 Project Section 

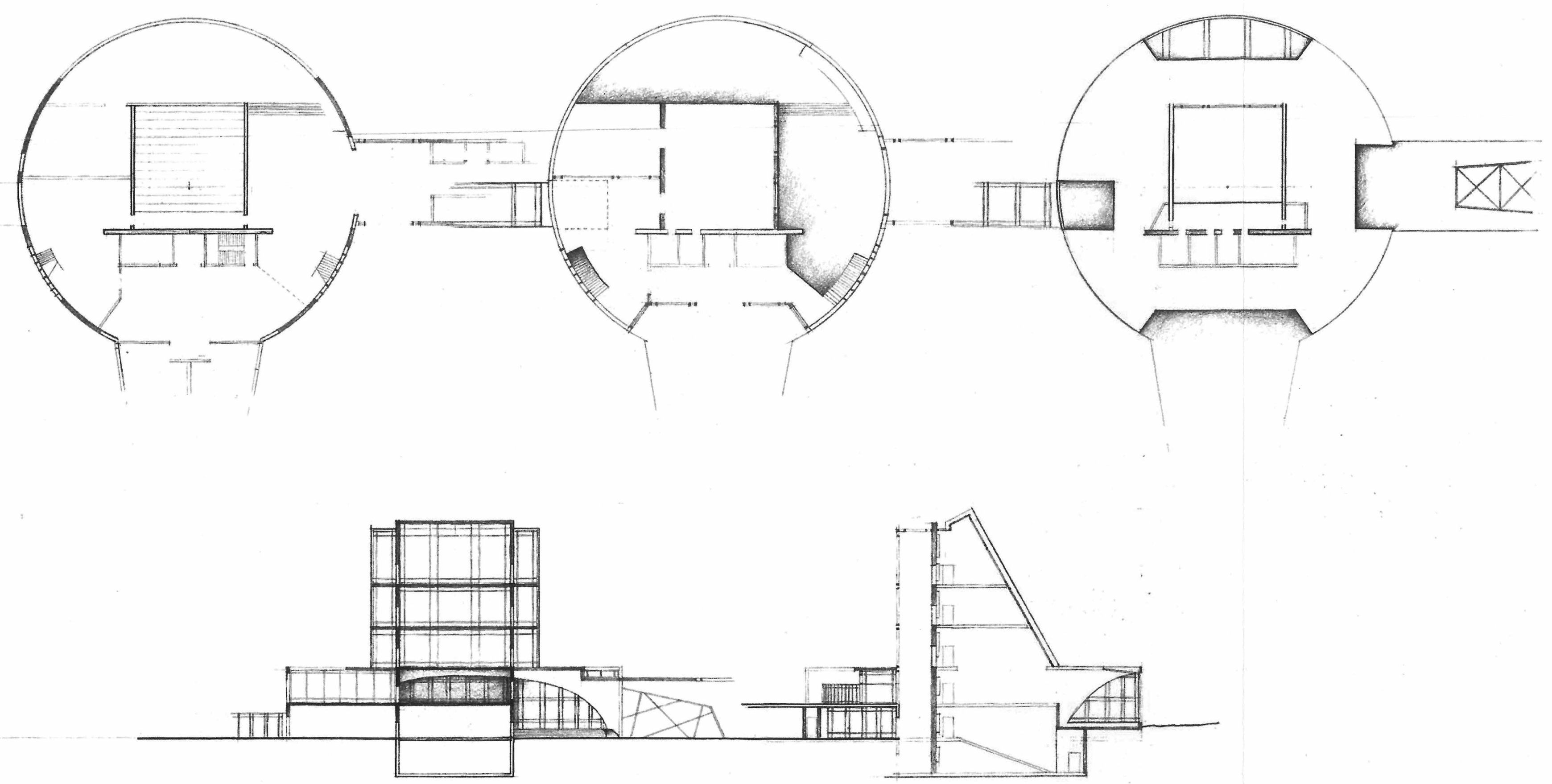

Fig. 62 Community Centre Drawing Showing Plans and Sections 

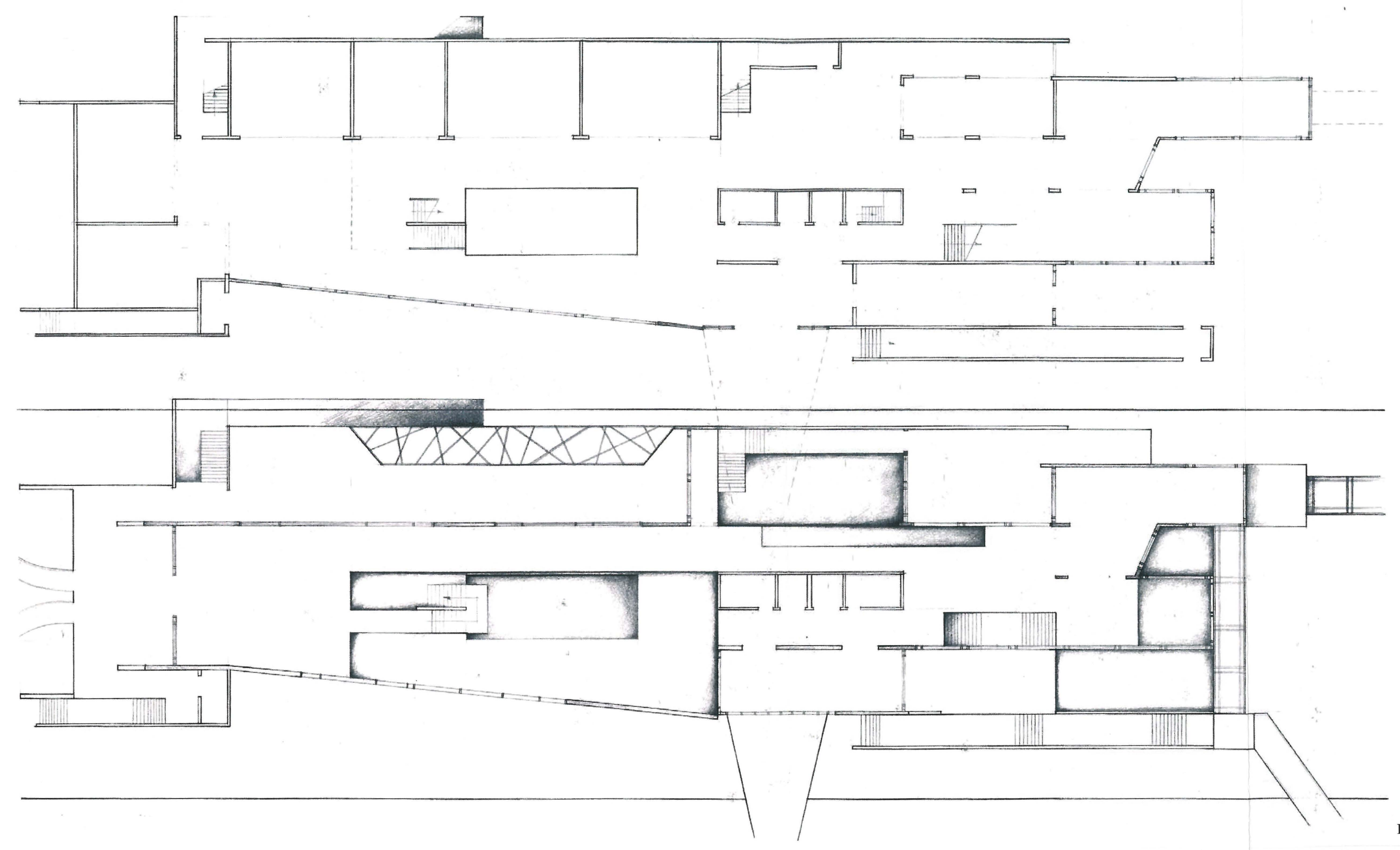

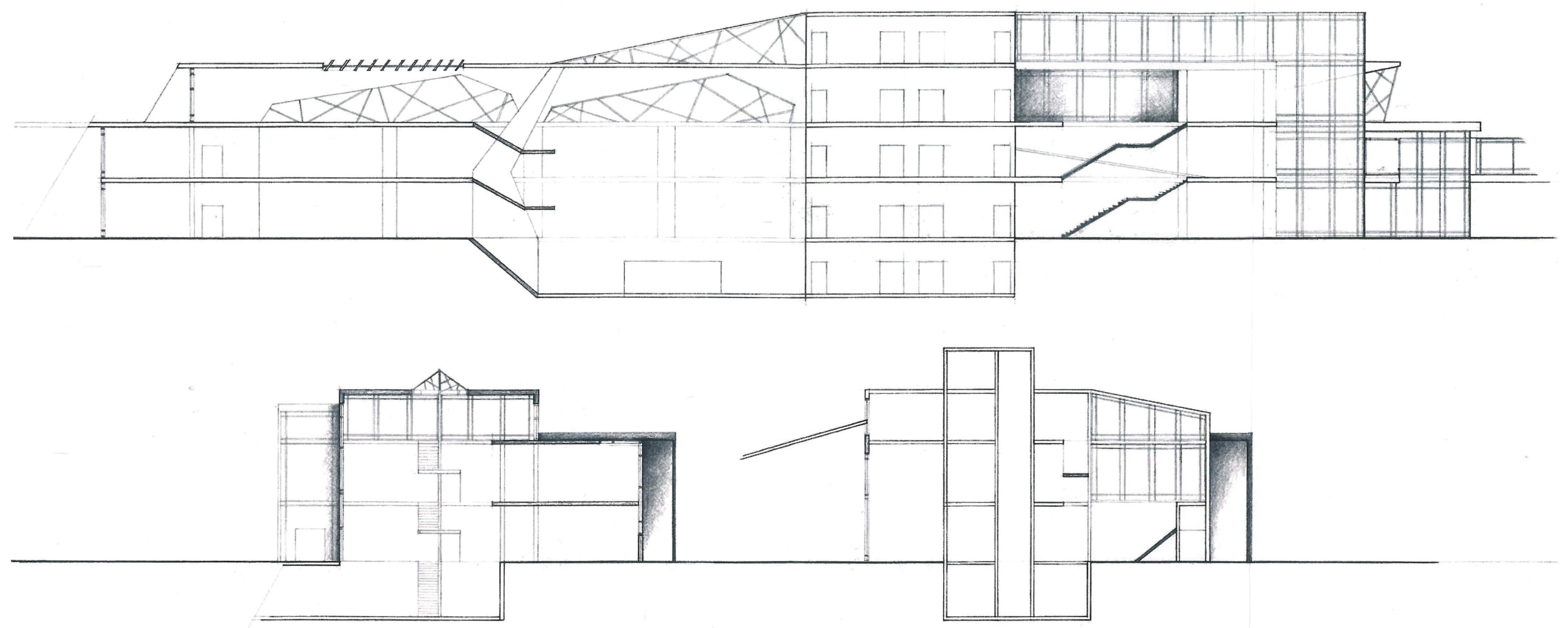

Fig. 64 Train Station Sections 

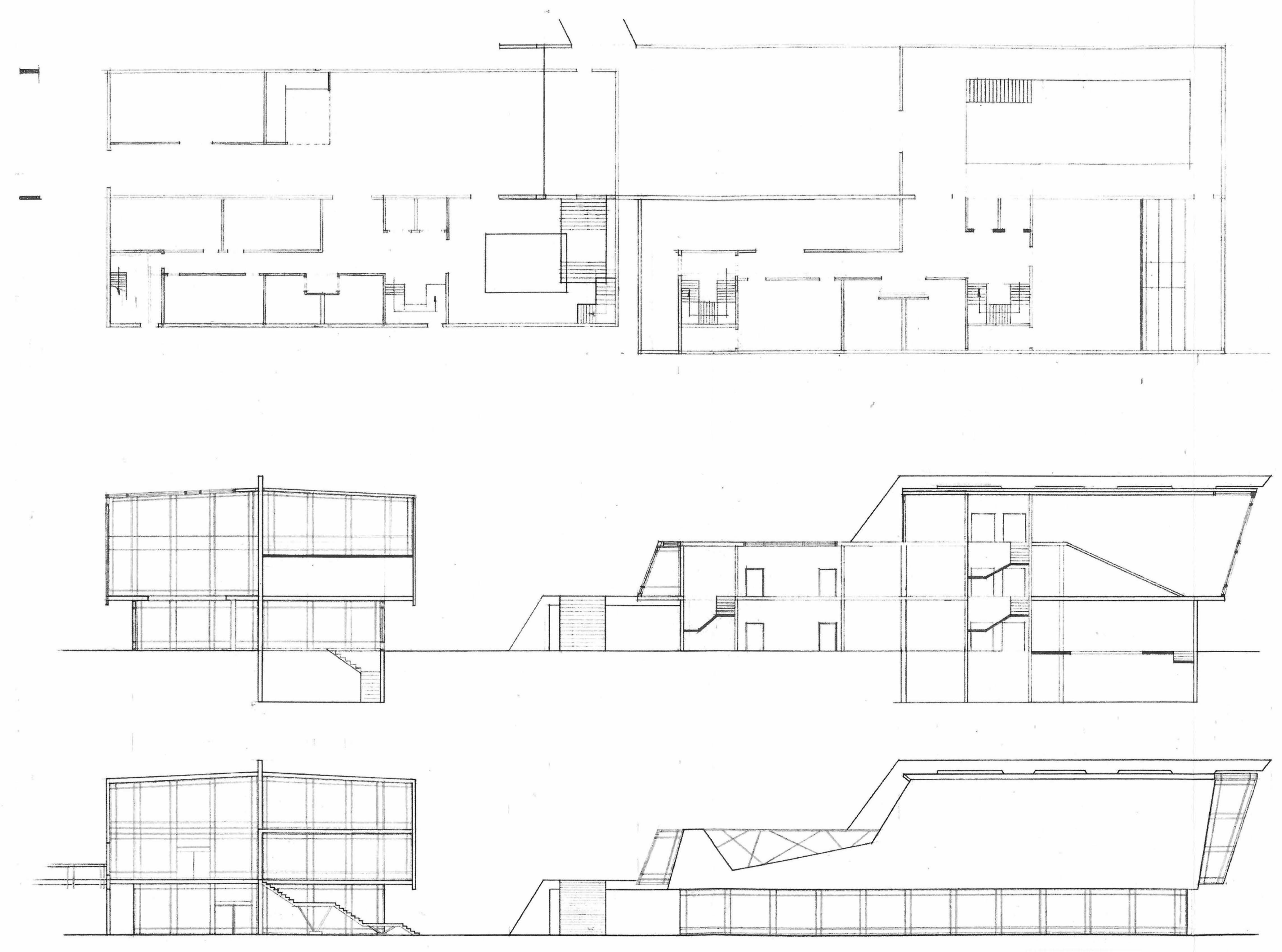

Fig. 65 Library Drawing 

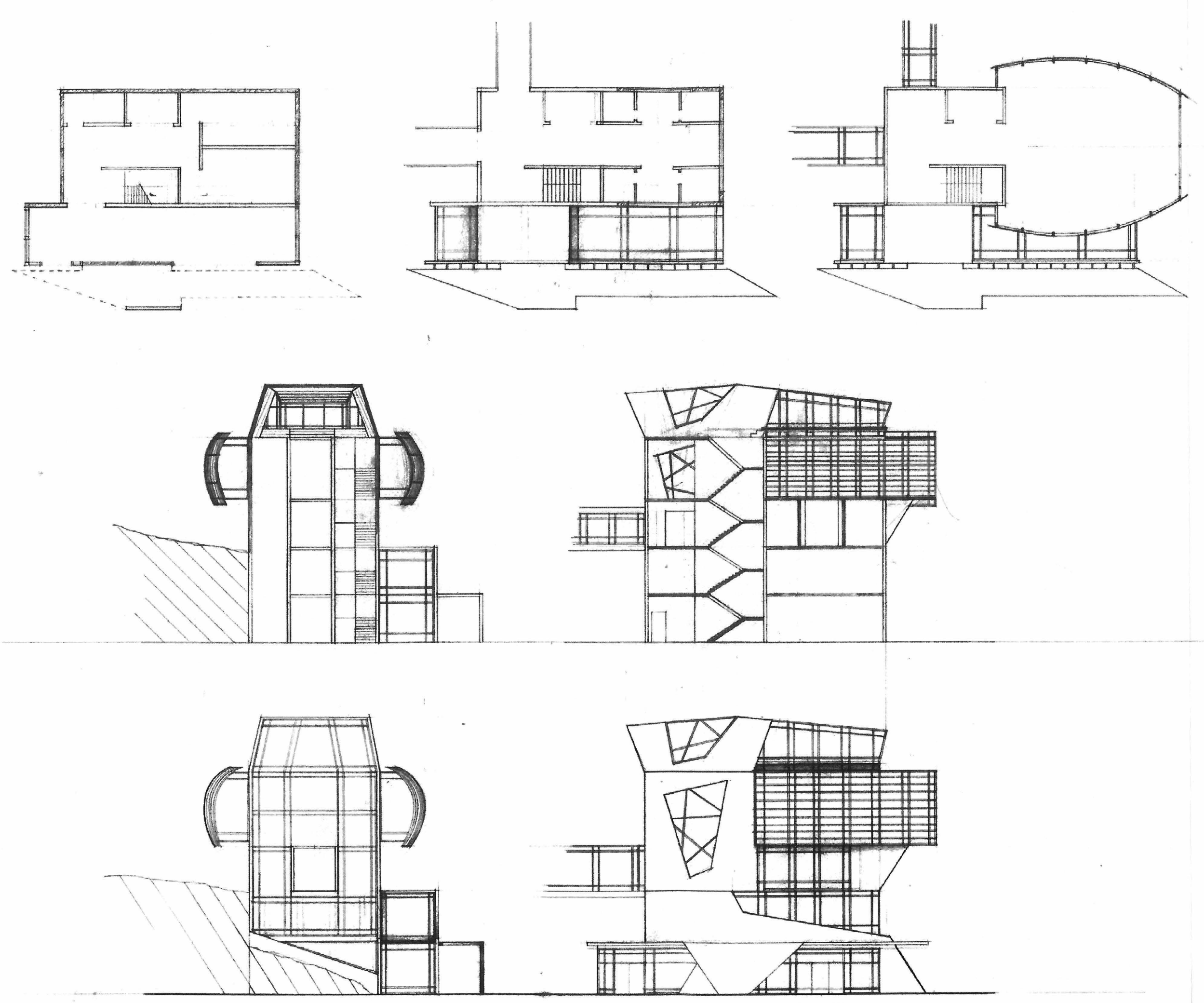